\author{
SCL-DR-720077 \\ March 1973
}

This report was prepared as an account of work sponsored by the United States Government. Neither the United States nor the United States Atomic Energy Commission, nor any of their employees, nor any of their contractors, subcontractors, or their employees, makes any warranty, express or implied, or assumes any legal liability or responsibility for the accuracy, completeness or usefulness of any information, apparatus, product or process disclosed, or represents that its use would not infringe privately owned rights.

\title{
ROLL CONTROL RESONANCE TEST VEHICLE (RCRTV) SYSTEM POSTFLIGHT EVALUATION REPORT
}

J. K. Kryvoruka

Exploratory Development Division II, 8178

Sandia Laboratories, Livermore

\begin{abstract}
This report presents the flight test results for a reentry vehicle spinfin roll control system. The test vehicle, designated the Roll Control Resonance Test Vehicle, was flight tested on May 10, 1972, at the Sandia Laboratories Tonopah Test Range. The purposes of the flight were (1) to demonstrate and evaluate the capability of the control system to overcome a roll resonance flight instability and (2) to confirm the analytic predictions of system performance. The flight test vehicle had built-in asymmetries which, without roll control, would have caused a persistent roll resonance instability to occur. The test was successful in that all systems functioned properly and all program and flight test objectives were accomplished. Flight test data presented herein confirm analytic predictions and flight simulation methods. Results show that the system maintained roll rate control and prevented the roll resonance instability.

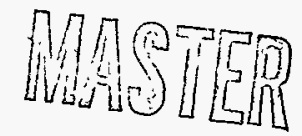

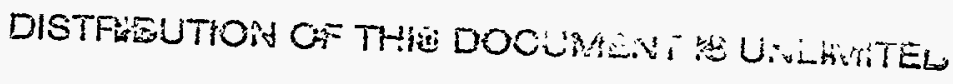




\section{DISCLAIMER}

This report was prepared as an account of work sponsored by an agency of the United States Government. Neither the United States Government nor any agency thereof, nor any of their employees, make any warranty, express or implied, or assumes any legal liability or responsibility for the accuracy, completeness, or usefulness of any information, apparatus, product, or process disclosed, or represents that its use would not infringe privately owned rights. Reference herein to any specific commercial product, process, or service by trade name, trademark, manufacturer, or otherwise does not necessarily constitute or imply its endorsement, recommendation, or favoring by the United States Government or any agency thereof. The views and opinions of authors expressed herein do not necessarily state or reflect those of the United States Government or any agency thereof. 


\section{DISCLAIMER}

Portions of this document may be illegible in electronic image products. Images are produced from the best available original document. 


\section{ACKNOWLEDGEMENT}

The author wishes to acknowledge the effort and support of a large number of individuals and organizations in connection with the RCRTV program. In particular, the significant contributions made by the following key personnel are gratefully noted: J. E. Suazo and E. W. Hall, Mechanical Design Division 5623; L. R. Rollstin, Rocket Systems Division, 5624; A. E. Hodapp, Aeroballistic Division 5625; D. W. Johnson, Deceleration and Recovery Systems Division 5626; R. G. Newman, Transducer Evaluation and Calibration Division 7511; G. W. Henderson and T. J. Weber, Exploratory Development Division 8176; W. T. Ashurst, H. W. Coleman, and E. C. Lemmon, Aerothermodynamics Division 8351; R. D. Robinett and R. E. Howell, Test Project Management Department 9310A; and R. H. Lanes and K. W. Shrock, Instrumentation Applications Division II 9483. 


\section{CONTENTS}

Introduction

RCRTV Program Objectives

Flight System Description

Booster

Flight Vehicle

Roll Control System

Flight Vehicle Instrumentation and Telemetry

Flight Trajectory Analysis

General Flight Characteristics 29

Flight Trajectory Data 33

Meteorological Data 34

Payload Separation Conditions and Vehicle Trajectory 34

Flight Dynamics Analysis $\quad 40$

Flight Motion Data $\quad 40$

Flight Motion Analysis $\quad 46$

Aerodynamic Analysis $\quad 51$

Aerodynamic Drag $\quad 51$

Static Stability 54

Aerodynamic Center of Pressure $\quad 59$

Dynamic Stability $\quad 61$

Rolling Moment Coefficient $\quad 62$

Theoretical Fin Aerodynamics 63

Effects of High Spin Rate $\quad 68$

$\begin{array}{ll}\text { Fin Aerodynamic Characteristics } & 70\end{array}$ 
Roll Control System Performance $\quad 72$

Roll Control System Dynamics $\quad 72$

$\begin{array}{ll}\text { Roll Control System Physical Properties } & 73\end{array}$

Uncontrolled Flight Performance $\quad 74$

Control System Flight Performance $\quad 76$

$\begin{array}{ll}\text { Flight Simulations } & 78\end{array}$

Roll Control System Evaluation $\quad 81$

Thermodynamic Analysis $\quad 83$

Thermodynamic Data $\quad 83$

Aerothermodynamic Analysis $\quad 89$

Tempilaq Experiment $\quad 91$

$\begin{array}{ll}\text { Conclusions } & 93\end{array}$

$\begin{array}{ll}\text { References } & 97\end{array}$ 


\section{ILLUSTRATIONS}

\section{Figure}

$\underline{\text { Page }}$

1. Roll Control Resonance Test Vehicle (RCRTV) $\begin{array}{ll}\text { Flight System } & 18\end{array}$

2. Preflight RCRTV 18

3. RCRT Vehicle 19

4. RCRT Vehicle Design Layout (TO3902) 21

5. Recovered RCRTV 22

6. Centrifugally Operated Fin Roll Control System 22

7. Drive Unit Design Detail (K77099) 24

8. Slave Unit Design Detail (K77108) 25

9. Detail of RCRTV Fin Mechanism 26

10. Roll Control System Detail (K77635) 27

11. RCRTV System Interface (DL24836) 28

12. RCRTV Trajectory Events 33

13. Payload Axial Acceleration vs. Time
( $\pm 30 \mathrm{~g}$ Accelerometer)

14. Payload Axial Acceleration vs. Time
( $\pm 50 \mathrm{~g}$ Accelerometer)

15. Flight Altitude History 36

16. Flight Velocity History 36

17. Air Temperature vs. Altitude 37

18. Air Density vs. Altitude 37

19. RCRTV Velocity History 38

20. RCRTV Mach Number History 39

21. RCRTV Dynamic Pressure History 39

22. Vehicle Pitch Angle From Stable Platform 41 
$\underline{\text { Figure }}$

Page

23. Vehicle Yaw Angle From Stable Platform

24. Pitch Angle vs. Yaw Angle ( $\mathrm{T}=0$ to $4 \mathrm{sec}$ ) 42

25. Pitch Angle vs. Yaw Angle ( $T=4$ to 8 sec) 42

26. Lateral Acceleration History 43

27. Normal Acceleration History 43

28. Resultant Lateral Acceleration History 44

29. Pitching Velocity History 44

30. Yawing Velocity History 45

31. Resultant Angular Velocity History 45

32. Vehicle Roll Rate History From Rate Gyro 47

33. Vehicle Roll Rate History Obtained From

MARS Platform Data

34. RCRTV Tricyclic Modal Amplitudes From Stable Platform Data

35. RCRTV Tricyclic Modal Frequencies From Stable Platform Data

36. Body Fixed Angle of Attack 52

37. Body Fixed Angle of Sideslip 52

38. Body Fixed Resultant Angle of Attack 53

39. Aerodynamic Roll Angle 53

40. Vehicle Axial Force Coefficient (From \pm 30 g Accelerometer) 55

41. Vehicle Axial Force Coefficient (From \pm 50 g Accelerometer) 55

42. Axial Force Coefficient vs. Mach Number 56

43. Axial Force Coefficient With and Without Fins vs. Mach Number

44. Ratio of $\mathrm{C}_{\mathrm{A}_{0}}$ (With Fins) to $\mathrm{C}_{\mathrm{A}_{0}}$ (Without Fins) vs. Mach Number

45. Static Stability Coefficient $\left(\mathrm{C}_{\mathrm{M}_{\alpha}}\right)$ History 58

46. Static Stability Coefficient With and Without

Fins vs. Mach Number 
Figure

47. Normal Force Coefficient (At $\alpha=0^{\circ}$ ) vs.

Niach Number

60

48. Aerodynamic Center-of-Pressure Location

With and Without Fins vs. Mach Number

61

49. Total Rolling Moment Coefficient

50. Roll Moment Coefficient Due to Vehicle

Asymmetries

64

51. Spin Fin Aerodynamics

65

52. Theoretical Cross Flow Angle for Blunt and Sharp Cones

53. Fin Roll Moment Coefficient Correlation

(Fin Cant, $\delta=0^{\circ}$ )

54. Fin Roll Moment Coefficient Correlation

(Fin Cant, $\delta=10^{\circ}$ )

55. RCRTV Theoretical Roll Moment Coefficient

Due to Fin Cant

56. RCRTV Theoretical Induced Roll Moment Coefficient 69

57. RCRTV Fin Cant Coefficient vs. Mach Number 71

58. RCRTV Spin Rate and Natural Pitch Frequency for Uncontrolled Trajectory

59. RCRTV Total Angle of Attack for Uncontrolled Trajectory

60. Flight Vehicle Spin Rate and Natural Pitch Frequency History

61. Flight Vehicle Total Angle-of-Attack History 77

62. Flight Vehicle Fin Cant History . 77

63. Spin Rate and Natural Pitch Frequency (Preflight

Simulation with Flight Separation Conditions)

64. Total Angle of Attack (Preflight Simulation With Flight Separation Conditions)

65. Spin Rate and Natural Pitch Frequency (Postîlight Simulation with Flight Derived Aerodynamics)

66. Total Angle of Attack (Postflight Simulation with Flight Derived Aerodynamics) 
67. RCRTV Flight Simulation from Steady State Starting Conditions--Spin Rate and Natural Pitch Frequency

68. RCRTV Flight Simulation from Steady State Starting Conditions--Total Angle-of-Attack

69. RCRTV Flight Simulation from Steady State Starting Conditions--Fin Cant

70. Cone Surface Heat Flux at Fin Station (4. 75 in From Base @ $135^{\circ}$ Orientation)

71. Cone Surface Heat Flux at Fin Station (4.75 in From Base @ $315^{\circ}$ Orientation)

72. Cone Surface Heat Flux at Forward Station (14. 5 in From Base @ 135 Orientation)

73. Cone Surface Heat Flux at Forward Station (14.5 in From Base @ 315: Orientation)

74. Fin Leading Edge Heat Flux (90 Orientation) 86

75. Fin Leading Edge Heat Flux (270 Orientation) 86

76. Cone Shell Backface Temperature at Fin Station (4. 75 in From Base @ 45 Orientation)

77. Cone Shell Backface Temperature at Fin Station (4.75 in From Base @ 225 Orientation)

78. Cone Shell Backface Temperature at Forward Station (14.5 in From Base @ 45 Orientation)

79. Cone Shell Backface Temperature at Forward Station (14.5 in From Base @ 225 Orientation)

80. Comparison of Actual and Theoretically Determined Fin Leading Edge Heat Flux

81. Comparison of Actual and Theoretically Determined Cone Surface Heat Flux at Forward Station (14. 5 in From Base)

82. Comparison of Actual and Theoretically Determined Cone Surface Heat Flux at Fin Station

(4. 75 in From Base)

83. Preflight Fixed-Fin Tempilaq Pattern 91

84. Preflight Moving-Fin Tempilaq Pattern 92

85. Postflight Fixed-Fin Tempilaq Pattern 92

86. Postflight Moving-Fin Tempilaq Pattern 93 


\section{TABLES}

Table

$\underline{\text { Page }}$

I. Flight Vehicle Physical Properties 19

II. Roll Control System Physical Properties 23

III. RCRTV Instrumentation and Function 30

IV. RCRTV Instrumentation $\quad 31$

V. RCRTV Telemetry System Subcarrier Assignments 32

VI. RCRTV Payload Separation Conditions 38

VII. Roll Control System Performance Parameters 73 


\title{
ROLL CONTROL RESONANCE TEST VEHICLE (RCRTV)
} SYSTEM POSTFLIGHT EVALUATION REPORT

\author{
Introduction
}

Flight test experience has indicated that ballistic reentry vehicles (RV) are plagued with problems of anomalous roll rate behavior. These problems, which include spin-up, roll reversal, and persistent roll resonance, can lead to serious flight performance degradation resulting in impact dispersions or catastrophic flight failure. Roll anomalies arise from small aerodynamic and mass asymmetries; and since these asymmetries are often ablation-induced, close control of RV manufacturing tolerances does not always eliminate the resulting flight instabilities. It is evident, therefore, that the flight performance of RVs can be improved by introducing roll rate control.

A study was conducted at Sandia Laboratories, Livermore (SLL), to investigate methods for exercising such control. One phase of the SLL roll control development program involved the design, development, and flight testing of a centrifugally actuated, fin roll control system. A system selected for detailed evaluation was one which employs variable-cant, aerodynamic spin fins. Among systems proposed, this one is unique in that (a) the fin motions are coupled and (b) a four-fin configuration is used, including two fins with variable cant and two with cant angle fixed at zero degrees. Included in the program to study fin roll control, was the task of developing both the analytic methods and the simulation techniques to describe the complex aerodynamics, thermodynamics, and flight dynamics of finned RVs. Results of the analysis indicated that such a system could be made to control the spin rate of a vehicle throughout reentry and that the system operation would remain stable through a wide range of environmental effects.

As a means for flight testing the candidate roll control systems, the Sandia Reentry Vehicle Resonance Test Vehicle (RVRTV) flight system was selected. The RVRTV program consists of a series of flights wherein vehicles with various types of built-in asymmetries are flown to investigate flight dynamic behavior during both persistent and transient resonance. 
Preceding the controlled flight reported here, a flight without roll control was made to demonstrate the persistent roll resonance (roll lockin) behavior of the vehicle and to verify the analytic prediction methods for its uncontrolled flight. Then the present spin-fin roll control system configuration, designated the Roll Control Resonance Test Vehicle (RCRTV) ${ }^{1}$ was flight tested to demonstrate the capability of the system to control the spin rate of the asymmetrical vehicle and, again, to verify the analytic method used to predict flight behavior.

The RCRTV test flight on May 10, 1972, at the Sandia Tonopah Test Range (TTR), was made at a low altitude trajectory and a supersonic Mach . number. The test was successful. This report describes the RCRTV system and flight test, and it presents the flight test results together with the analysis and evaluation of those data.

Results indicate that (1) the system maintained control through a severe roll resonance instability; (2) the vehicle aerodynamic drag and static stability were sharply increased by the fins; (3) the fin aerodynamic roll moment characteristics were in good agreement with the analytic predictions; and (4) the flight simulations accurately represented the actual flight performance, thus confirming the analytical models.

All program and flight test objectives were accomplished. The test therefore served as an intermediate step to the full-scale flight test of the Roll Control Test Vehicle (RCTV) 2 flown during October 1972.

RCRTV Program Objectives

The purpose of the RCRTV program is to conduct a free-flight test and evaluate the performance of the centrifugally actuated, hydraulically coupled, spin-fin roll control system. The general program and flight test objectives are as follows:

1. Demonstrate the capability of the fin roll control system to control the spin rate of an asymmetric flight vehicle that would otherwise exhibit a sustained roll resonance instability;

2. Develop the necessary analytical prediction and simulation techniques needed to describe the aerodynamic, thermodynamic, and flight dynamic performance of finned RVs;

3. Develop the necessary analysis and ground testing techniques needed to specify the characteristics and dynamic performance of the roll control system; and 
4. Provide an intermediate step to full-scale flight testing. ${ }^{2}$

In addition, the following detailed flight test objectives are to be accomplished:

1. Obtain aerodynamic data on fins, verify preflight analytic predictions, and demonstrate the credibility of a four-fin configuration;

2. Obtain detailed data on body and control system dynamics (acceleration and angular rate components as well as angular position) and verify flight simulation methods;

3. Obtain fin leading edge and cone surface thermodynamic data (heat flux and temperature) and verify preflight analytic predictions; and

4. Recover payload intact by means of a parachute.

Flight System Description

\section{Booster}

The RCRTV boost system is a two-stage NIKE-HERCULES rocket system. * Each stage consists of a Nike M5 motor having a burn time of 3.5 seconds, and each nominally delivers 40,000 pounds of thrust. The boost system is equipped with a telemetry system so that the proper separation and ignition signals may be provided. After first-stage burnout and before second-stage ignition, the two motors are separated by aerodynamic drag. The vehicle is deployed from the second-stage motor by an explosive separation and booster retardation system. The complete RCRTV flight system before flight is shown in Figure 1.

Flight Vehicle

Shown in Figure 2 is the Roll Control Resonance Test Vehicle before flight. A schematic of the flight vehicle is given in Figure 3 , while a description of the physical properties is provided in Table I. **

*Booster interface is provided by L. R. Rollstin, Rocket Systems

Division 5624.

**The payload design was provided by J. E. Suazo, Mechanical Design

Division 5623. 


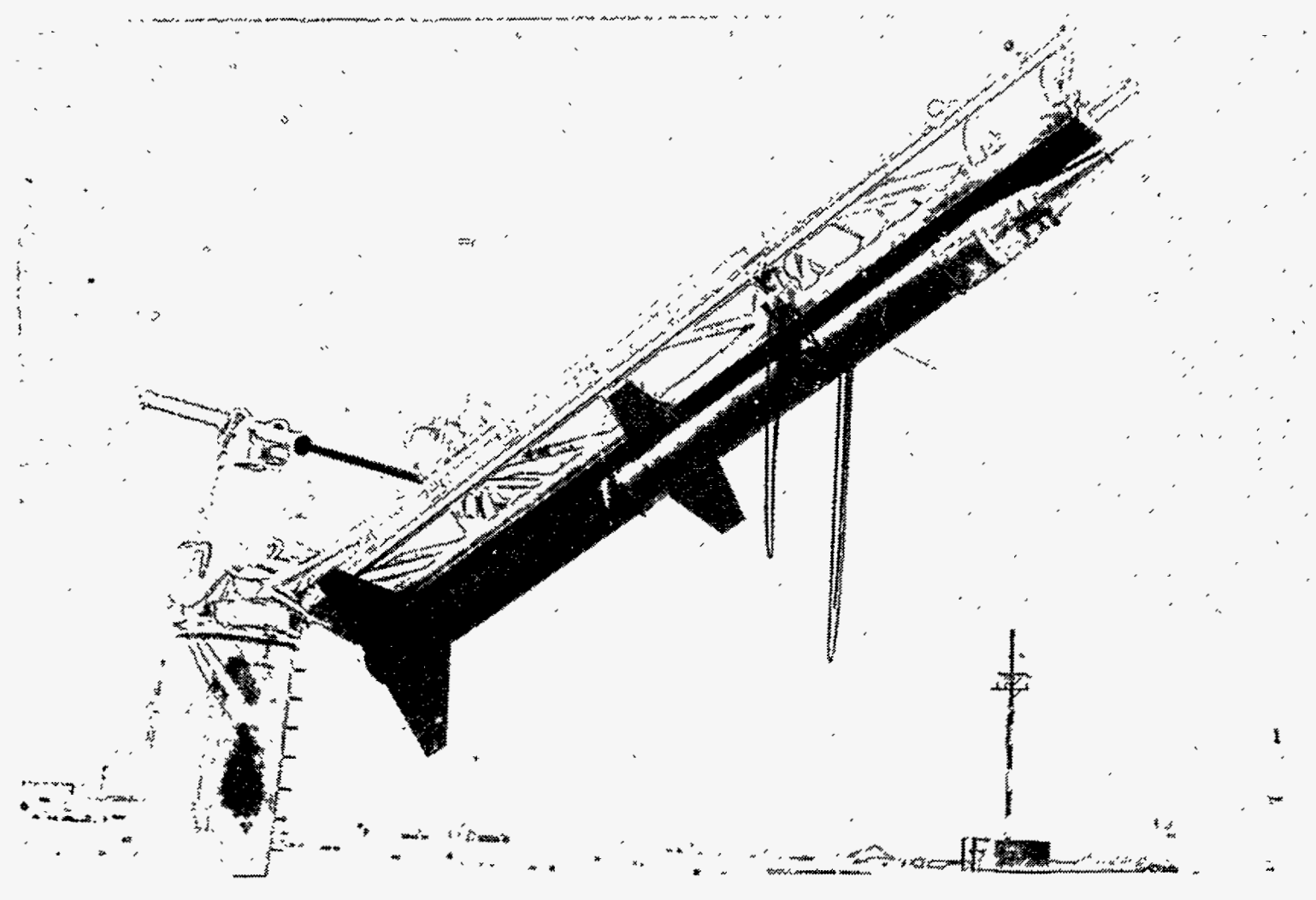

Figure 1. Roll Control Resonance Test Vehicle (RCRTV) Flight System

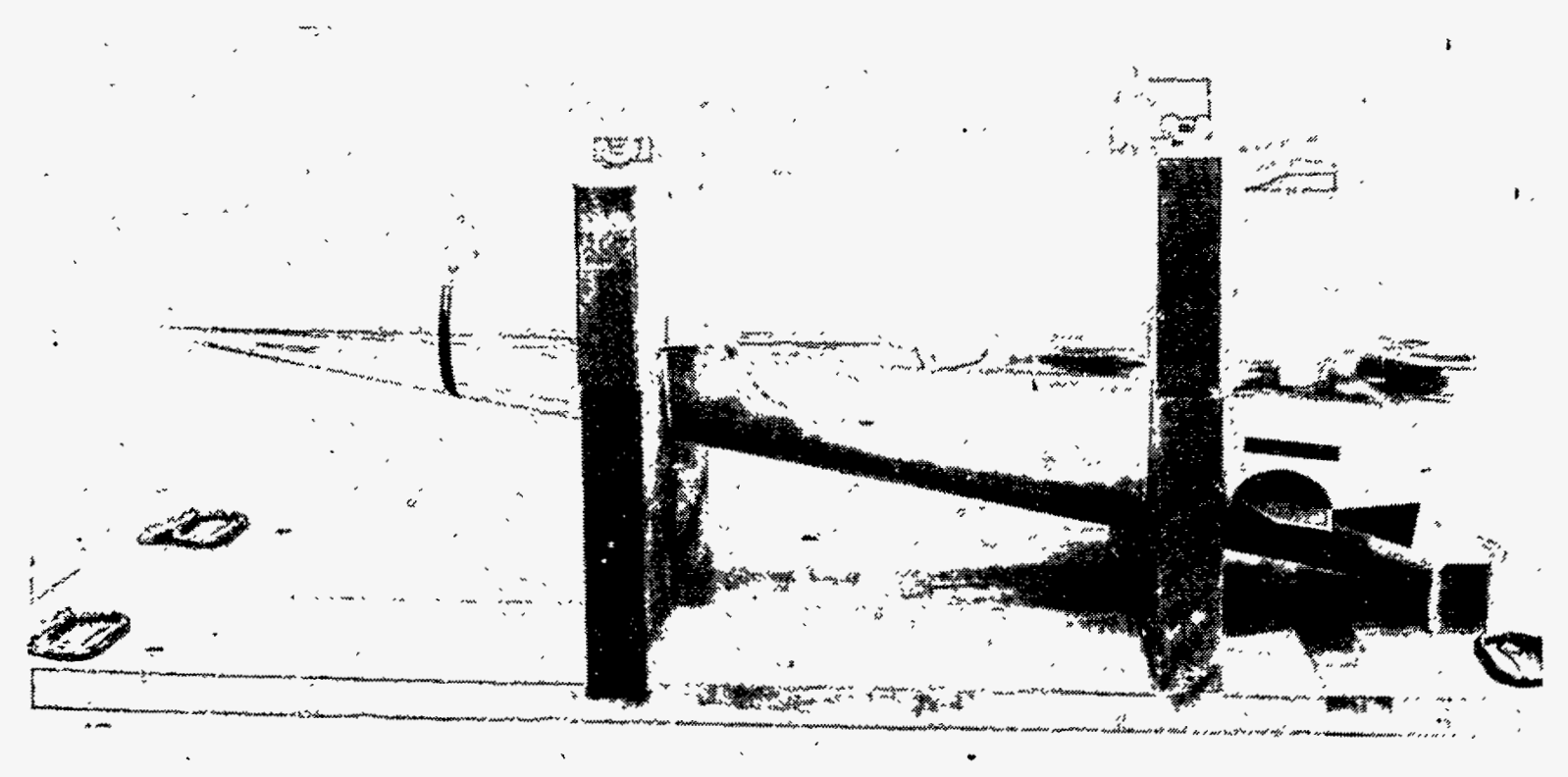

Figure 2. Preflight RCRTV 


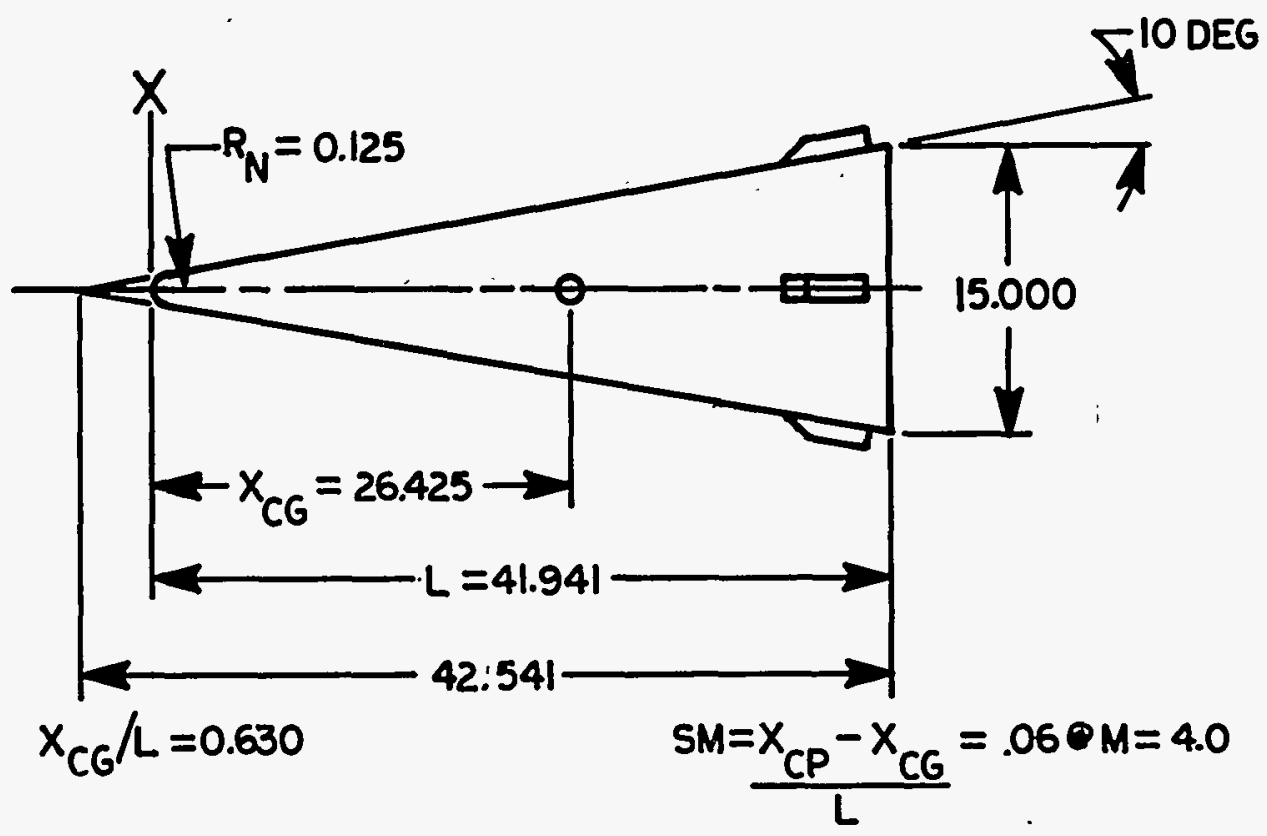

Figure 3. RCRT Vehicle

TABLE I

FLIGHT VEHICLE PHYSICAL PROPERTIES

Cone half angle $10^{\circ}$

Bluntness ratio 0.017

Base diameter 15 in

Vehicle actual length 41. 941 in

Weight $106.4 \mathrm{Ib}$

Center-of-mass distance from nose (63\% of length) 26.425 in

Pitch moment of inertia $I_{y}$

Yaw moment of inertia $I_{z}$

Roll moment of inertia $I_{x}$

Product of inertia $I_{x y}$

2. 945 slug- $\mathrm{ft}^{2}$

2. 937 slug- $\mathrm{ft}^{2}$

0.317 slug-ft ${ }^{2}$

0.0122 slug-ft ${ }^{2}$

Principal axis inclination

$0.27^{\circ}$

Center-of-mass offset (along body $Z$ axis)

0.10 in

Static margin (with fins)

$6.2 \%$ of length 
The vehicle is a sharp, 10-degree half-angle cone with a 15 -inch base diameter and a total weight of 106.3 pounds. The external geometry of this vehicle, excluding the fins, is the same as that for a standard dynamic stability correlation model used by the Supersonic Tunnel Association and the AGARD. * It has compound mass and inertia asymmetries sufficient to produce, in the absence of roll control, a sustained roll resonance instability. The vehicle principal axis is inclined 0.25 degree relative to the geometric centerline. Normal to the plane containing these axes, the center of mass is displaced $0.1 \mathrm{inch}$. It is the combined effects of these two asymmetries that is the source of a destabilizing roll torque.

The details of the flight vehicle design are shown in Figure 4 . The unit is made of an aluminum-magnesium alloy, Al Mag 35. The forward 10 inches of the nose of the vehicle serves as a telemetry antenna and is therefore insulated from the body by a quartz ring. Four aluminum fins are used to provide spin rate control. Two of these are driven by the centrifugally actuated roll control system; two are fixed at a zero geometric cant angle.

The payload is mounted to the booster adapter and separation system** by three explosive bolts equally spaced around the base of the vehicle. At second-stage burnout, the simultaneous detonation of these bolts and deployment of booster aerodynamic retardation plates (drag brakes) separate the vehicle from the booster.

A parachute recovery system $* * *$ is included and packaged in the aft end of the flight vehicle. The system consists of a 3-foot-diameter pilot deployed 23 seconds after launch and a 12-foot-diameter main parachute deployed 33 seconds after launch. The recovery system performed properly and the vehicle was recovered intact (Figure 5).

\section{Roll Control System}

The vehicle roll control system is shown conceptually in Figure 6. **** Vehicle roll torque and roll control are provided by means of external aerodynamic control surfaces (spin fins). Fin cant is determined by the radial

*R. Fail and H. C. Garner, Calibration Models for Dynamic Stability

Tests, Report 563, Advisory Group for Aerospace Research and

Development (AGARD), Nevilly-Sur-Seine, France, 1968.

**Design provided by J. E. Suazo and E. W. Hall, Mechanical Design

Division 5622

***Designed by D. W. Johnson, Deceleration and Recovery Systems

Division 5626

*****The system was designed by T. J. Weber, Exploratory Development Division I 8178 (Reference 3 ). 

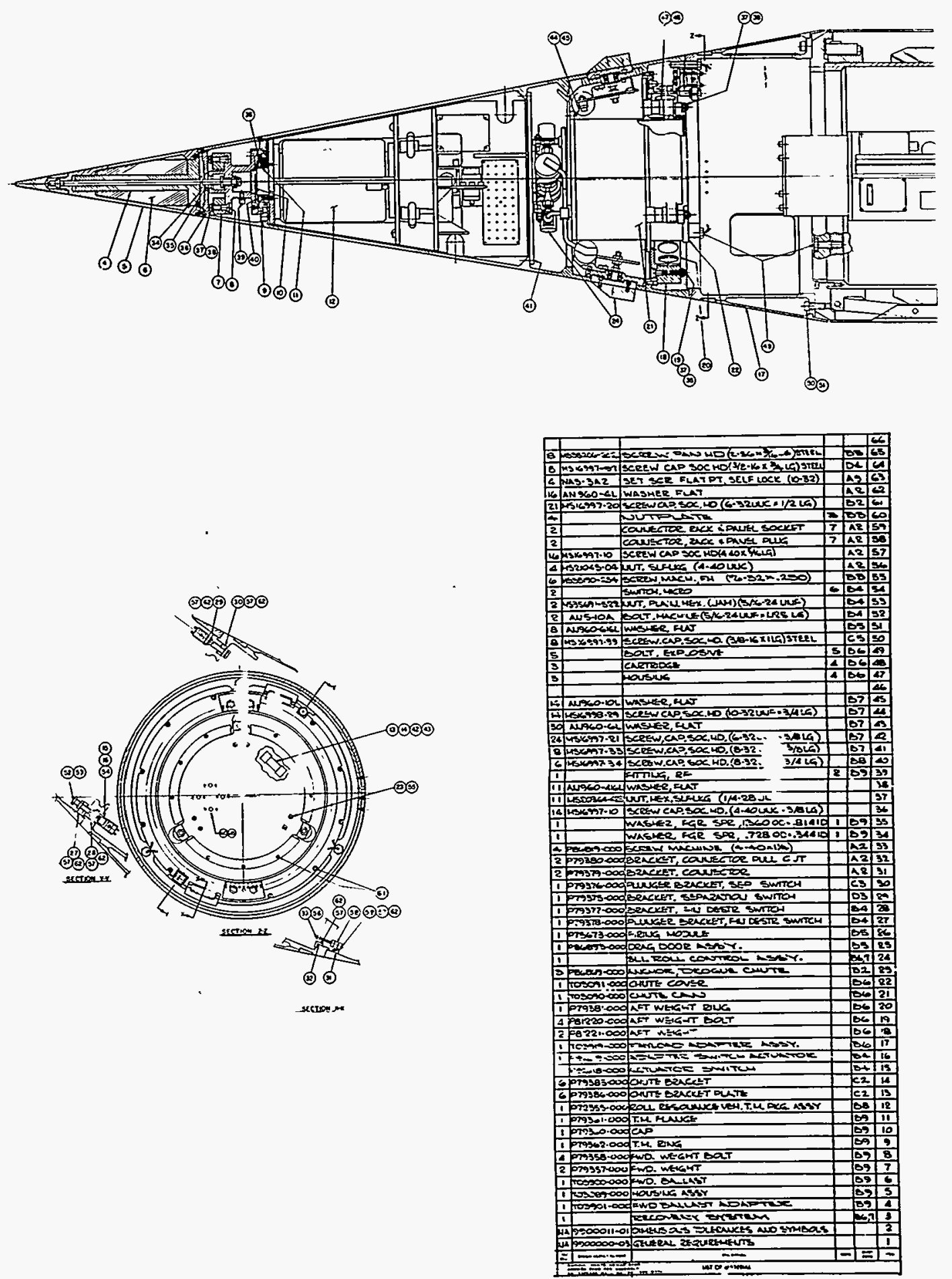

Figure 4. RCRT Vehicle Design Layout (TO3902) 


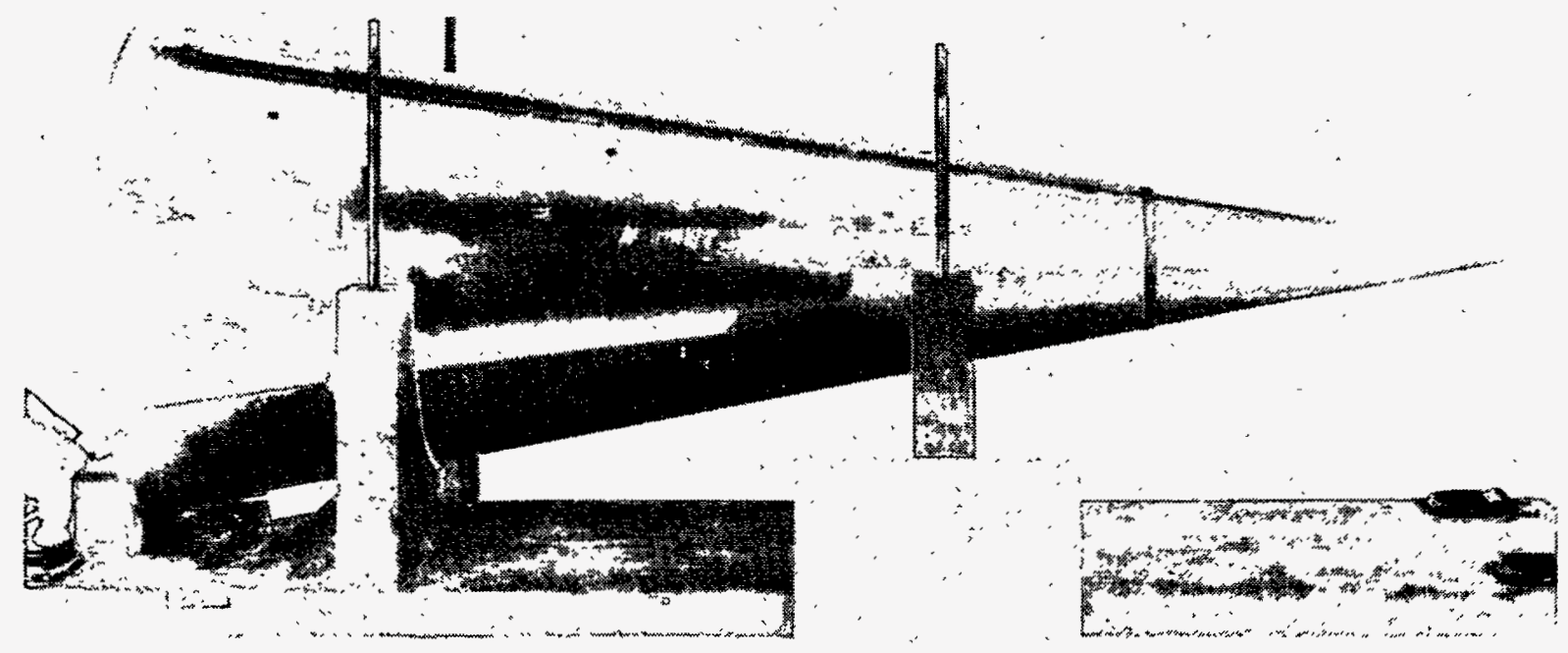

Figure 5. Recovered RCRTV

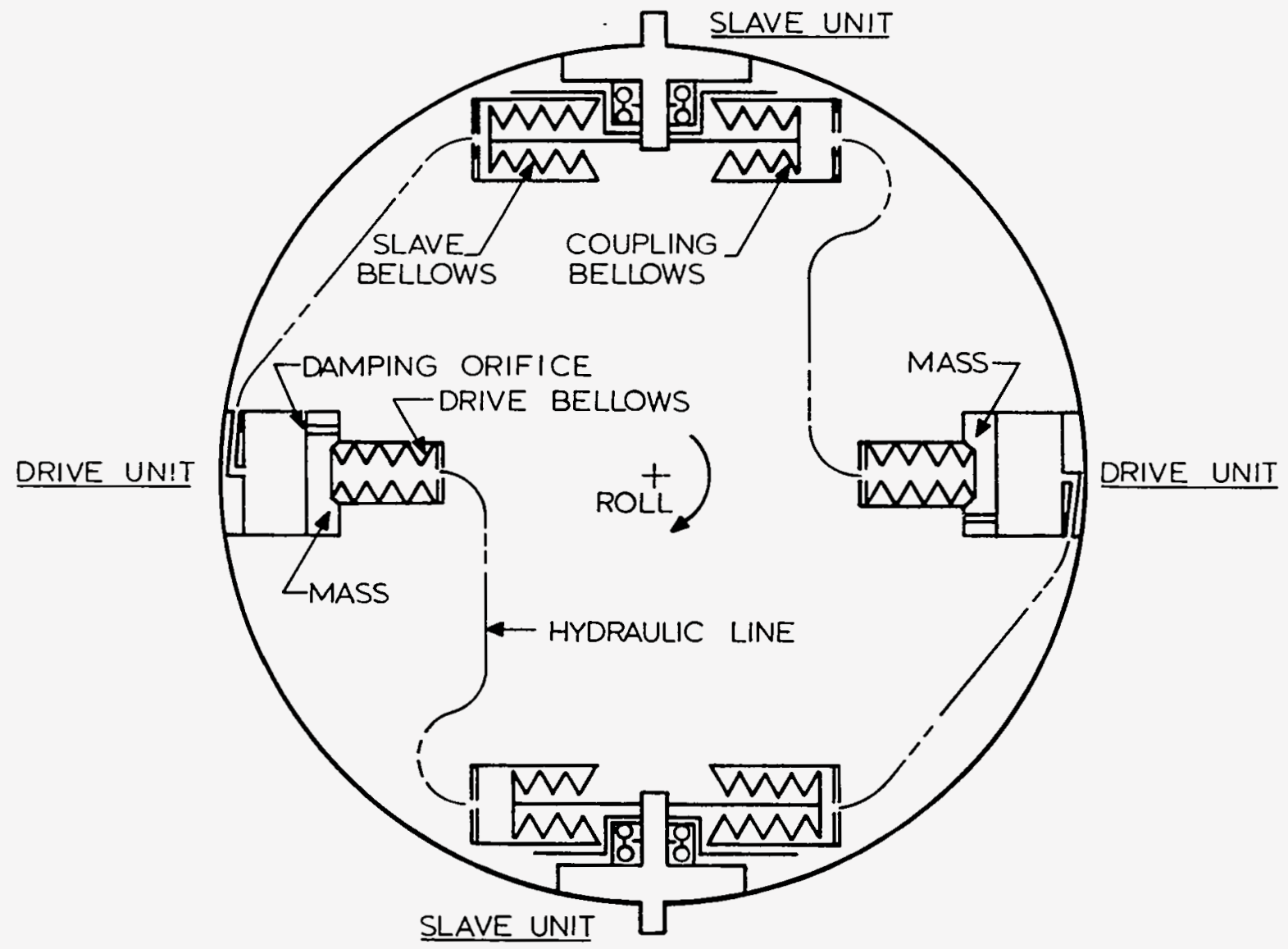

Figure 6. Centrifugally Operated Fin Roll Control System 
position of the two system sensing/drive masses. Mass position is given by the summation of the system spring forces and centrifugal forces (as provided by the vehicle spin rate). Any movement of a mass causes a displacement of hydraulic fluid in a drive bellows, and through a hydraulic line, an equivalent displacement in a slave bellows. The slave bellows, through a rod and bell crank, actuates a fin. The coupling bellows is hardmounted to the slave bellows and hydraulically linked to the opposite drive mass. The circuit is completed by the coupling hydraulic line which leads to a second slave unit.

If the hydraulic fluid is considered incompressible, and if there is no compliance in the hydraulic lines and bellows, the masses and fins are coupled. The system is thus centrifugally actuated and hydraulically coupled. Ideally, the system displacement is governed by a second-order differential equation.

The roll control system physical properties are listed in Table II. Each sensing mass weighs 0.75 pound and is constructed of tungsten $\left(18 \mathrm{~g} / \mathrm{cm}^{2}\right)$. The total system weight (including instrumentation) is 7.2 pounds.

TABLE II

ROLL CONTROL SYSTEM PHYSICAL PROPERTIES

\begin{tabular}{|c|c|c|}
\hline $\begin{array}{l}\text { Weight } \\
\text { (including all instrumentation) }\end{array}$ & $7.194 \mathrm{lb}$ & \\
\hline$\overline{\mathrm{x}}$ & 7.706 in (from base) & \multirow{3}{*}{$\begin{array}{l}\text { RCS center-of- } \\
\text { mass position }\end{array}$} \\
\hline $\bar{Y}$ & 0.0 in $\left.\}_{\text {(from geometric }}\right\}$ & \\
\hline$\overline{\mathrm{z}}$ & 0.0 in $\int$ centerline) & \\
\hline$I_{x}$ & 0.0262 slug-ft ${ }^{2}$ & \multirow{3}{*}{$\begin{array}{l}\text { moments of } \\
\text { inertia about } \\
\text { center of mass }\end{array}$} \\
\hline$I_{y}$ & 0.0212 slug-ft ${ }^{2}$ & \\
\hline$I_{z}$ & 0.0137 slug-ft ${ }^{2}$ & \\
\hline
\end{tabular}

Details of the drive and slave unit design are shown in Figures 7 and 8, those of the fin drive mechanism, in Figure 9. Detailed descriptions of the roll control system componentry and its interface with the flight vehicle are given in Figures 10 and 11, respectively. The reader is referred to Reference 3 for further design details. 

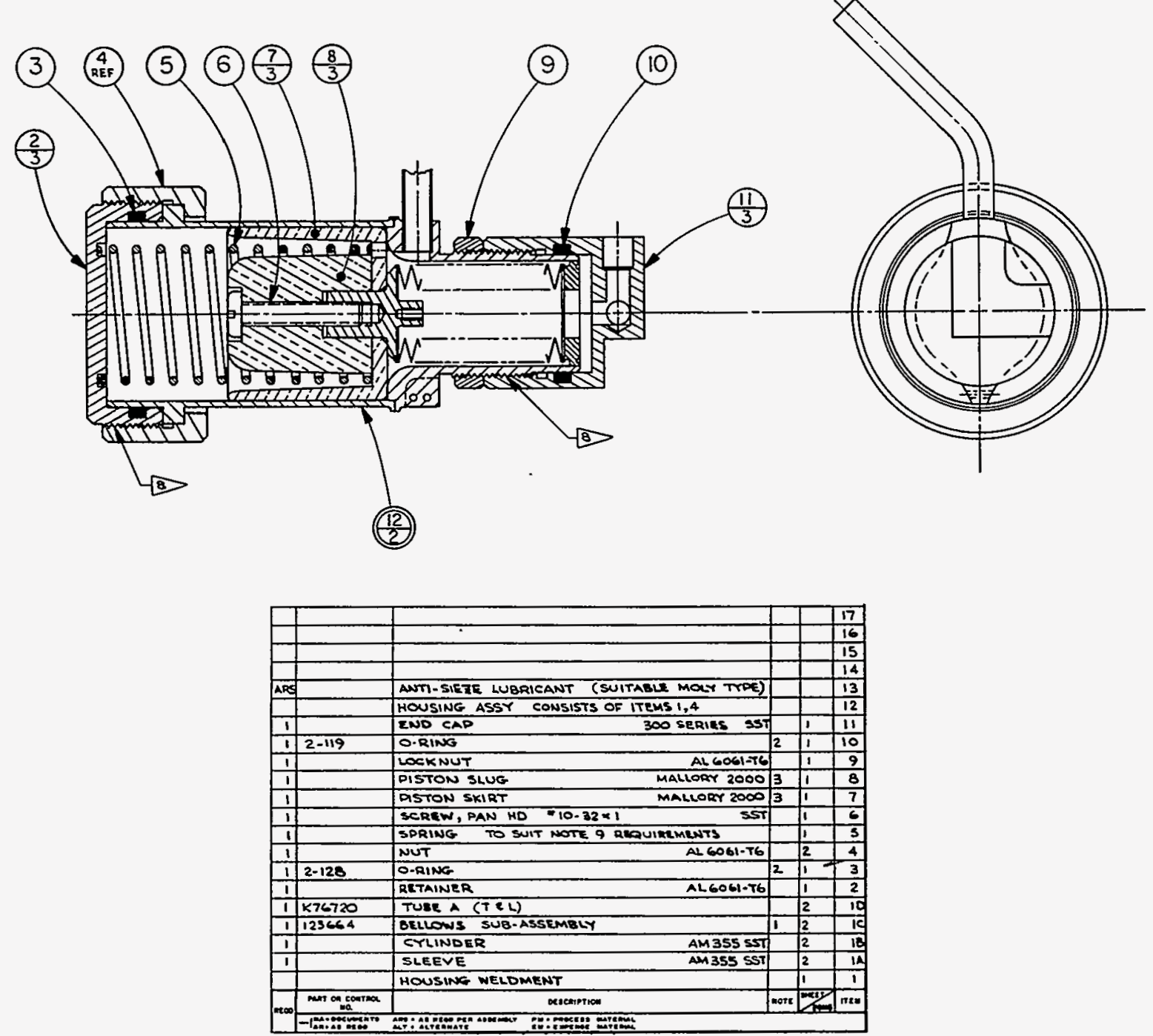

Figure 7. Drive Unit Design Detail (K77099) 

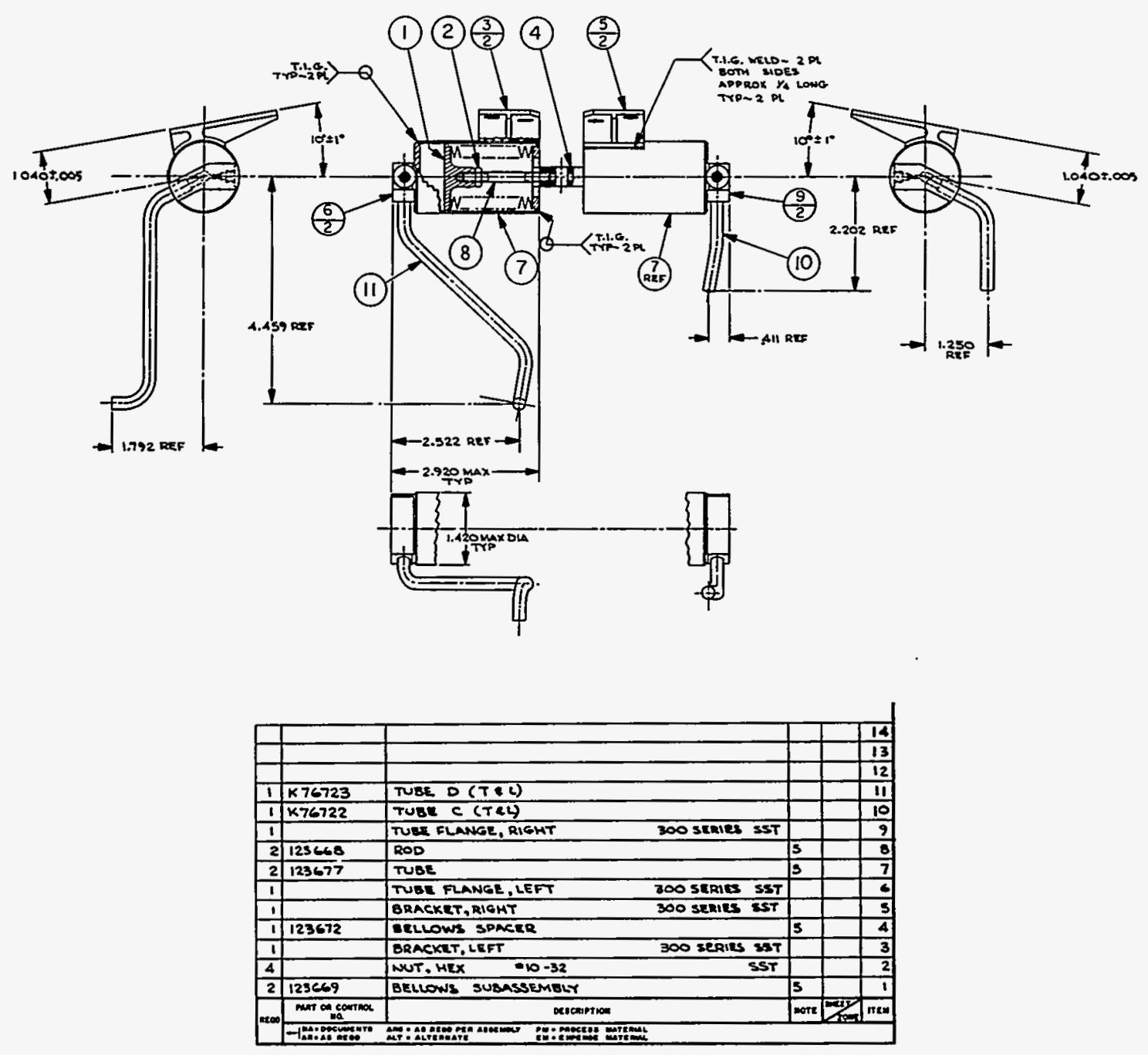

Figure 8. Slave Unit Design Detail (K77108) 


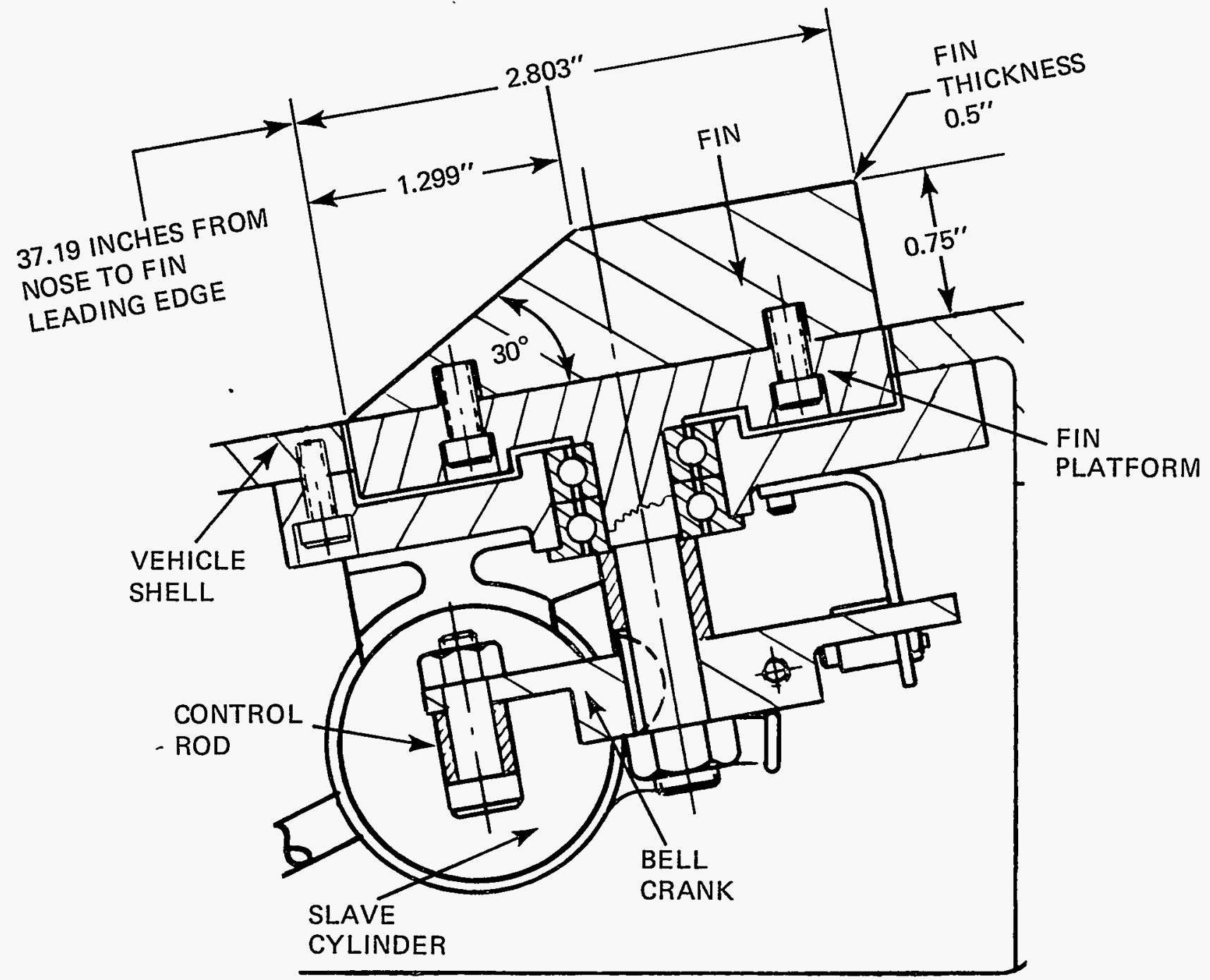

Figure 9. Detail of RCRTV Fin Mechanism 

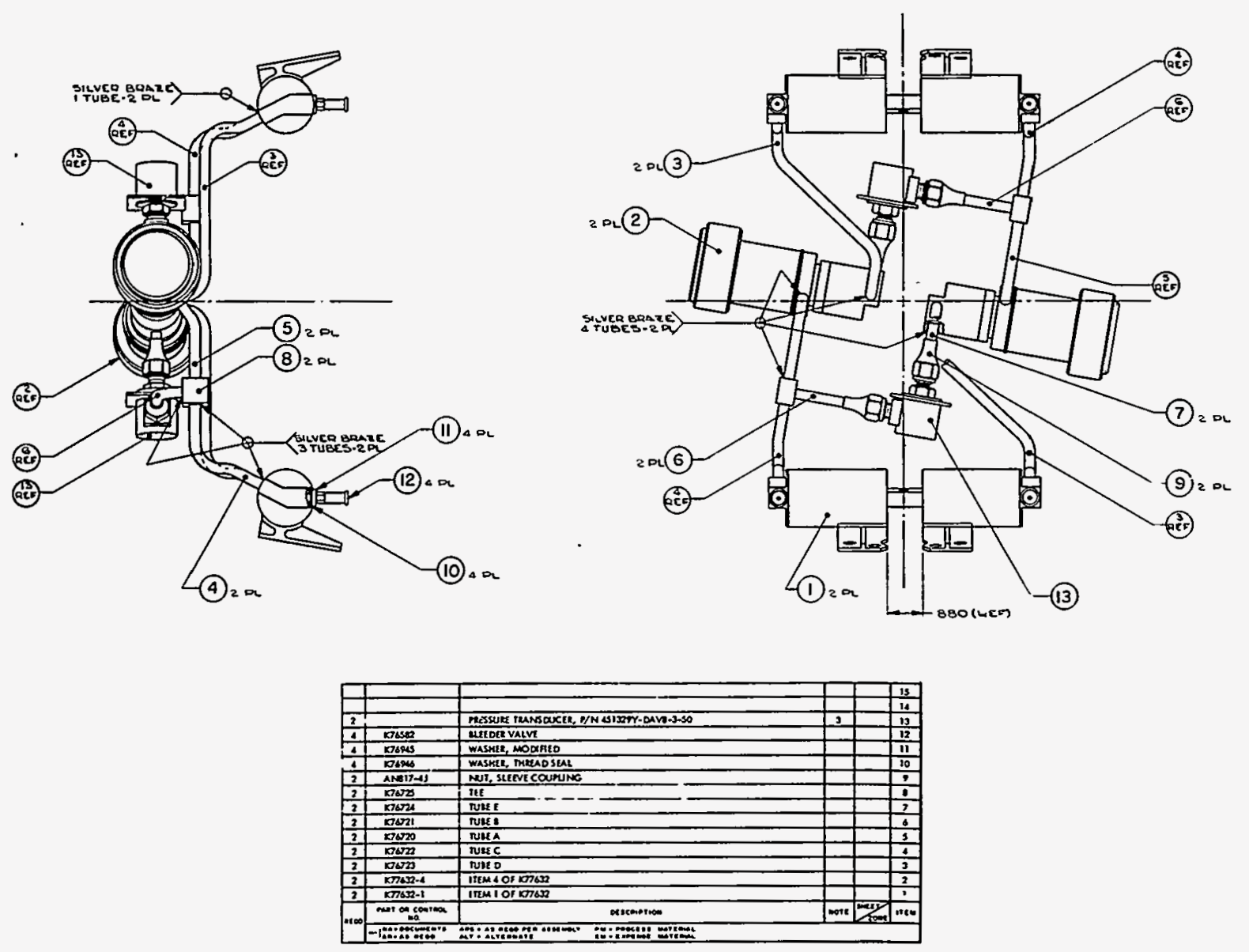

Figure 10. Roll Control System Detail (K77635) 

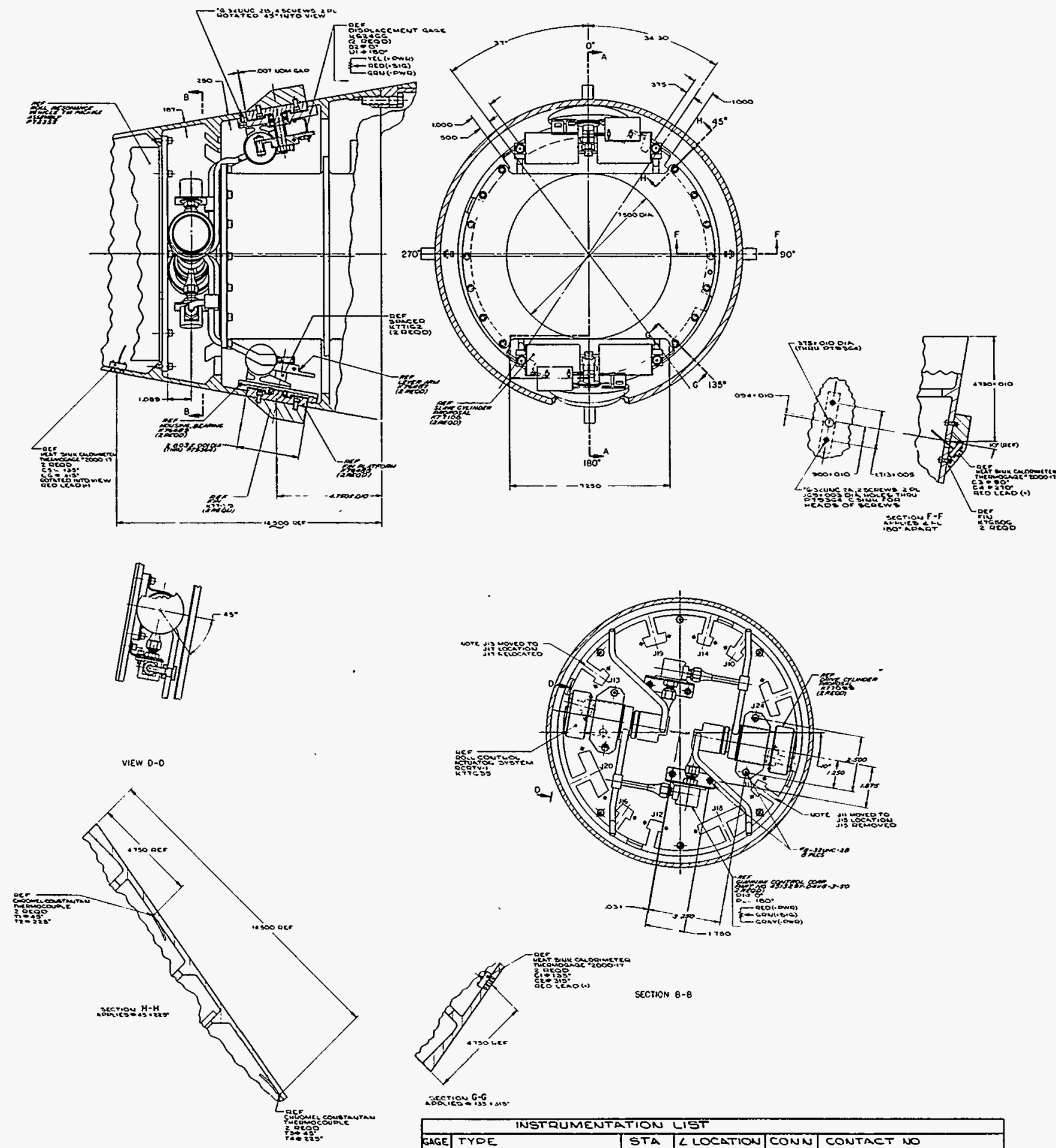

\begin{tabular}{|c|c|c|c|c|c|}
\hline \multicolumn{3}{|c|}{ INSTRUMENTATION } & \multicolumn{3}{|l|}{ LIST } \\
\hline GAGE & TYOE & STA & LLOCATION & CONN & CONTACT NO \\
\hline 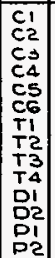 & $\begin{array}{l}\text { CALORIMETER } \\
" 1 " \\
" " \\
\text { "" } \\
\text { THERMOCOUDLE } \\
\text { "" } \\
\text { OISP" GAGE } \\
\text { PRESS TRANSOUCER }\end{array}$ & $\begin{array}{l}475 \\
" 1 " \\
1450 \\
4 " 75 \\
4 " 50 \\
14 " 10 \\
3.50 \\
8.60\end{array}$ & $\begin{array}{l}135^{\circ} \\
315^{\circ} \\
90^{\circ} \\
270^{\circ} \\
135^{\circ} \\
315^{\circ} \\
45^{\circ} \\
225^{\circ} \\
45^{\circ} \\
225^{\circ} \\
180^{\circ} \\
0^{\circ} \\
180^{\circ}\end{array}$ & 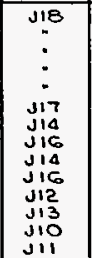 & 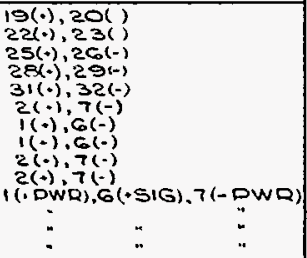 \\
\hline
\end{tabular}

Figure 11. RCRTV System Interface (DL24836) 
Flight Vehicle Instrumentation and Telemetry

Instrumentation on board the payload is designed to provide a detailed evaluation of body and control-system dynamics. ${ }^{1,4}$ These data are comprehensive enough to allow an assessment of the analytic prediction techniques used in the development of the system. The payload includes vehicle dynamic, roll control system dynamic, and thermodynamic instrumentation, as well as a p-band telemetry system that transmits through a nose antenna. The function of each sensor is given in Table III, and a detailed listing of each measurement (including range and sampling rate) is given in Table IV. *

The telemetry system is a 2-watt transmitter operating at 248.6 $\mathrm{MHz}$. The transmitter is frequency-modulated with the subcarrier oscillator frequencies and subcarrier assignments shown in Table $V$. Only the thermodynamic instrumentation (thermocouples and calorimeters) is commutated, and the rate for the commutated information is 30 samples per second.

In addition to the foregoing instrumentation, passive thermodynamic instrumentation in the form of heat-sensitive (temperature-sensitive) paint (Tempilaq) ** is used on both the interior and exterior of the flight unit. Tempilaq tints responsive to various temperatures are placed on the top and sides of the fins, on the fin platforms, and on cone surface areas located aft and on either side of each fin. A detailed description of the Tempilaq placement is given in Reference 5.

A detailed description of range instrumentation and support is given in Reference 6.

Flight Trajectory Analysis

General Flight Characteristics

The flight trajectory sequence of events and the altitude history are depicted in Figure 12. Each Nike rocket booster has a nominal burn time of 3.5 seconds. Approximately 1.0 second is expended for staging after first-stage burn. At second-stage burnout, the vehicle is separated from the launch vehicle at the conditions shown in Figure 12.

*Payload instrumentation and telemetry designs were provided by

R. H. Lanes and K. W. Shrock, Instrumentation Applications

Division II 9483.

**A product of Tempil Corporation, New York, N.Y. 
TABLE III

RCRTV INSTRUMENTATION AND FUNCTION

\begin{tabular}{|c|c|}
\hline Sensor & Function \\
\hline Tri-axis rate gyro & $\begin{array}{l}\text { Measures pitch, yaw, and roll } \\
\text { angular velocities about body fixed } \\
\text { axes. }\end{array}$ \\
\hline $\begin{array}{l}\text { MARS (miniature altitude reference } \\
\text { system) stable platform }\end{array}$ & $\begin{array}{l}\text { Measures inertial pitch, yaw, and } \\
\text { roll angles. }\end{array}$ \\
\hline Accelerometers & $\begin{array}{l}\text { Measure accelerations along body } \\
\text { fixed axes and provide static and } \\
\text { dynamic stability data. }\end{array}$ \\
\hline Linear potentiometers & $\begin{array}{l}\text { Measure roll control system mass } \\
\text { position and fin cant. }\end{array}$ \\
\hline Differential pressure transducers & $\begin{array}{l}\text { Measure pressure differential } \\
\text { across slave bellows assembly } \\
\text { (determines applied torque on the } \\
\text { fin). }\end{array}$ \\
\hline Thermocouples & $\begin{array}{l}\text { Measure temperatures on the vehicle } \\
\text { shell backface. These sensors are } \\
\text { located at two body-axial positions, } \\
\text { two each at the fin station and approxi } \\
\text { mately } 14 \text { inches forward of the fin } \\
\text { station. At each axial location, the } \\
\text { thermocouples are diametrically } \\
\text { opposed in a plane } 45^{\circ} \text { from the plane } \\
\text { containing the moving fins. }\end{array}$ \\
\hline Calorimeters & $\begin{array}{l}\text { Measure heat flux at the vehicle } \\
\text { surface and fin leading edge. A } \\
\text { calorimeter is located on the leading } \\
\text { edge of each fixed fin. The cone } \\
\text { surface calorimeters are located } \\
\text { in the same stations as the thermo- } \\
\text { couples. They are diametrically } \\
\text { opposed and in a plane normal to } \\
\text { the thermocouple plane. }\end{array}$ \\
\hline
\end{tabular}


TABLE IV

RCRTV INSTRUMENTATION

\begin{tabular}{lll}
\hline \multicolumn{1}{c}{ Measurement } & Range & Sampling Rate \\
\hline \hline Vehicle Dynamics & & \\
\hline Roll rate & $\pm 4000 \mathrm{deg} / \mathrm{s}$ \\
Pitch rate & $\pm 400 \mathrm{deg} / \mathrm{s}$ \\
Yaw rate & $\pm 400 \mathrm{deg} / \mathrm{s}$ \\
Pitch & $\pm 360 \mathrm{deg}$ \\
Yaw & $\pm 85 \mathrm{deg}$ \\
Roll & $\pm 360 \mathrm{deg}$ \\
X acceleration & $\pm 50 \mathrm{~g}$ & \\
X acceleration & $\pm 30 \mathrm{~g}$ \\
Y acceleration & $\pm 50 \mathrm{~g}$ \\
Z acceleration & $\pm 50 \mathrm{~g}$
\end{tabular}

*Instrumentation supplied by Components \& Instrumentation Section 8183-1; all other instrumentation supplied by Instrumentation Applications Division III 9483 


\section{TABLE V}

RCRTV TELEMETRY SYSTEM SUBCARRIER ASSIGNMENTS

(MAIN CARRIER FREQUENCY 248. $6 \mathrm{MHz}, 2$ WATTS)

\begin{tabular}{|c|c|}
\hline $\begin{array}{c}\text { Subcarrier Frequency } \\
(\mathrm{MHz})\end{array}$ & Assignment \\
\hline 1.3 & $\mathrm{X}$ acceleration \\
\hline 1.7 & $\mathrm{X}$ acceleration \\
\hline 2.3 & pitch rate \\
\hline 3.0 & yaw rate \\
\hline 3.9 & roll rate \\
\hline 5.4 & yaw \\
\hline 7.35 & pitch \\
\hline 10.5 & roll \\
\hline 14.5 & $\mathrm{Z}$ acceleration \\
\hline 22.0 & Y acceleration \\
\hline 30.0 & $0^{\circ}$ fin displacement (D2) \\
\hline 40.0 & $180^{\circ}$ fin displacement (D1) \\
\hline 52.5 & $\begin{array}{c}180^{\circ} \text { fin differential } \\
\text { pressure (P2) }\end{array}$ \\
\hline 70.0 & $\begin{array}{l}0^{\circ} \text { fin differential } \\
\text { pressure }(\mathrm{P} 1)\end{array}$ \\
\hline \multirow[t]{2}{*}{93.0} & Commutator \\
\hline & $\begin{array}{l}4 \text { thermocouples } \\
2 \text { fin calorimeters } \\
4 \text { cone calorimeters }\end{array}$ \\
\hline
\end{tabular}




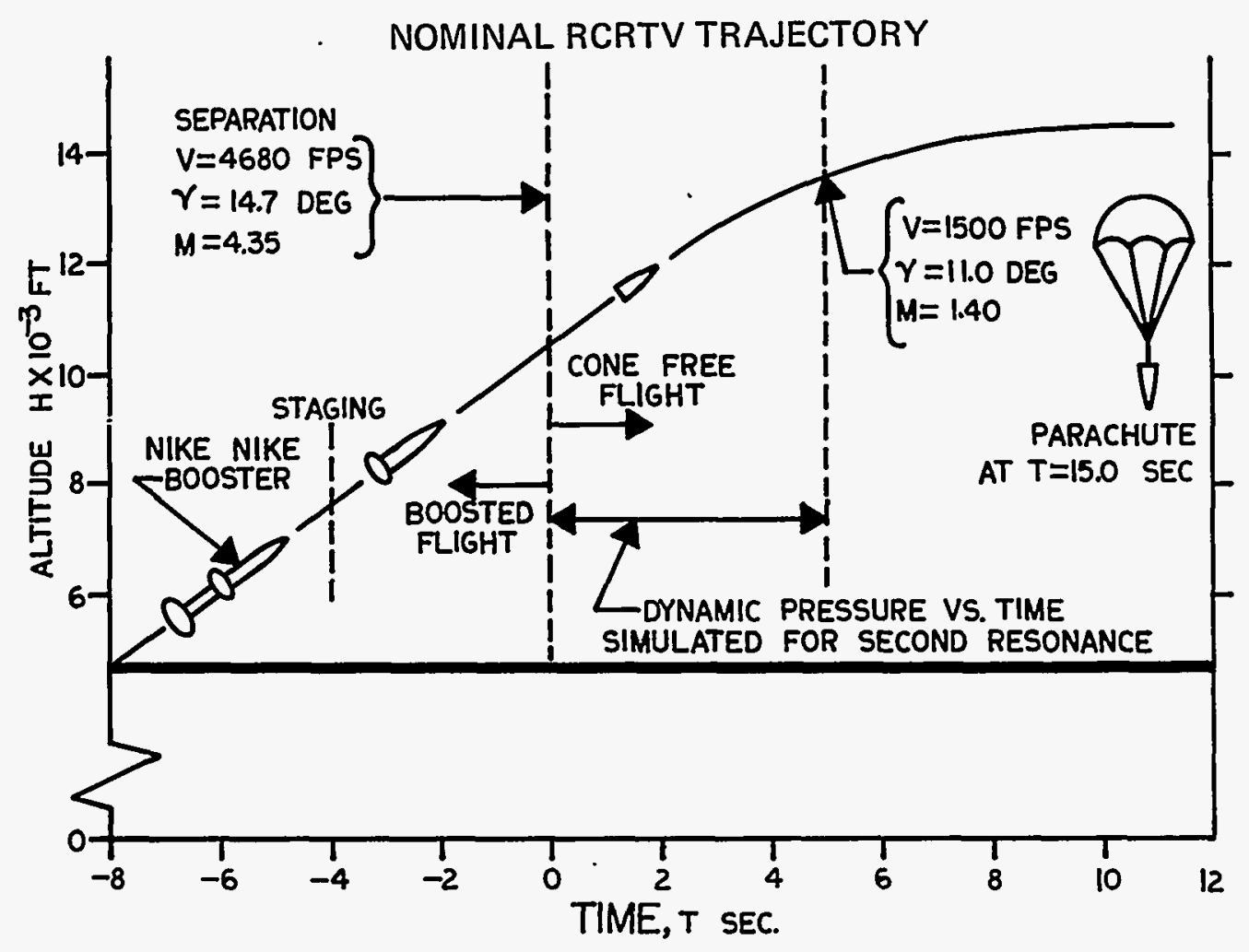

Figure 12. RCRTV Trajectory Events

The total boost phase duration is therefore approximately 8 seconds. The payload free-flight position of the trajectory simulates the dynamic pressure and vehicle natural pitch frequency histories for a second-reso nance encounter. At approximately 15 seconds after vehicle separation, a 3-footdiameter pilot parachute is deployed. This is followed at $\mathrm{T}=25$ seconds by the 12-foot-diameter main parachute. (Note: Except where otherwise specified, $\mathrm{T}=$ time from vehicle separation. )

\section{Flight Trajectory Data}

The flight vehicle trajectory is reconstructed from the radar ${ }^{7}$ and payload telemetry data. These data in conjunction with trajectory simulations are used in establishing the payload separation conditions as well as the time history of the trajectory performance variables. The radar measured position and velocity are used primarily to establish the boost phase trajectory and payload separation conditions. 
Two accelerometers with different ranges ( $\pm 30 \mathrm{~g}$ and $\pm 50 \mathrm{~g}$ ) were used to monitor payload axial acceleration history. The measured axial acceleration from these instruments is shown as a function of flight time in Figures 13 and 14. These accelerations (excluding any instrument bias) may be integrated to determine the payload axial velocity history. Because the $\pm 30 \mathrm{~g}$ accelerometer becomes saturated from $T=6.0$ to $7.5 \mathrm{sec}$ from launch and again from $T=8.0$ to 9.0 seconds from launch, it is not used in determining the velocity history. The axial velocity history is considered equal to the total velocity. This assumption is true since during the boost phase, the angle of attack is essentially zero and during the payload free flight period, the angle of attack is small enough so that the axial velocity is within $1 / 2$ percent of the total velocity.

The results of the trajectory analysis are summarized in Figures 15 and 16, in which the flight vehicle altitude and velocity history are presented. Data from both radar and accelerometers, which yield the same payload separation velocity are used to construct the velocity history. The initial conditions for the payload trajectory simulation included in Figures 15 and 16 are comprised of the separation velocity and separation altitude determined from radar. The simulation is obtained with the SPINFIN 8,9 trajectory program. The foregoing methods have provided an excellent characterization of the flight trajectory and payload separation conditions.

$\underline{\text { Meteorological Data }}^{10}$

Immediately before the flight, atmospheric data was obtained by means of rawinsonde balloons released in the neighborhood of the launch area. The air temperature and density data obtained (presented as a function of altitude in Figures 17 and 18, respectively) are used with the trajectory computations to determine dynamic pressure and Mach number. The actual atmospheric data used in this case deviate about 5 percent from the standard 1962 model atmosphere in the altitude range of interest. This deviation would produce some small errors in all trajectory performance variables.

\section{Payload Separation Conditions and Vehicle Trajectory}

The vehicle separation conditions (Table IV), as determined from the sources previously discussed, were very close to those expected. These conditions are read in as initial conditions to the SPINFIN trajectory simulation program to determine the payload trajectory characteristics. The RCRTV payload velocity, Mach number, and dynamic pressure history thus determined (presented as functions of time from separation, Figures 19, 20, and 21) are used in the aerodynamic and flight dynamic analyses. 


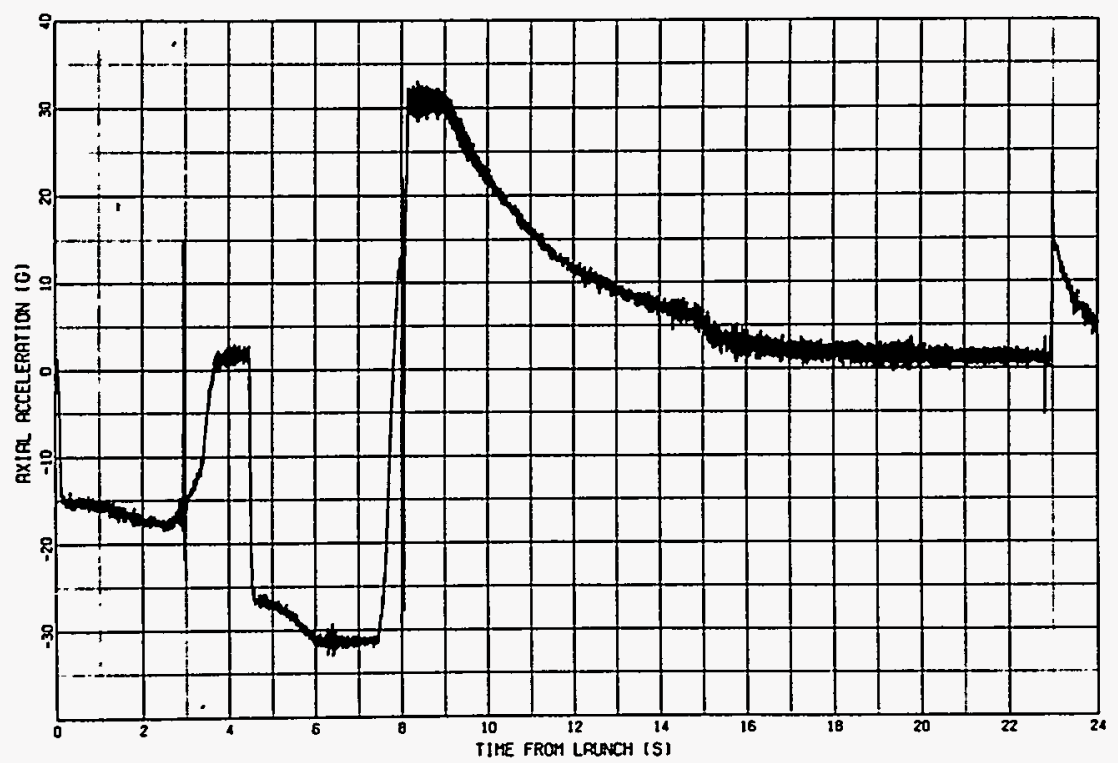

Figure 13. Payload Axial Acceleration vs. Time ( $\pm 30 \mathrm{~g}$ Accelerometer)

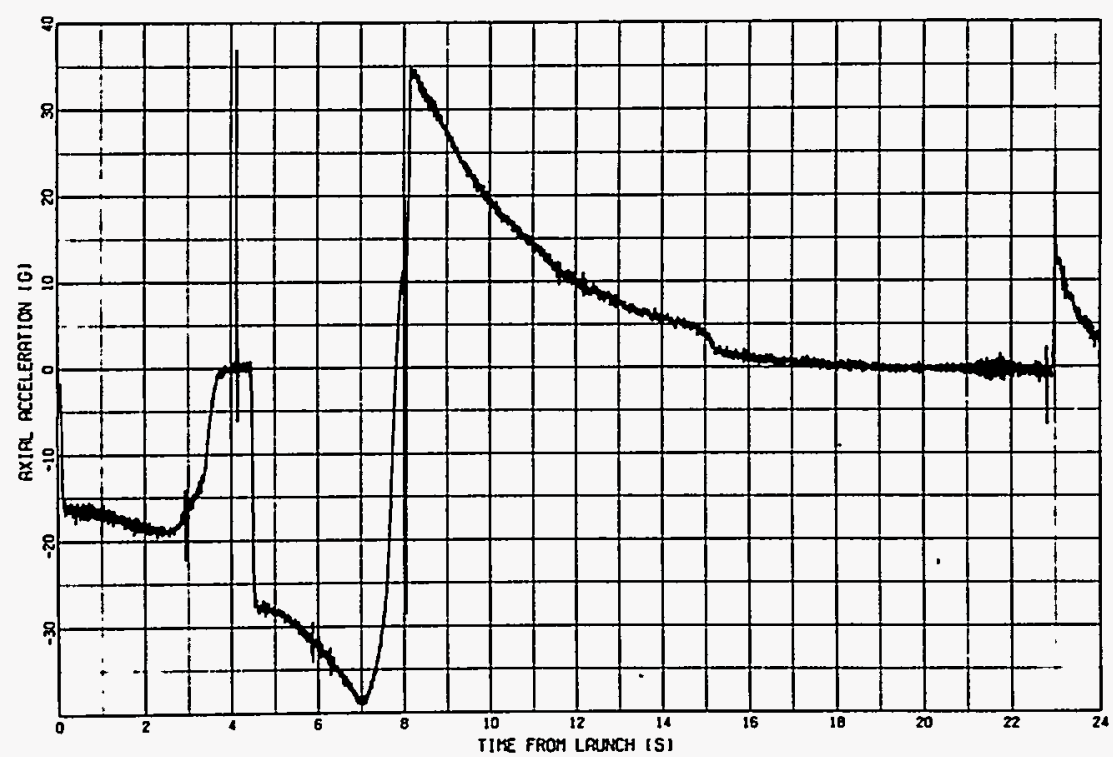

-Figure 14. Payload Axial Acceleration vs. Time ( $\pm 50 \mathrm{~g}$ Accelerometer) 


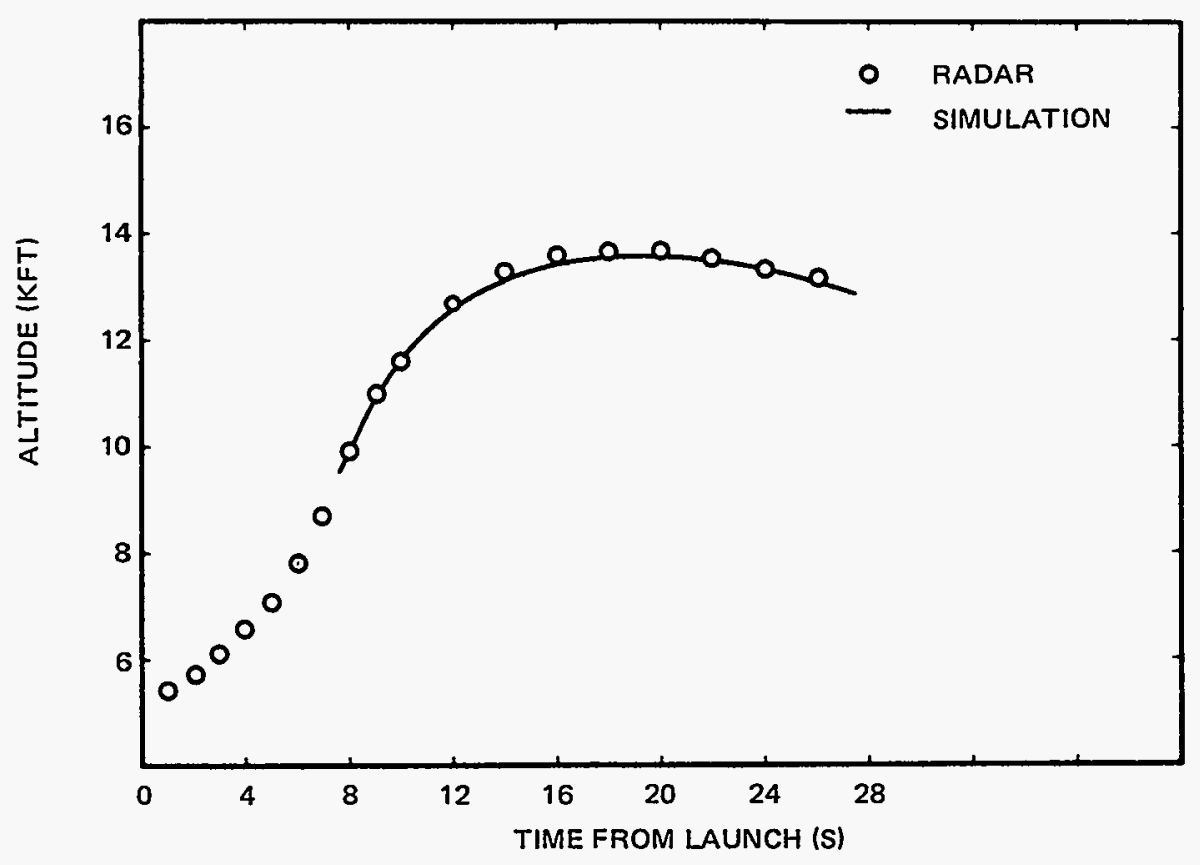

Figure 15. Flight Altitude History

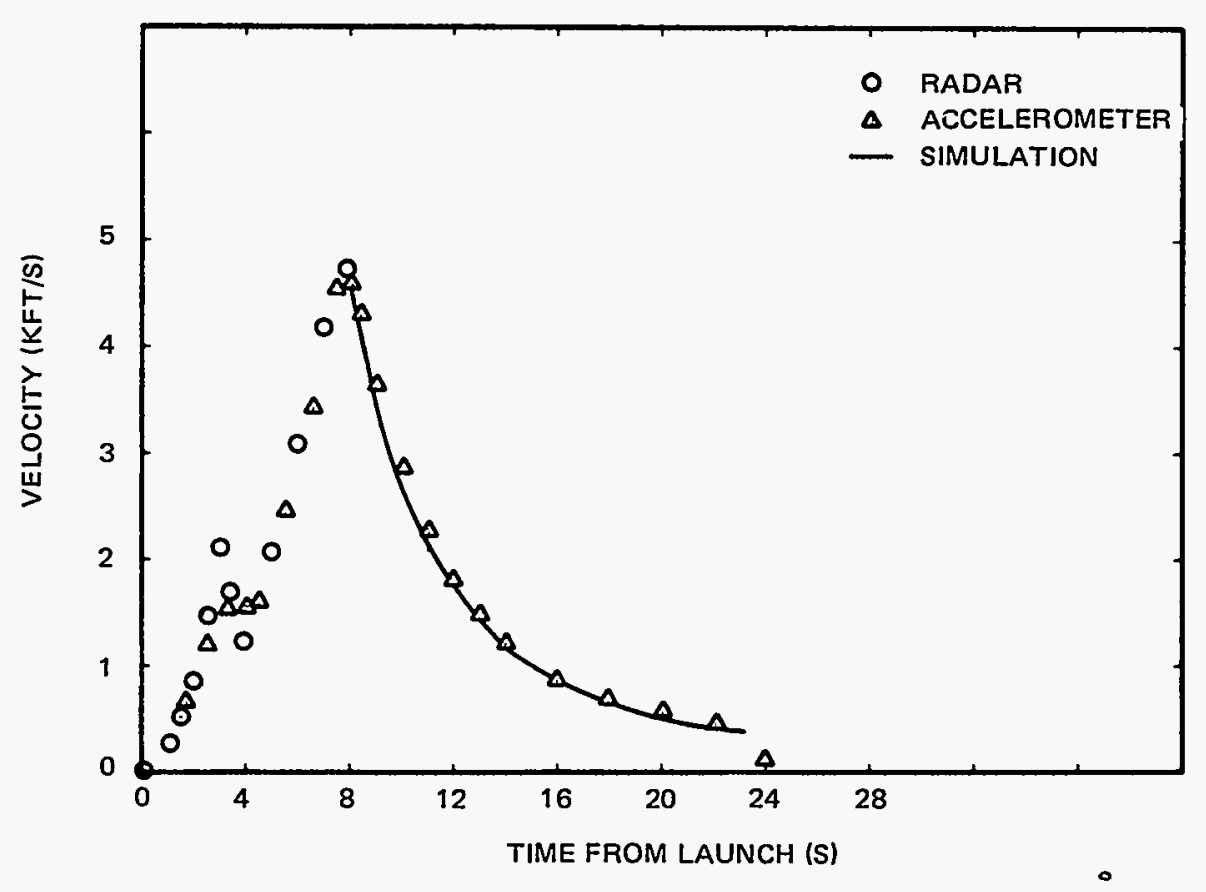

Figure 16. Flight Velocity History 


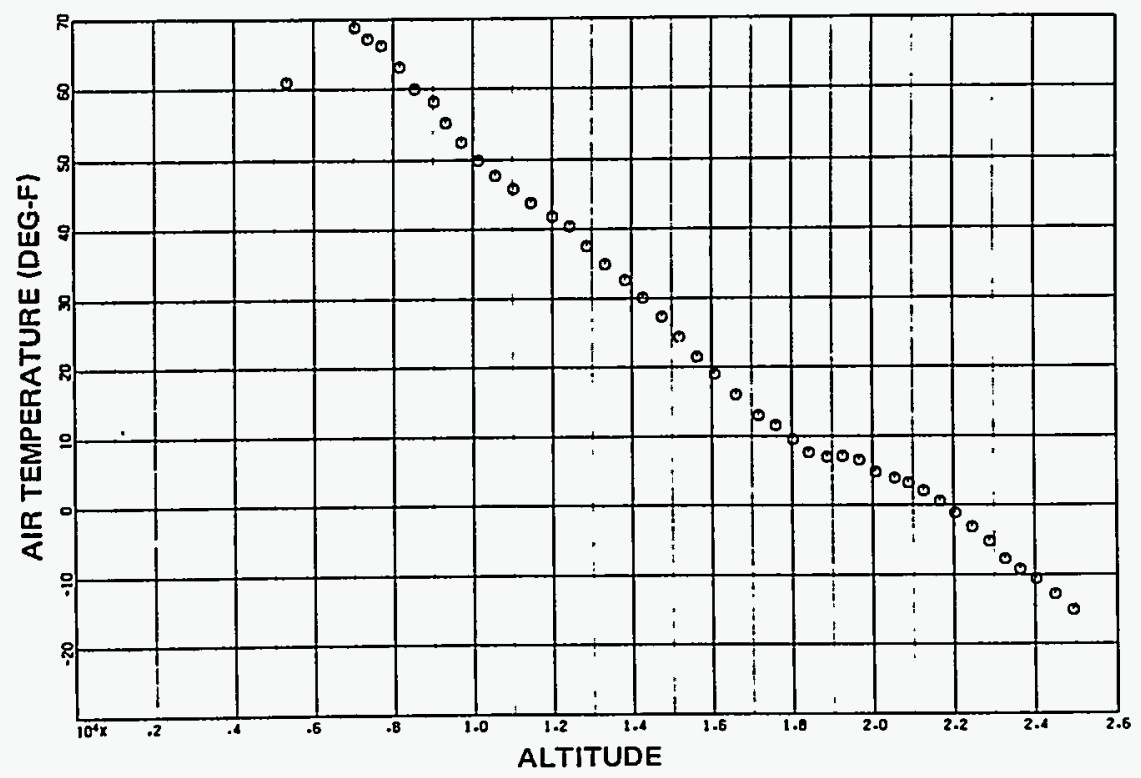

Figure 17. Air Temperature vs. Altitude

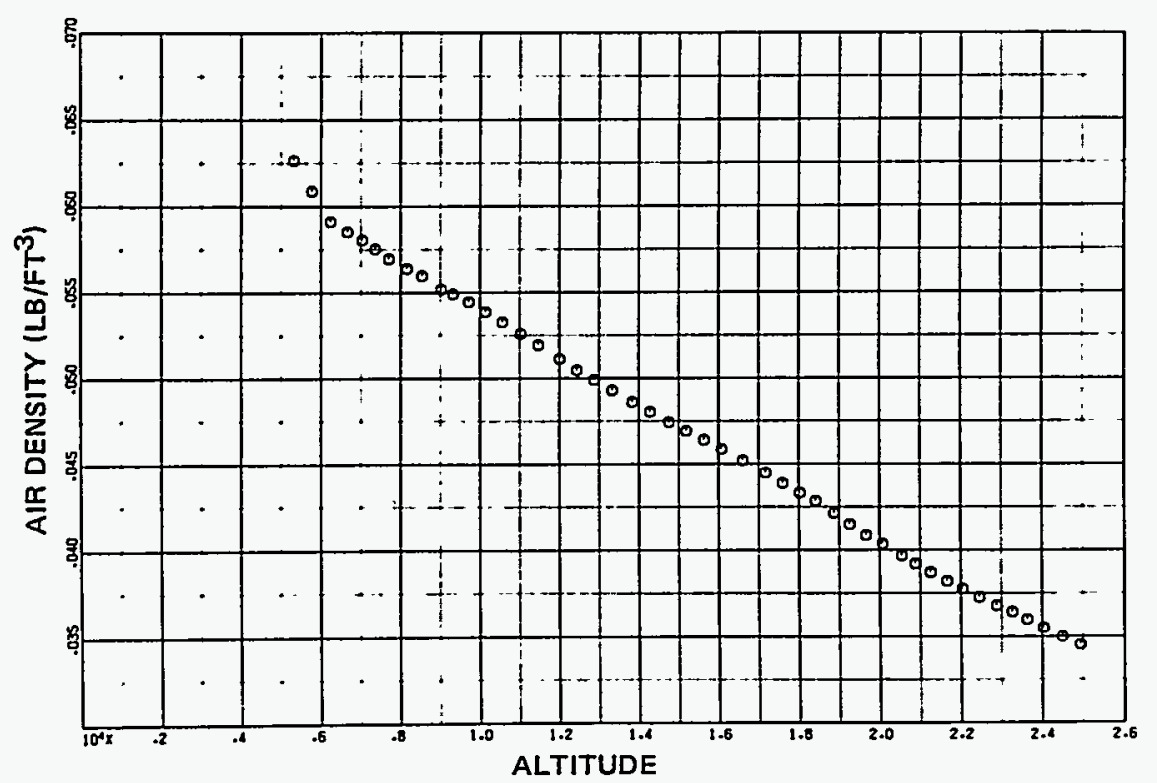

Figure 18. Air Density vs. Altitude 
TABLE VI

RCRTV PAYLOAD SEPARATION CONDITIONS

\begin{tabular}{lc}
\hline Velocity & $4770 \mathrm{ft} / \mathrm{s}$ \\
Mach number & 4.3 \\
Flight path angle & $14.6^{\circ}$ \\
Altitude & $9765 \mathrm{ft}$ \\
Dynamic pressure & $19210 \mathrm{lb} / \mathrm{ft}^{2}$ \\
Roll rate & $5.44 \mathrm{cycles} / \mathrm{s}$ \\
\hline
\end{tabular}

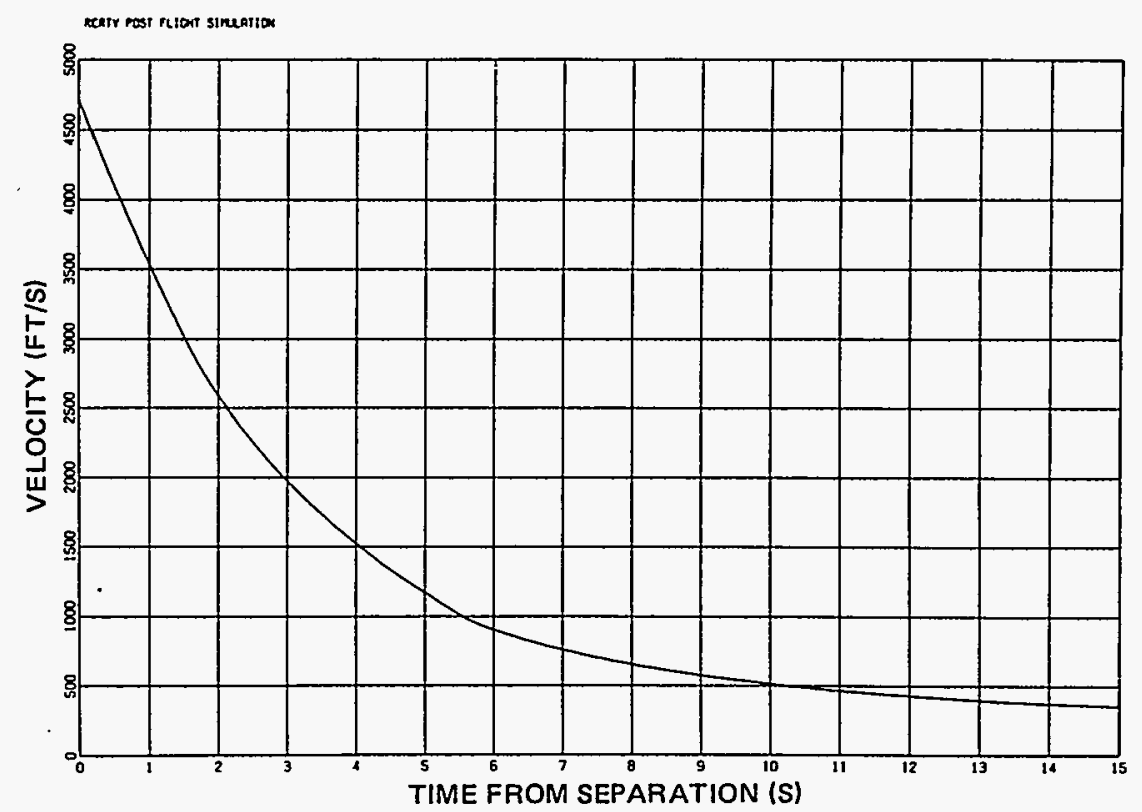

Figure 19. RCRTV Velocity History 


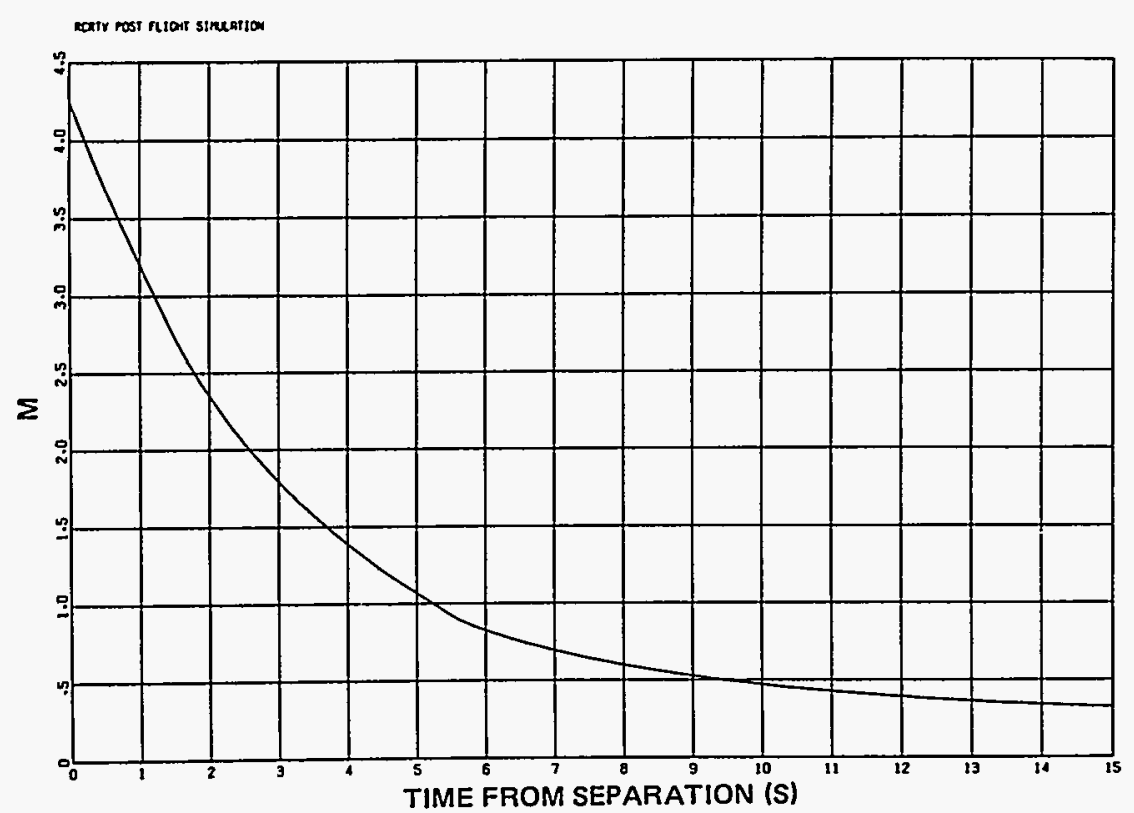

Figure 20. RCRTV Mach Number History

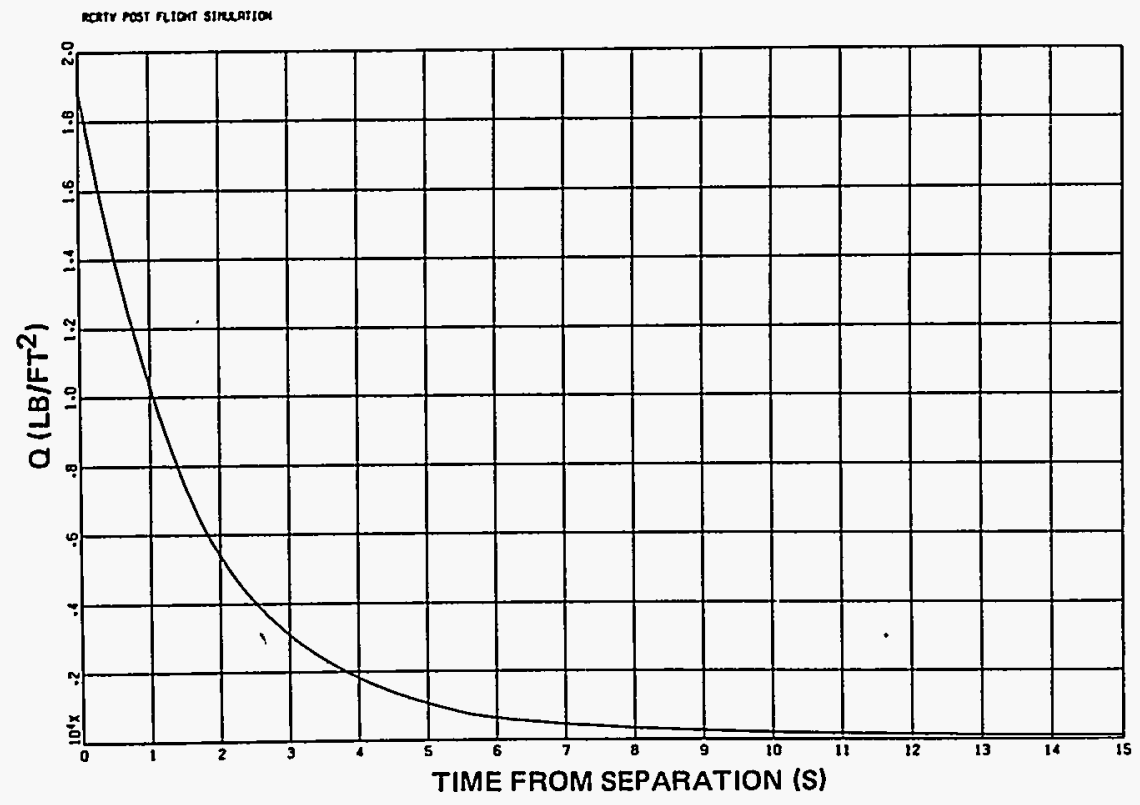

Figure 21. RCRTV Dynamic Pressure History 


\section{Flight Dynamics Analysis}

Flight Motion Data

The flight vehicle carried instrumentation to provide the body fixed angular velocity components, pitch rate, yaw rate, and roll rate p, $q, r$, and the body fixed components of translational acceleration $A_{x}, A_{y}, A_{z} \cdot$ In addition, the vehicle was equipped with a miniature attitude reference system (MARS) stable platform which provided the vehicle angular attitude, pitch, yaw, and roll $\theta, \psi, \phi$ relative to a nonrolling (aeroballistic) coordinate system. This instrumentation is described completely in a previous section.

Though the motion data was obtained continuously from lift-off to impact, only the data from payload separation to parachute deployment are of interest in this section. Therefore, the motion data are presented here as a function of time from separation. The data reduction, * which included filtering $(40 \mathrm{~Hz})$ in most cases, is generally of high quality.

Shown in Figures 22 and 23 are the vehicle pitch and yaw attitude angles $(\theta$ and $\psi$ ) as obtained from the MARS platform, plotted as functions of time from separation. The data are given up to the time of parachute deployment. The pitch angle shown includes the effect of trajectory curvature. Also presented is the vehicle pitch angle as a function of yaw angle, in Figure 24 at $\mathrm{T}=0$ to 2.0 seconds and in Figure 25 at $\mathrm{T}=2.0$ to 6.0 seconds. The vehicle angular motion, which is essentially circular, diverges initially because of the effects of roll resonance; and it converges again after the vehicle breaks out of resonance.

The vehicle lateral acceleration histories (Figures 26 and 27) are shown as functions of time from separation. The normal ( $Z$ axis) acceleration, which reaches a peak of $20 \mathrm{~g}^{\prime} \mathrm{s}$ at $\mathrm{T}=1.3$ seconds after separation, is about twice the level expected because the flight vehicle experienced resonance earlier in the flight and at a dynamic pressure higher than expected. The resultant lateral acceleration history is given in Figure 28.

The flight vehicle angular velocity components obtained by the tri-axis rate gyro are presented in Figures 29 and 30; and the resultant lateral angular velocity, in Figure 31. The influence of roll resonance is clearly evident in these data.

\footnotetext{
*The data reduction was provided by Mrs. L. S. Converse, Data Processing Division 8411.
} 


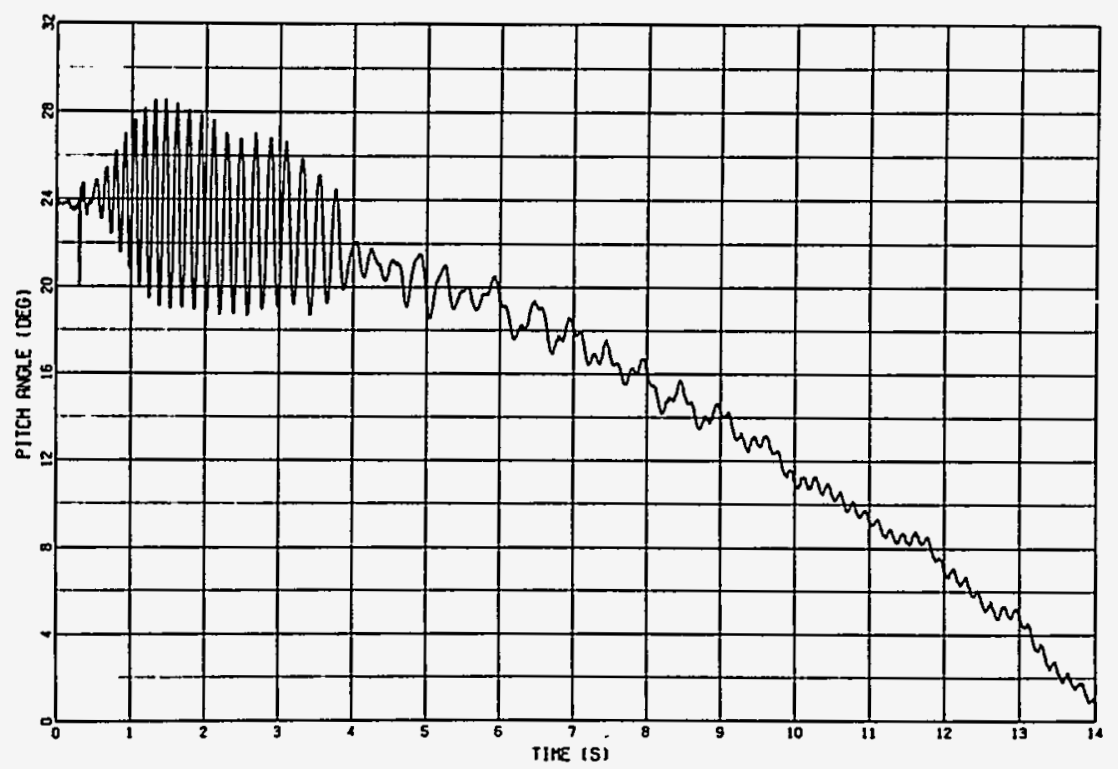

Figure 22. Vehicle Pitch Angle From Stable Platform

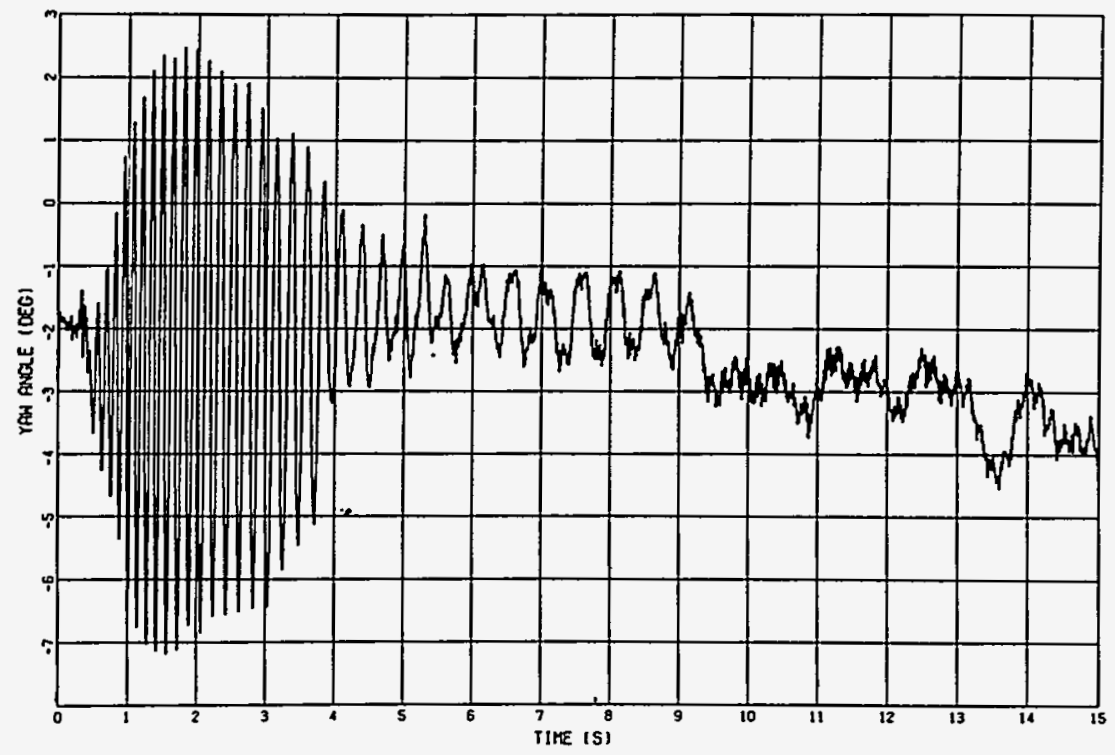

Figure 23. Vehicle Yaw Angle From Stable Platform 


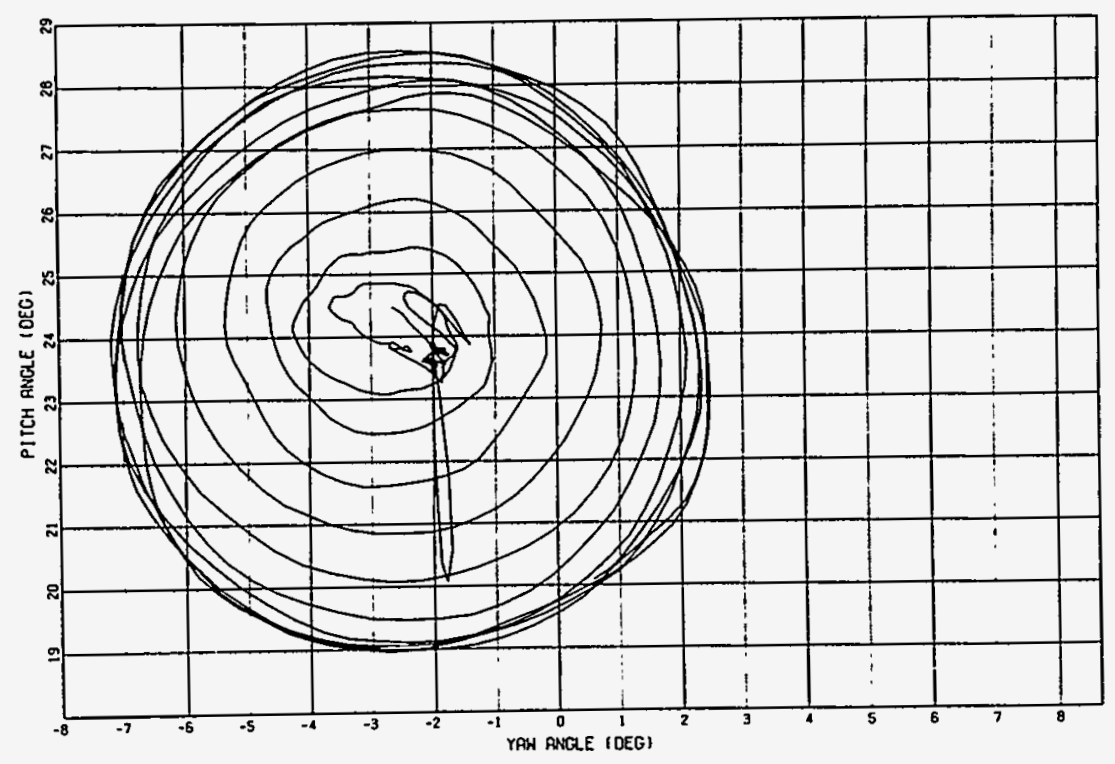

Figure 24. Pitch Angle vs. Yaw Angle ( $T=0$. to $4 . \mathrm{sec})$

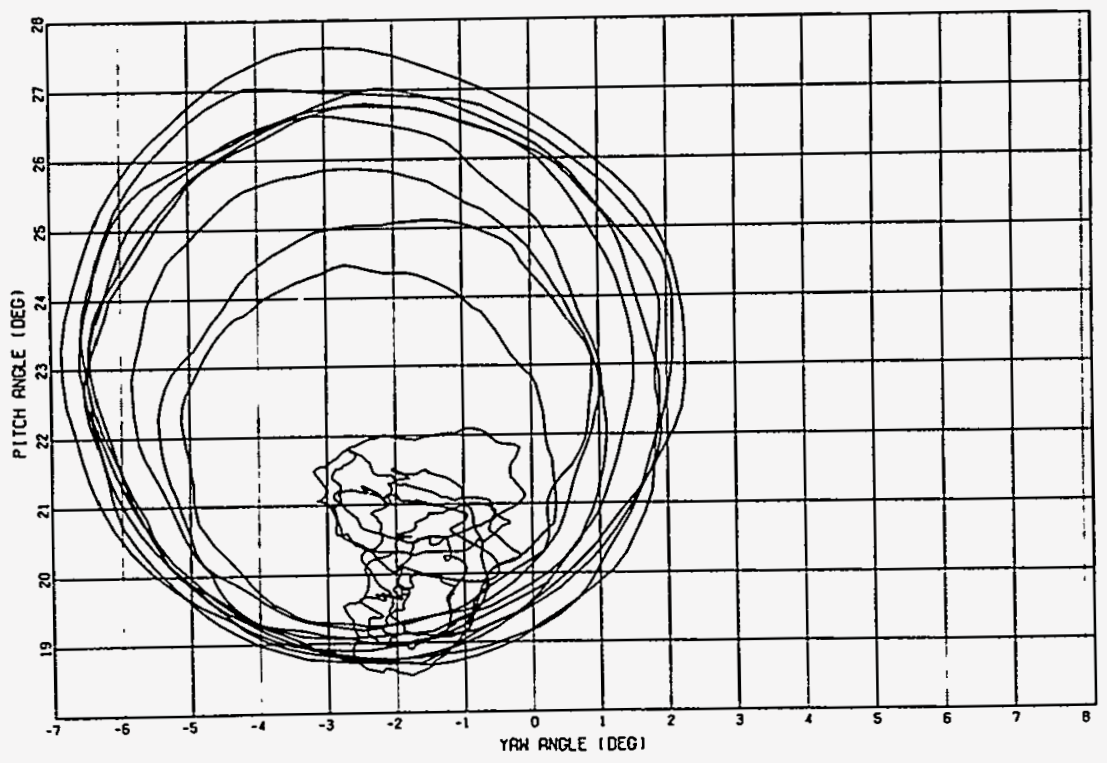

Figure 25. Pitch Angle vs. Yaw Angle ( $T=4$. to 8. $\mathrm{sec})$ 


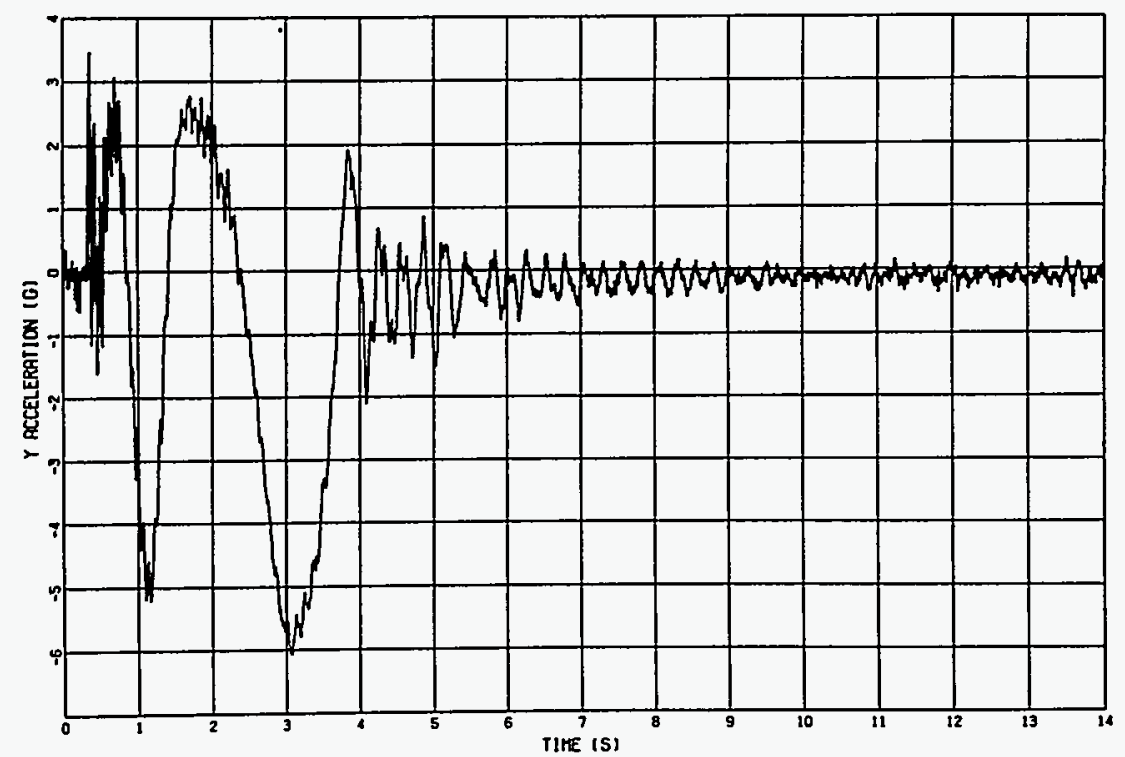

Figure 26. Lateral Acceleration History

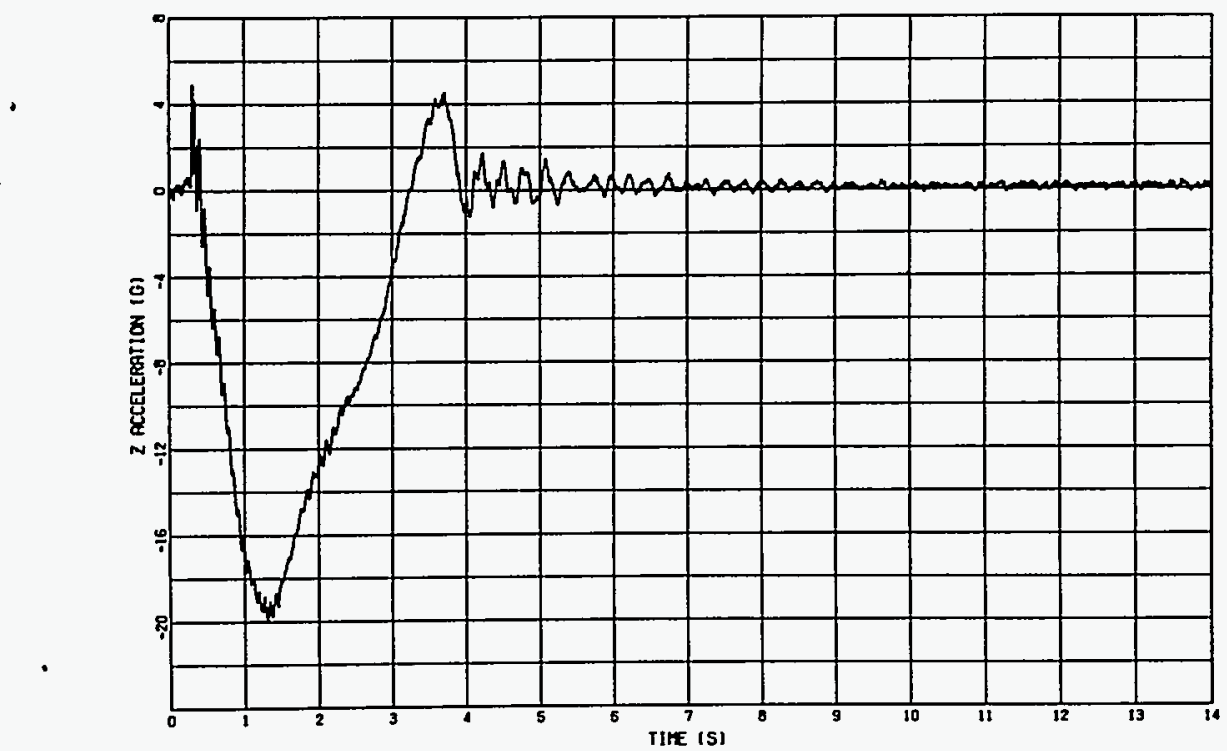

Figure 27. Normal Acceleration History 


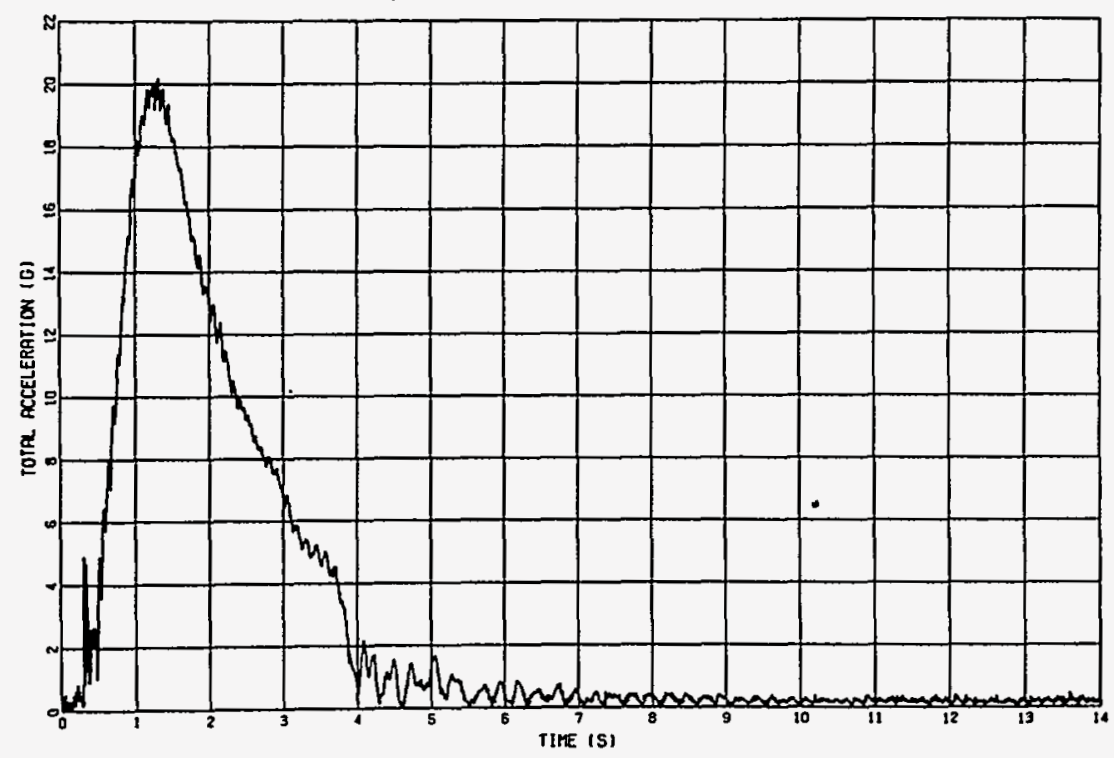

Figure 28. Resultant Lateral Acceleration History

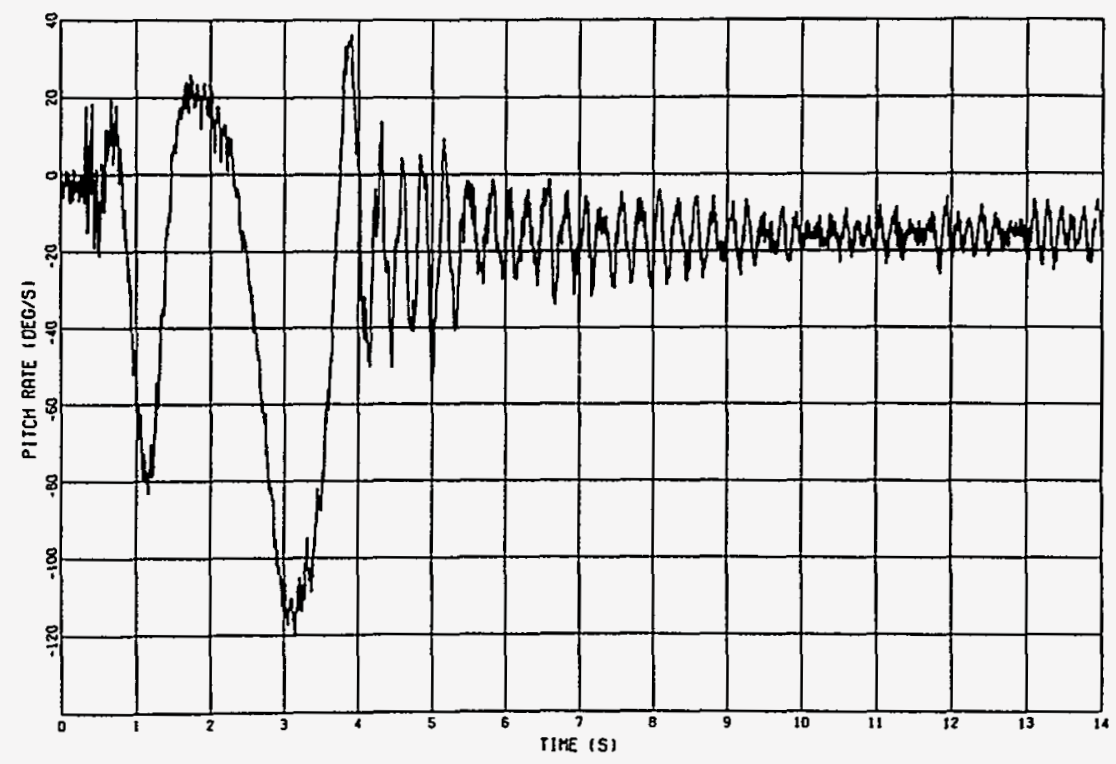

Figure 29. Pitching Velocity History 


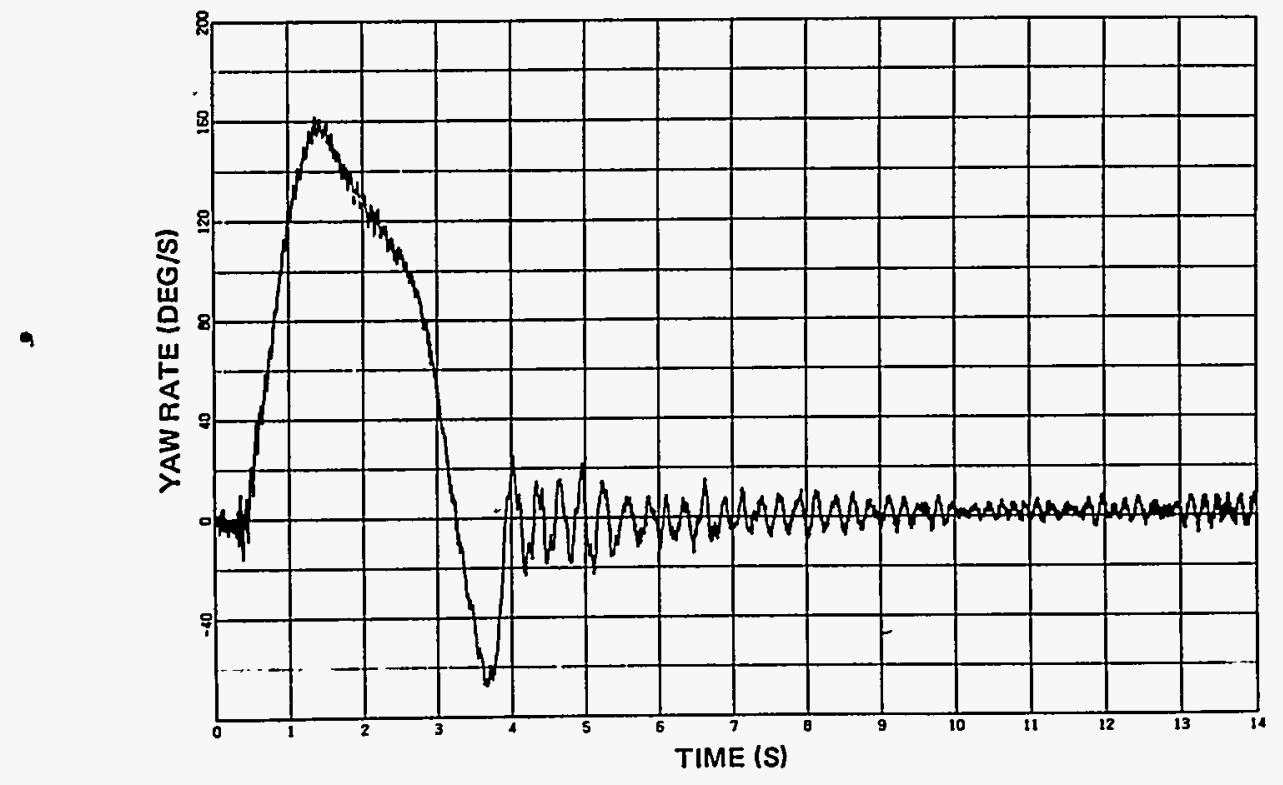

Figure 30. Yawing Velocity History

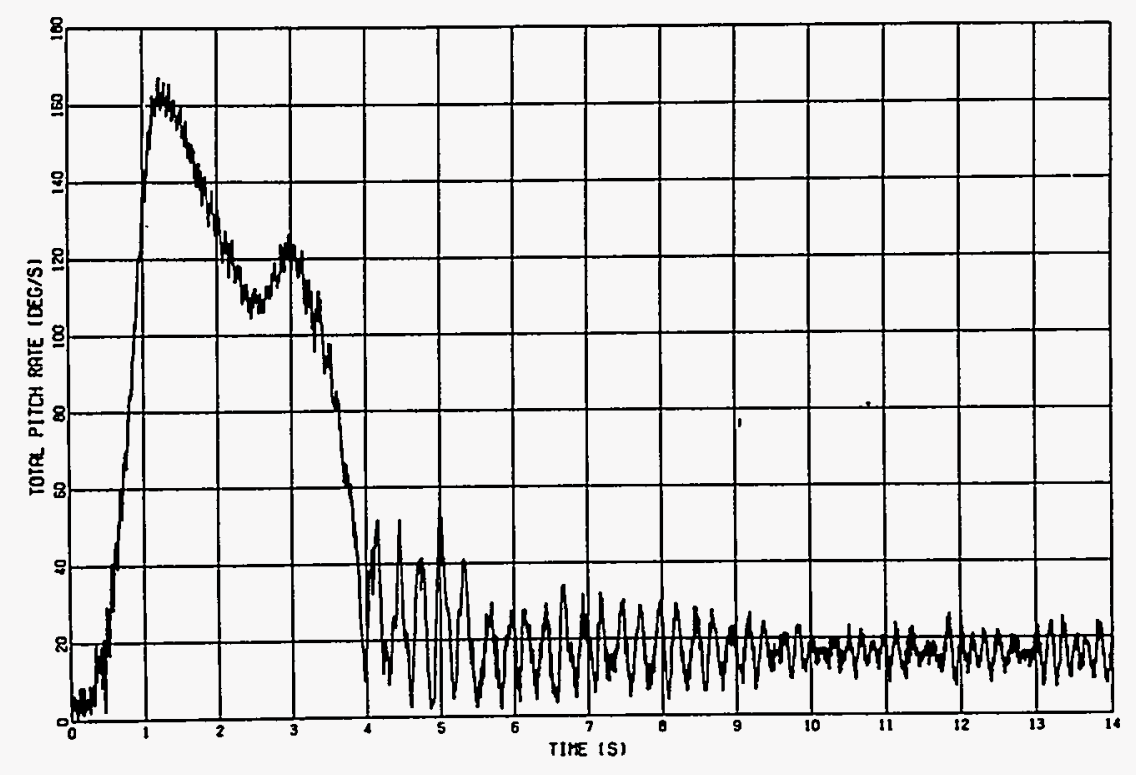

Figure 31. Resultant Angular Velocity History 
The vehicle roll rates obtained from the rate gyro and from the MARS stable platform, respectively, are shown as a function of time from launch in Figures 32 and 33. The roll rate from the rate gyro is measured directly, while that from the stable platform is obtained from the derivative of the roll angle as measured by the MARS. The roll rate variations obtained from both sources are in good agreement. From the expected zero rate during first-stage burn ( $T=0$ to 3.5 seconds), the booster spins up as the velocity and dynamic pressure increase during second stage burn. This. spin-up continues through deployment of the aerodynamic drag brakes and separation of the payload, which at this point has a spin rate of approximately $1960 \mathrm{deg} / \mathrm{s}$ (5. $44 \mathrm{cps})$. The vehicle then spins on up into resonance at $\mathrm{T}=8.5$ seconds from launch, attaining a maximum spin rate of approximately $2900 \mathrm{deg} / \mathrm{s}(8.05 \mathrm{cps})$. At this point, a roll spin-down begins as the vehicle locks into resonance, and would continue until it reaches a minimum rate of $1750 \mathrm{deg} / \mathrm{s}(4.86 \mathrm{cps})$ at $\mathrm{T}=11.0$ seconds. The roll control fins, however, counter this instability and pull the vehicle out of resonance. Though some overshoot of the roll rate is obtained as the terminal rolling velocity of $2150 \mathrm{deg} / \mathrm{s}(6.0 \mathrm{cps})$ is reached, the terminal rolling velocity is nevertheless in good agreement with the preflight design value.

\section{Flight Motion Analysis}

Since the angular attitude data measured by the MARS are relative to a nonrolling inertial reference system, the vehicle angular motion is governed by the tricyclic theory of angular motion developed by Nicolaides. 12 For the special case of the inertial angular attitude data, the complex pitch angle is given by

$$
\vec{\theta}=K_{N} e^{\left(\lambda_{N}+i \omega_{N}\right) t}+K_{P} e^{\left(\lambda_{P}+i \omega_{P}\right) t}+K_{T} e^{i P^{t}}+K_{R}
$$

where

$$
\begin{array}{cl}
\vec{\theta}=\theta+i \psi & (\theta \text { and } \psi \text { are the pitch and yaw angles measured } \\
\text { by the MARS })
\end{array}
$$

The motion therefore consists of three rotating vector modes $\mathrm{K}_{\mathrm{N}}$ (nutation), $\mathrm{K}_{\mathrm{P}}$ (precession), and $\mathrm{K}_{\mathrm{T}}$ (trim). The nutation and precession modes are transient amplitudes determined from initial conditions. These converge or diverge according to the damping factors $\lambda_{\mathrm{N}}$ and $\lambda_{\mathrm{P}}$, and $\mathrm{K}_{\mathrm{T}}$ is the magnitude of trim angle resulting from vehicle asymmetries. The $K_{R}$ term includes the effects of trajectory curvature, instrument bias, and so on; the nutation and precession modes rotate with circular frequencies $\omega_{N}$ and 


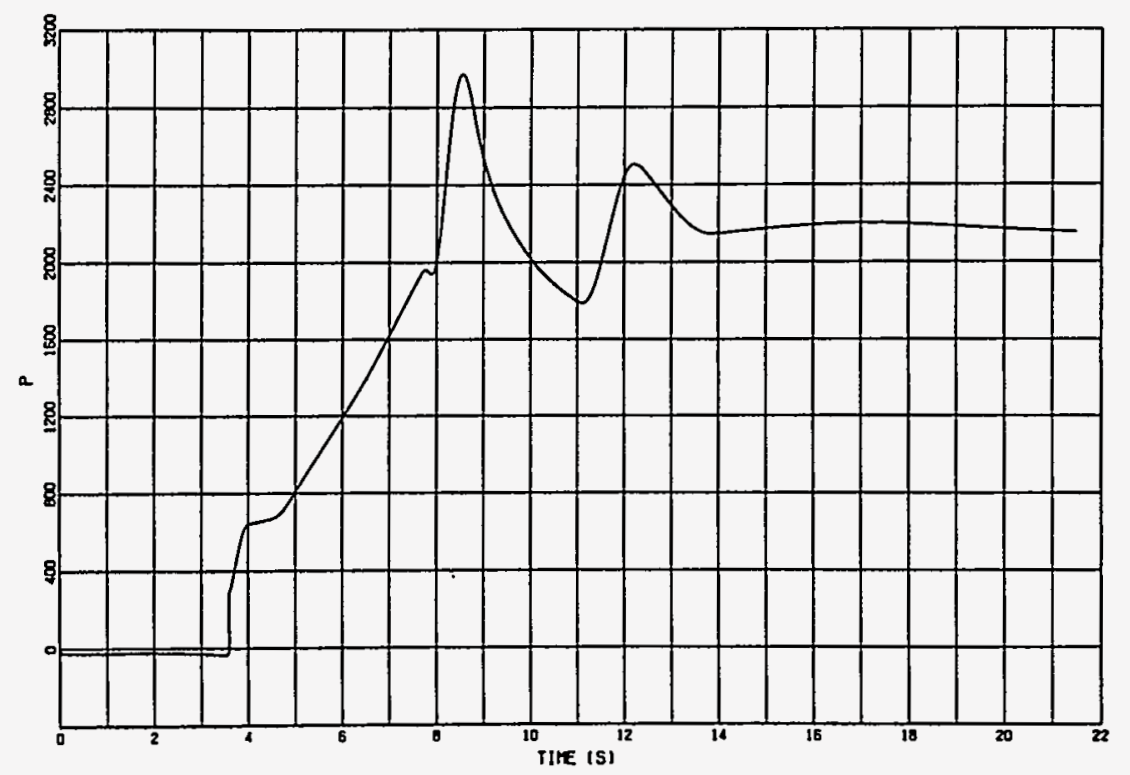

Figure 32. Vehicle Roll Rate History From Rate Gyro

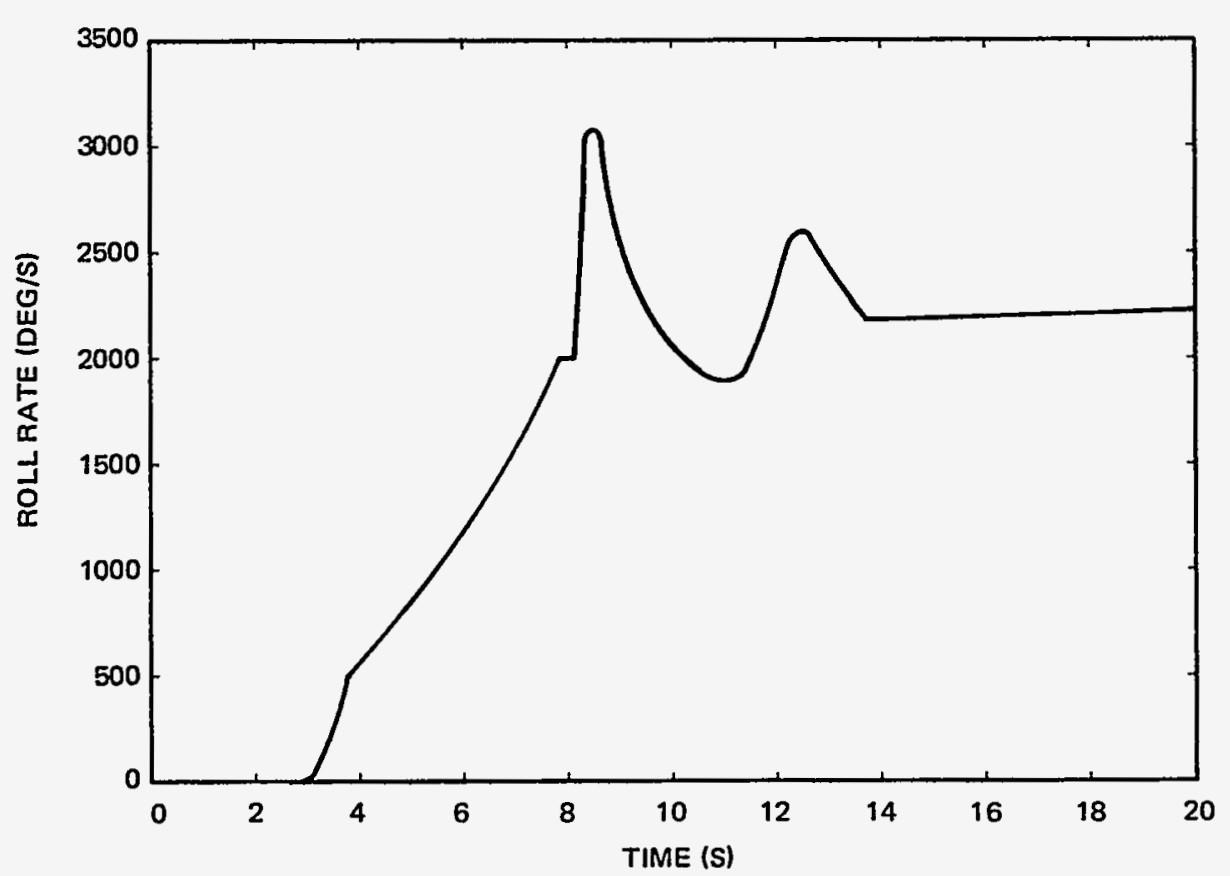

Figure 33. Vehicle Roll Rate History Obtained From MARS Platform Data 
$\omega_{\mathrm{P}}$, respectively; and the frequency of the trim component is equal to the roll rate p. All parameters of the tricyclic equation may vary with time.

The flight dynamic data are analyzed to determine the parameters (characteristic frequencies and damping factors) of the analytic model; then by means of these parameters, to determine the aerodynamic stability coefficients of the flight vehicle. This task is accomplished by means of a differential corrections curve-fitting technique, 13 used to fit the model to the observed angular attitude data. Since the tricyclic equation is a quasisteady solution to the linearized equations of motion, if one assumes that the spin rate, dynamic pressure, and so on, are constants, the fitting technique can be applied over small sections of data where these assumptions are satisfied. The methods presented in References 13, 14, and 15 are used in the flight dynamic analysis of the motion data.

Shown in Figures 34 and 35 are the modal amplitudes and frequencies resulting from a fit of Equation (1) to the MARS stable platform data $\theta, \psi$. The complete tricyclic model was not applicable to the data for the entire trajectory. During resonance, the trim and nutational frequencies are the same; therefore, the two modes cannot be distinguished from one another. The maximum angle of attack is nearly 5 degrees at $\mathrm{T}=1.5$ seconds. Only the nutation component of Equation (1) can be fitted from separation to $\mathrm{T}=4.0$ seconds, at which time a slight divergence in the nutation amplitude occurs, and the precession mode also becomes excited. The latter quickly damps out, however; and from $T=5.0$ seconds on, the trim amplitude can be distinguished. The nutation mode eventually damps out at about $T=13.0$ seconds, and the steady-state trim angle is determined to be approximately 0.25 degree. The modal frequencies determined from the fitting process are shown in Figure 35.

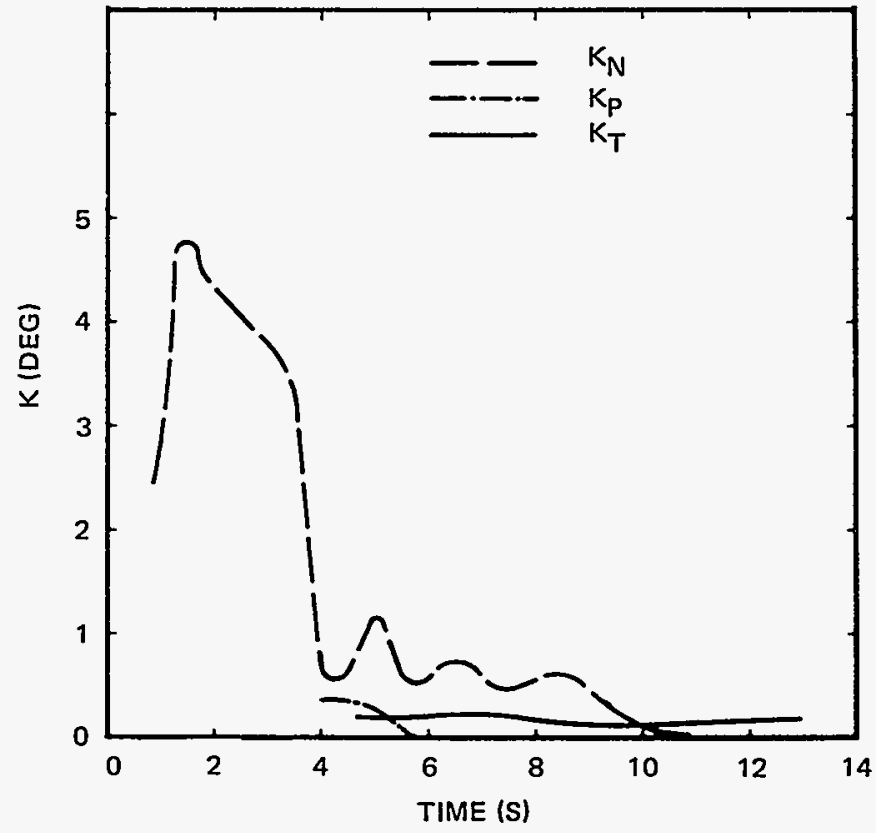

Figure 34. RCRTV Tricyclic Modal Amplitudes From Stable Platform Data 


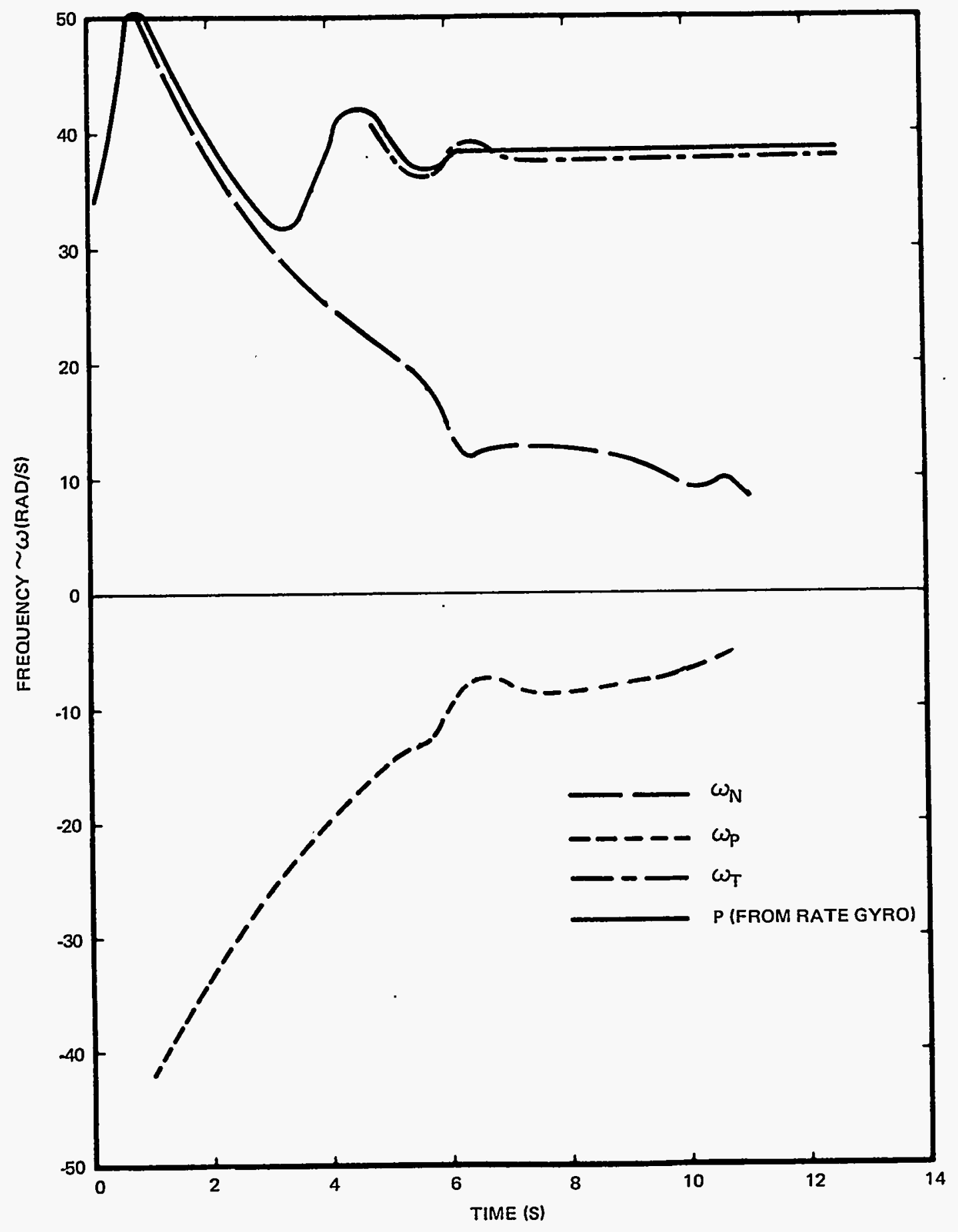

Figure 35. RCRTV Tricyclic Modal Frequencies From Stable Platform Data 
The precession mode was only determined for a short period of time; however, if the nutation and trim frequencies are known, the precession frequency can be determined from the relation

$$
\omega_{P}=-\omega_{N}+P \frac{I}{I}
$$

This calculated precession frequency, shown in Figure 35, agrees well with the fit values at $T=4$ to 6 seconds. The fitted trim frequency $T$, presented in Figure 35, is in good agreement with the measured roll rate determined from the rate gyro; and the roll lock-in period from $\mathrm{T}=0.5$ to 3 seconds is clearly evident.

The outputs of the lateral accelerometers may be used to reconstruct the vehicle body fixed angle of attack. The components of the body fixed angle of attack are given as follows:

$$
\begin{aligned}
& \alpha=\frac{-\mathrm{WA}_{\mathrm{Z}}}{\mathrm{C}_{\mathrm{N}_{\alpha} \mathrm{QS}}} \\
& \beta=\frac{-W A_{\mathrm{Y}}}{\mathrm{C}_{\mathrm{N}_{\alpha}} \mathrm{QS}}
\end{aligned}
$$

where

$$
\begin{aligned}
& \alpha \text { - angle of attack (deg) } \\
& \beta \text { - angle of sideslip (deg) } \\
& W \text { - vehicle weight (lb) } \\
& A_{Z} \text { - Z-axis (pitch) accelerometer (g) } \\
& A_{Y}-\text { Y-axis (yaw) accelerometer (g) } \\
& Q \text { - dynamic pressure }\left(\mathrm{lb} / \mathrm{ft}^{2}\right) \\
& \mathrm{S} \text { - reference area, vehicle base area }\left(\mathrm{ft}^{2}\right) \\
& \mathrm{C}_{N_{\alpha}} \text { - normal force coefficient slope }\left(\mathrm{deg}^{-1}\right)
\end{aligned}
$$

This method assumes, of course, that the vehicle aerodynamic normal force coefficient slope $\mathrm{C}_{\mathrm{N}_{\alpha}}$ is known. The theoretical values of $\mathrm{C}_{\mathrm{N}_{\alpha}}$, which are used in the foregoing calculations, are discussed in the aerodynamic analysis section of this report. The angle-of-attack components determined from 
the foregoing relations are given in Figures 36 and 37, respectively. The total angle of attack given by

$$
\begin{aligned}
\vec{\alpha} & =\sqrt{\alpha^{2}+\beta^{2}} \\
& =\frac{W}{\mathrm{C}_{N_{\alpha}} \mathrm{QS}} \sqrt{\mathrm{A}_{Z}^{2}+\mathrm{A}_{\mathrm{Y}}^{2}}
\end{aligned}
$$

is presented in Figure 38. The angular orientation of the vehicle windward meridian is given by the aerodynamic roll angle from the following expression

$$
\begin{aligned}
\phi_{A} & =\tan ^{-1}\left(\frac{\alpha}{\beta}\right) \\
& =\tan ^{-1}\left(\frac{A_{Z}}{A_{Y}}\right)
\end{aligned}
$$

The aerodynamic roll angle is presented in Figure 39 . From $\mathrm{T}=0.5$ to 2.5, the windward meridian is nearly stationary at $\phi \cong \pi$, since the vehicle is locked into resonance. Then, as the vehicle starts to break out of resonance, the windward ray moves around the body and becomes oscillatory just before $\mathrm{T}=4$ seconds. The upper envelope of the angle-of-attack data is in good agreement with the stable platform data (and with the fit of the stable platform data), and it indicates a maximum angle of attack of about 5 degrees.

\section{Aerodynamic Analysis}

\section{Aerodynamic Drag}

The vehicle axial force coefficient may be obtained from the expression

$$
C_{A}=\frac{-W A}{Q S}
$$

where

$$
\begin{aligned}
& C_{A} \text { - vehicle axial force coefficient } \\
& W \text { - vehicle weight (lb) } \\
& Q \text { - dynamic pressure }\left(1 \mathrm{~b} / \mathrm{ft}^{2}\right) \\
& \mathrm{S} \text { - reference area (base area) }\left(\mathrm{ft}^{2}\right) \\
& A_{X}-\mathrm{X} \text {-axis (longitudinal axis) acceleration (g) }
\end{aligned}
$$




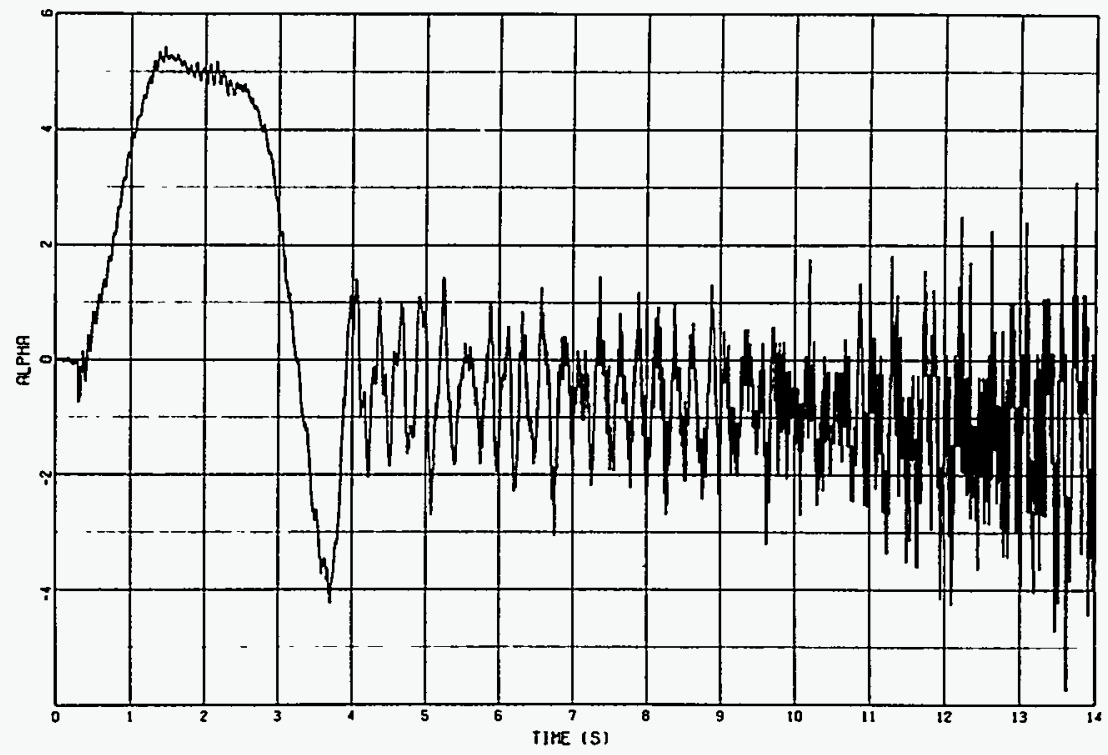

Figure 36. Body Fixed Angle of Attack

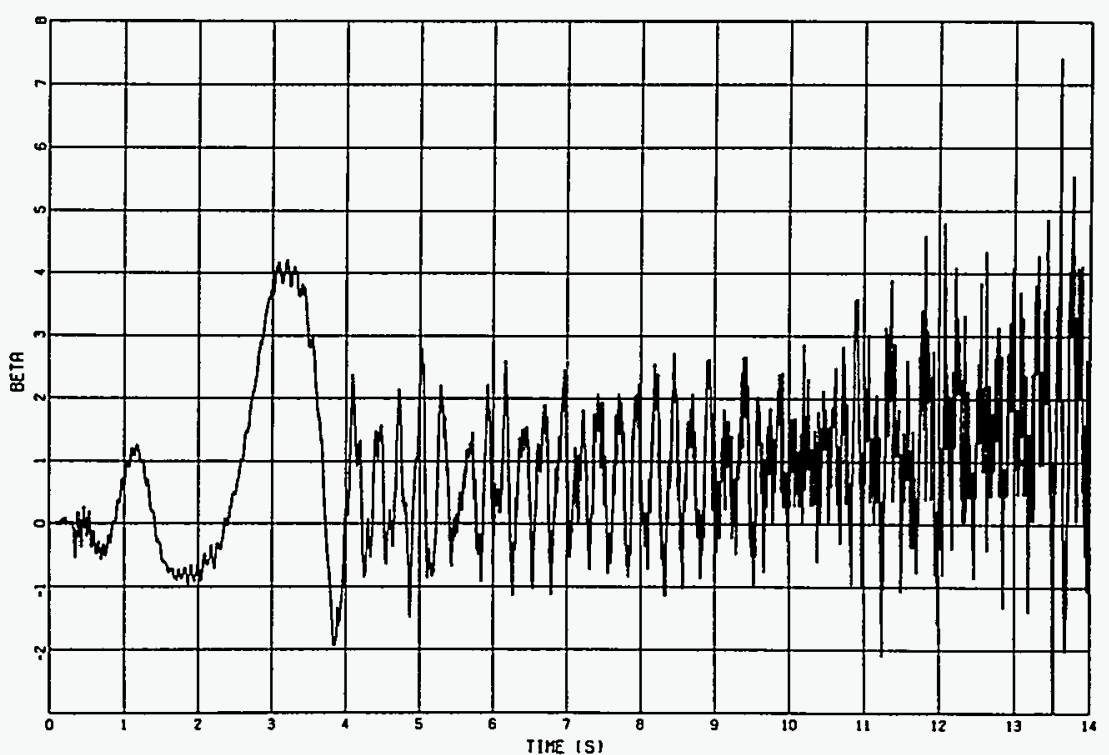

Figure 37. Body Fixed Angle of Sideslip 


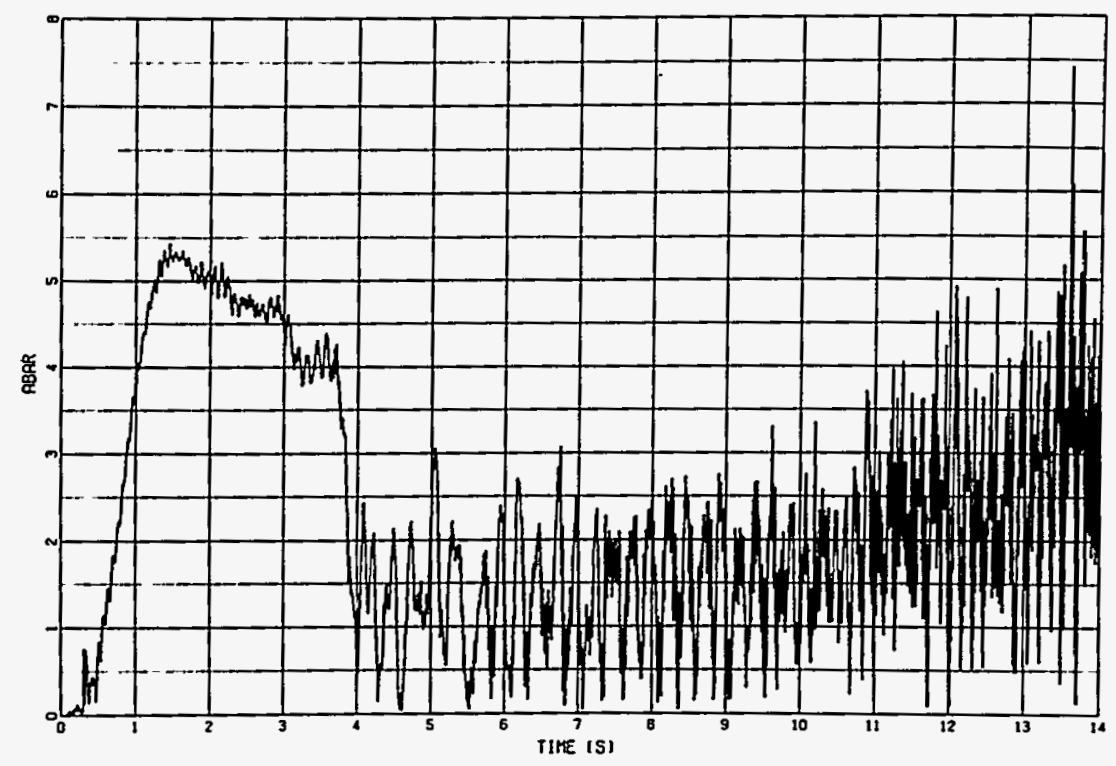

Figure 38. Body Fixed Resultant Angle of Attack

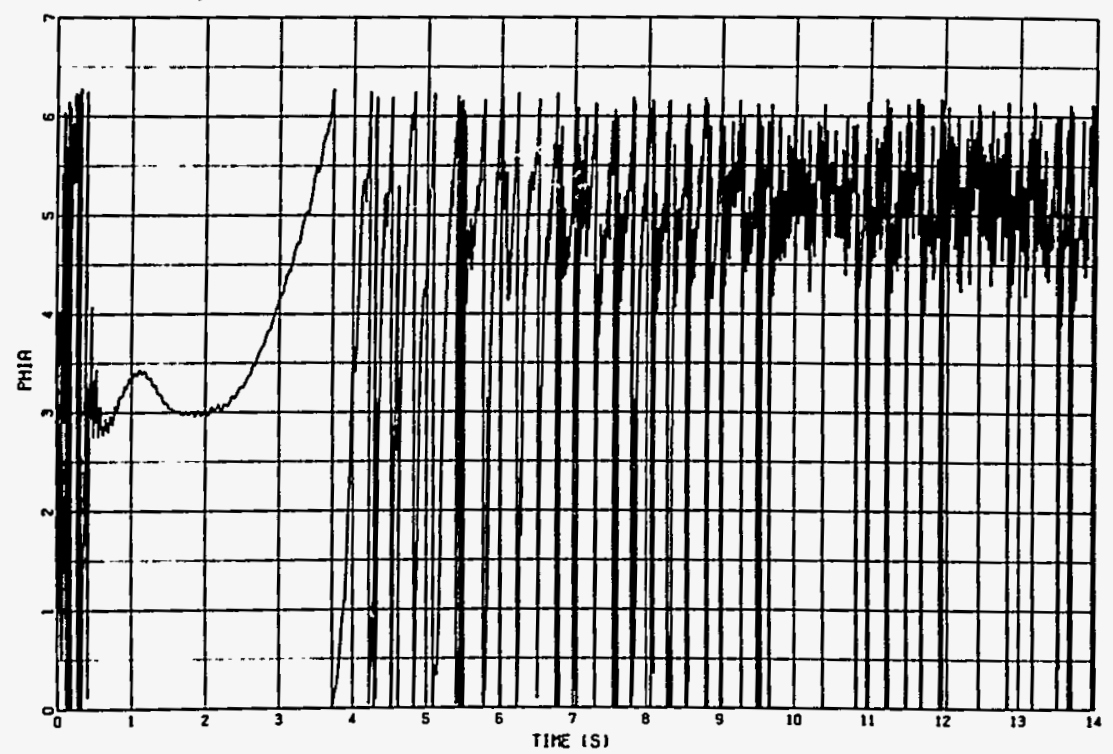

Figure 39. Aerodynamic Roll Angle 
The output from the two on-board axial accelerometers (Figures 13 and 14) are used in Equation (6) to calculate the axial force coefficient. The resulting coefficients are shown in Figures 40 and 41 as functions of time from payload separation. In these calculations, $C_{X_{1}}$ results from the $\pm 30 \mathrm{~g}$ accelerometer $A_{X_{1}}$, while $C_{X_{2}}$ is determined from the $\pm 50 \mathrm{~g}$ accelerometer $\mathrm{A}_{\mathrm{X}_{2}}$. From $\mathrm{T}=0$ to 0.5 seconds, the data do not provide a correct determination of the vehicle axial force coefficient since the base pressure is strongly influenced by the presence of the booster. The coefficients, which peak at a Mach number of approximately 0.9 , are determined through supersonic and transonic velocities and are presented as functions of flight Mach number in Figure 42. Data obtained from the two sources are in excellent agreement. Since the angles of attack are small throughout the trajectory, the axial force coefficient is equivalent to the vehicle drag coefficient. In addition, because of the small angles of attack and some minor variations of axial force coefficient with angle of attack for these Mach numbers, the measured value of $\mathrm{C}_{\mathrm{A}}$ is considered equivalent to the zero angle-of-attack value $\mathrm{C}_{\mathrm{A}_{0}}$.

The influence of fins on the vehicle drag can be seen in Figure 43. The RVRTV flight data 16,17 were obtained on a vehicle configuration the same as that used for the RCRTV but without fins; and a reaction-type hot gas (hydrazine) roll control system was used to keep the angle of attack small and the spin rate under control. The RCRTV coefficients shown in Figure 43 are an average of the data $\mathrm{C}_{\mathrm{X}_{1}}, \mathrm{C}_{\mathrm{X}_{2}}$ obtained previously from the two accelerometers. Throughout the Mach number range, the 4 fins generate a considerable increase in drag. The relative drag increase is perhaps better illustrated by presenting as a function of Mach number the ratio of $\mathrm{C}_{\mathrm{A}_{0}}$ with fins to $\mathrm{C}_{\mathrm{A}_{0}}$ without fins (Figure 44 ). The 4 fins increase

the total drag by 35 percent at Mach 4. The drag increment drops to 13 percent near Mach 1 but returns to the 40 percent level at subsonic velocities.

$\underline{\text { Static Stability }}$

A measurement of the vehicle static stability is given by the pitching moment coefficient derivative $\mathrm{C}_{\mathrm{M}_{\alpha}} \cdot$ This is the slope of the pitching moment $C_{M}$ versus angle-of-attack curve, and for static stability $C_{M_{\alpha}}$ must be negative. The values of the static stability coefficient are determined from the frequency response of the flight dynamic data by means of the relation 


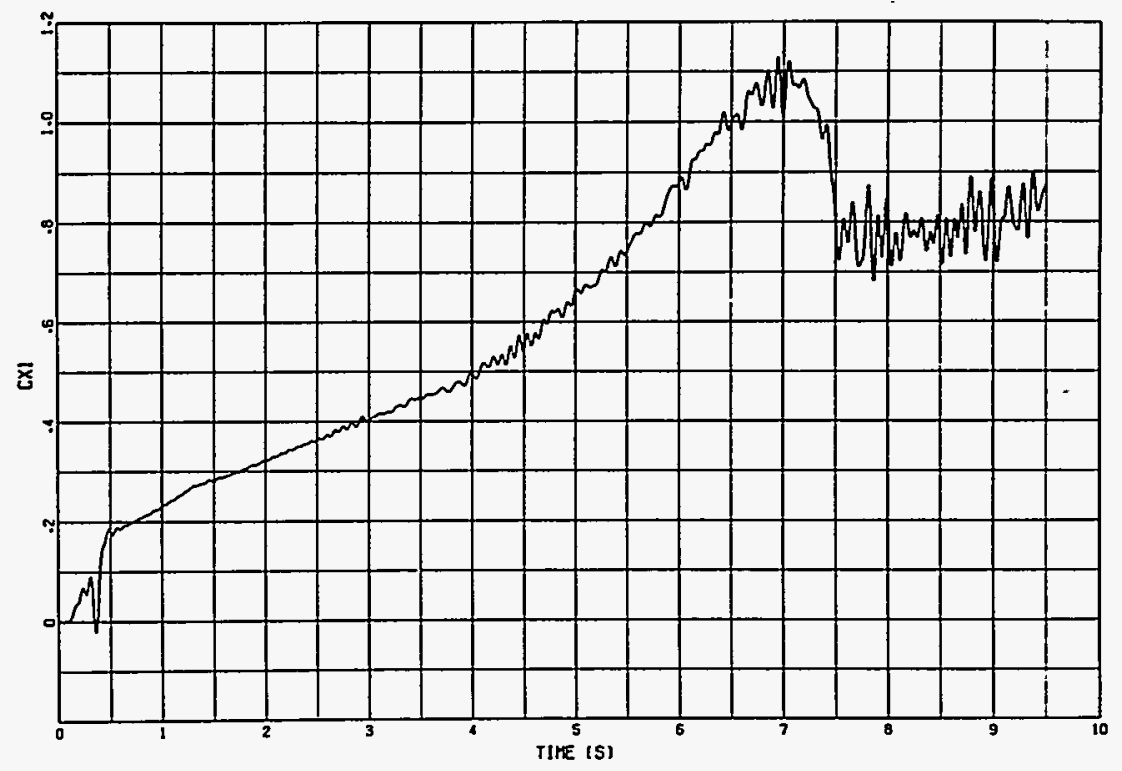

Figure 40. Vehicle Axial Force Coefficient (From \pm 30 g Accelerometer)

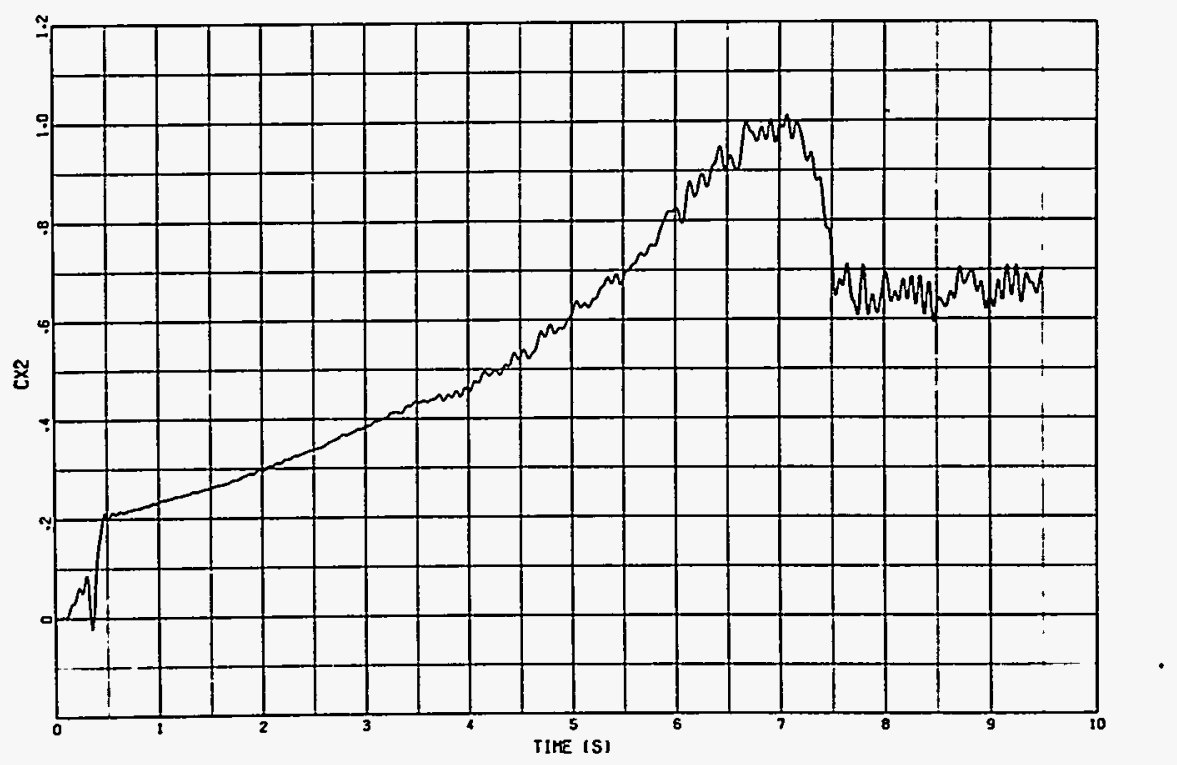

Figure 41. Vehicle Axial Force Coefficient (From \pm 50 g Accelerometer) 


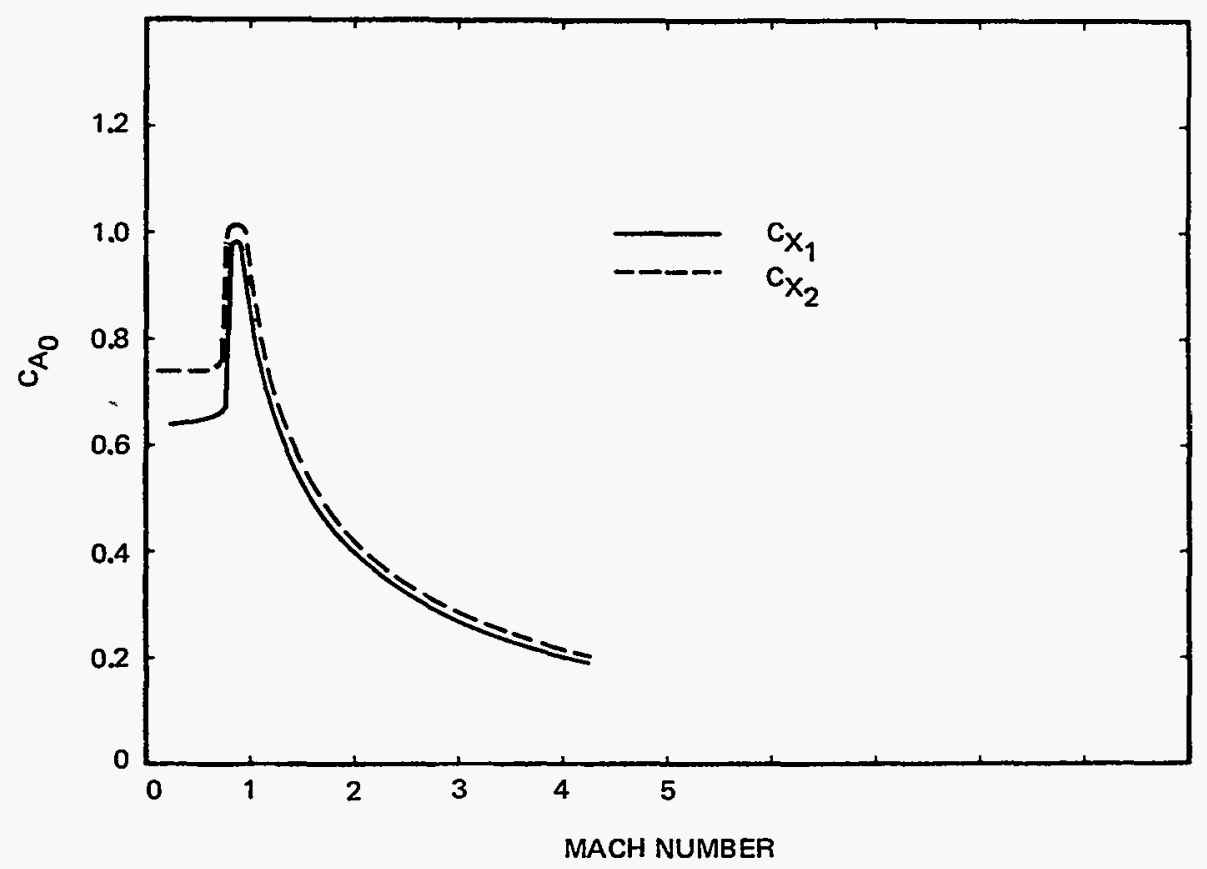

Figure 42. Axial Force Coefficient vs. Mach Number

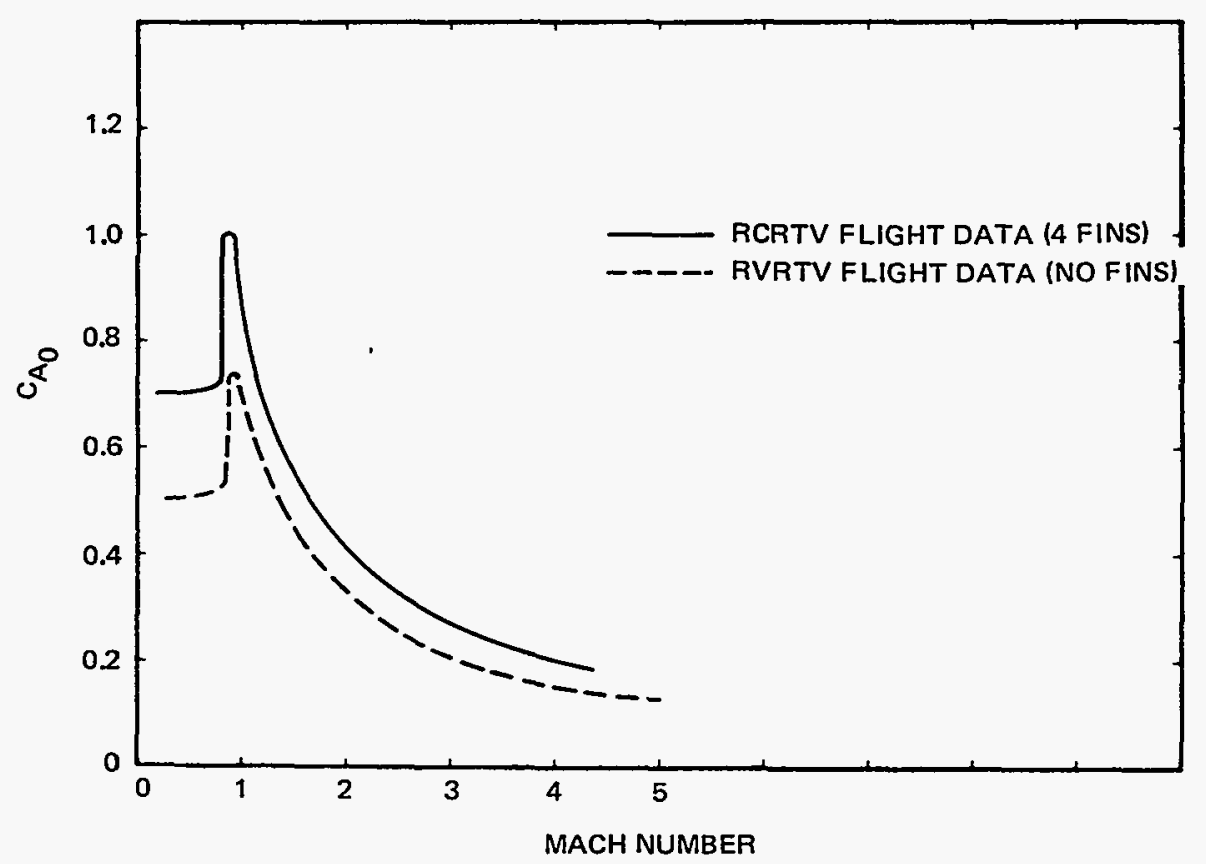

Figure 43. Axial Force Coefficient With and Without Fins vs. Mach Number 


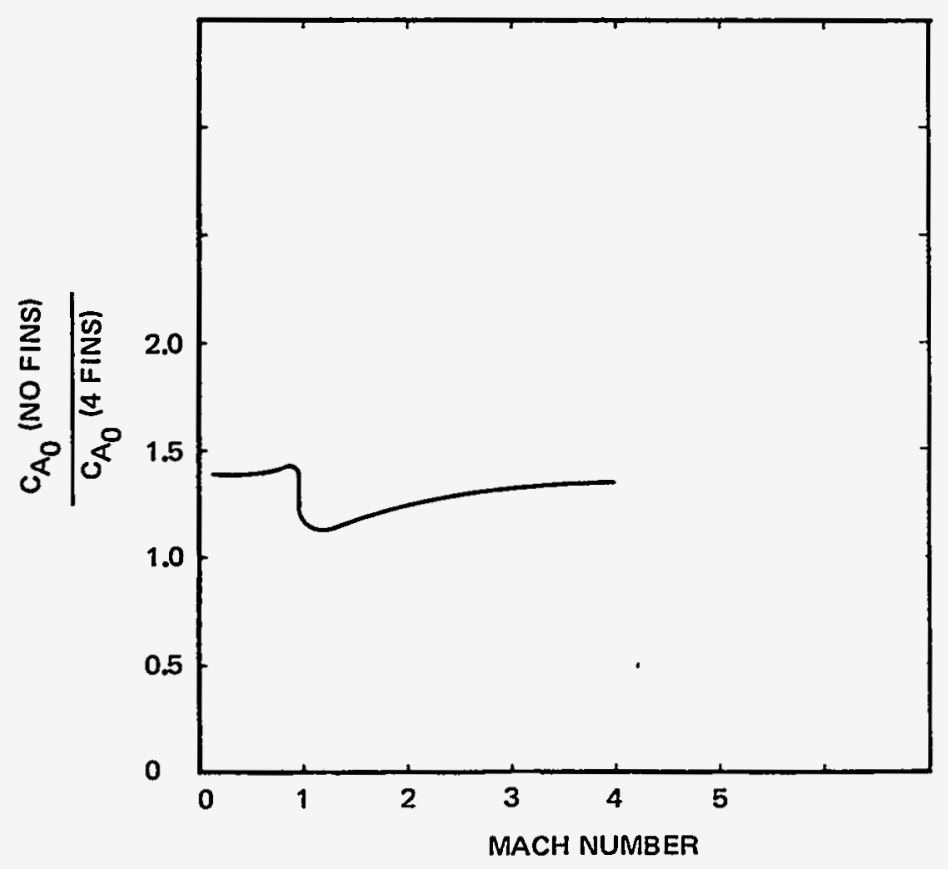

Figure 44. Ratio of $\mathrm{C}_{\mathrm{A}_{0}}$ (With Fins) to $\mathrm{C}_{\mathrm{A}_{0}}$ (Without Fins) vs. Mach Number

$$
\mathrm{C}_{\mathrm{M}_{\alpha}}=\frac{{ }_{N}{ }^{\omega} \mathrm{P} I}{\mathrm{QSd}}
$$

where

$$
\begin{aligned}
& \mathrm{C}_{\mathrm{M}_{\alpha}} \text { - pitching moment coefficient slope }\left(\partial \mathrm{C}_{\mathrm{M}} / \partial \alpha\right)-\left(\mathrm{rad}^{-1}\right) \\
& \omega_{\mathrm{N}}, \omega_{\mathrm{P}} \text { - modal frequency histories (rad/s) } \\
& \text { I - vehicle lateral moment of inertia }\left(\mathrm{slug}-\mathrm{ft}^{2}\right) \\
& \mathrm{Q} \text { - frustum dynamic pressure }\left(\mathrm{lb} / \mathrm{ft}^{2}\right) \\
& \quad \mathrm{S} \text { - vehicle reference area (base area) }\left(\mathrm{ft}^{2}\right) \\
& \mathrm{d} \text { - vehicle reference diameter (base diameter) (ft) }
\end{aligned}
$$

The moment reference point is taken as the vehicle center of gravity. The modal frequency histories $\omega_{N}$ and $\omega_{P}$ used in the foregoing relation are those obtained from the fit of the tricyclic equation to the MARS platform data. These frequencies were determined in the previous section and are given as functions of time in Figure 35. When these values are used in Equation (7), $\mathrm{C}_{\mathrm{M}_{\alpha}}$ is determined as a function of time from separation, and 
the results are presented in Figure 45. The static stability coefficient is represented as a function of flight Mach number in Figure 46 along with the $\mathrm{C}_{\mathrm{M}_{\alpha}}$ data on the flight vehicle without fins. These data are a combination of wind-tunnel and free-flight results on the same configuration without fins. The free-flight data were obtained from the RVRTV flight test program. 16,17 At Mach number of 3.0 and above, the static stability coefficient is found to be approximately 20 percent higher on the finned configuration than on the finless vehicle; and additional wind tunnel tests at higher Mach numbers verify the 20 percent differential on this configuration. The increase in static stability is obviously attributable to the fins and, as will be seen, is a result of an increase in static margin. As will be shown in a subsequent section, the vehicle asymmetries were still sufficient--even with the increase in stability--to provide sustained roll-resonance instability. The $\mathrm{C}_{\mathrm{MI}_{\alpha}}$ data increase as Mach number decreases until just before $\mathrm{M}=1$, where the stability drops off considerably. The vehicle therefore had excellent static stability throughout the flight; and in fact, the fins aided the stability significantly.

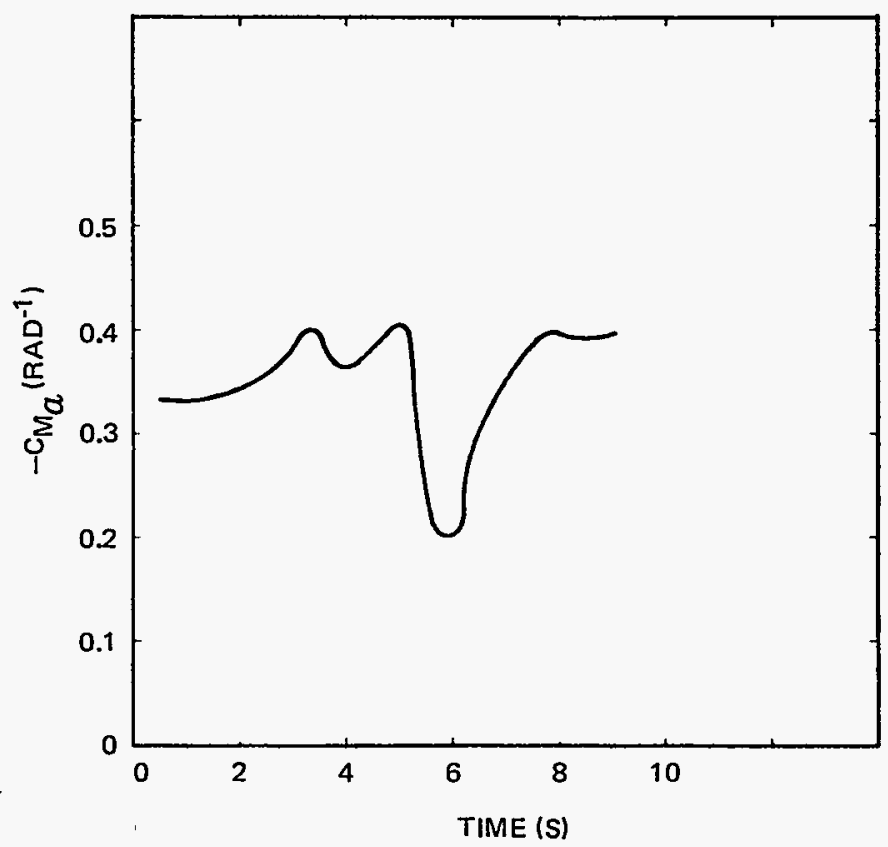

Figure 45. Static Stability Coefficient $\left(\mathrm{C}_{\mathrm{M}_{\alpha}}\right)$ History 


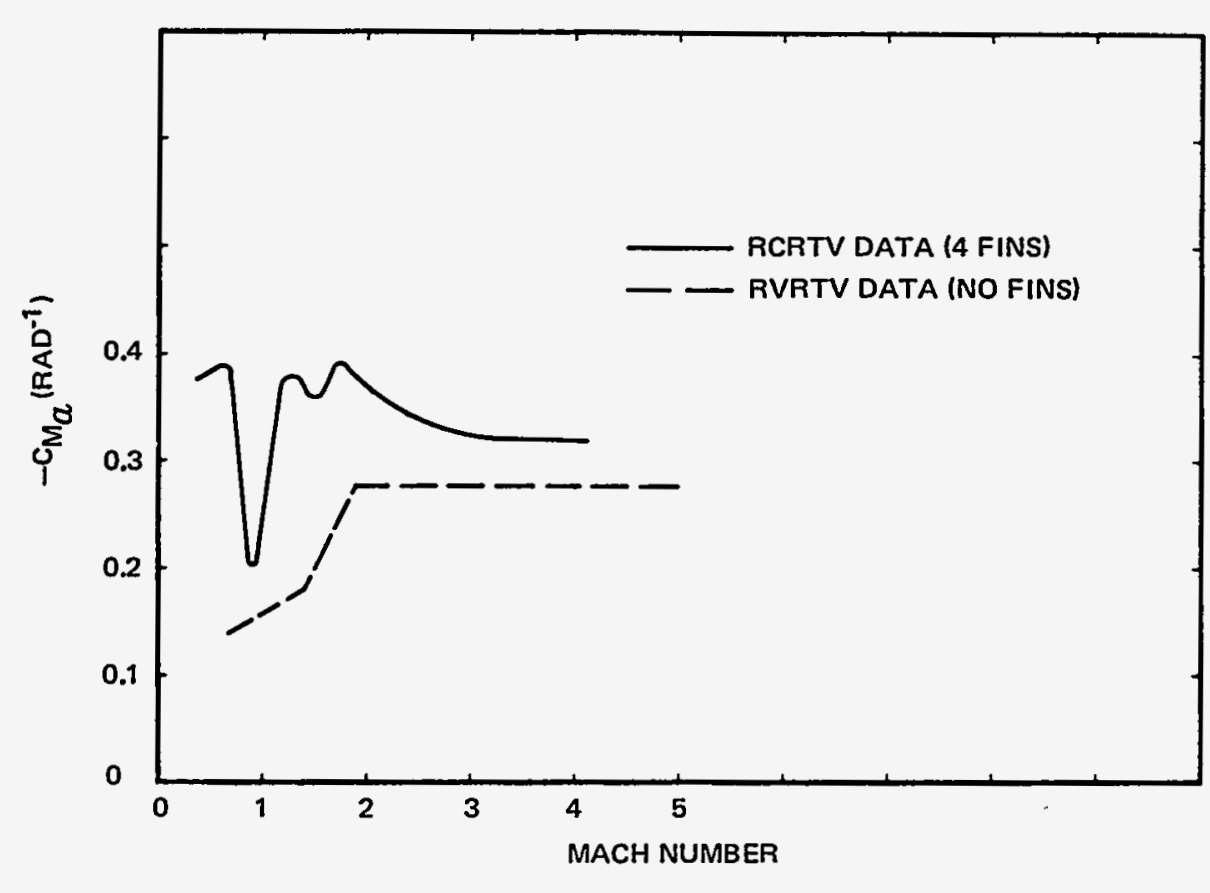

Figure 46. Static Stability Coefficient With and Without Fins vs. Mach Number

Aerodynamic Center of Pressure

The static stability coefficient $\mathrm{C}_{\mathrm{M}_{\alpha}}$, determined in the previous section, may be expressed in terms of the vehicle normal force coefficient and center-of-pressure location as follows

$$
\mathrm{C}_{\mathrm{M}_{\alpha}}=\mathrm{C}_{\mathrm{N}_{\alpha}} x_{\mathrm{cp}} / \mathrm{d}
$$

where

$$
\begin{aligned}
& \mathrm{C}_{\mathrm{M}_{\alpha}} \text { - pitching moment coefficient slope }\left(\partial \mathrm{C}_{\mathrm{MI}} / \partial \alpha\right)--\left(\mathrm{rad}^{-1}\right) \\
& \mathrm{C}_{\mathrm{N}_{\alpha}}-\text { normal force coefficient slope }\left(\partial \mathrm{C}_{\mathrm{N}} / \partial \alpha\right)--\left(\mathrm{rad}^{-1}\right) \\
& x_{\mathrm{cp}}-\begin{array}{l}
\text { distance from center of gravity to aerodynamic center of } \\
\text { pressure }(\mathrm{ft})
\end{array}
\end{aligned}
$$


The normal force coefficient slope is presented as a function of Mach number in Figure 47. As shown, the experimental data 18 are well represented by the aerodynamic characteristics computer program, HANDY, 19 and the theoretical method of Reference 20. Additional wind tunnel data on finned configurations indicate that the normal force coefficients are unchanged by the addition of the fins. The normal force coefficients calculated with HANDY are therefore used directly in Equation (8) along with the static stability coefficients $\mathrm{C}_{\mathbb{M}_{\alpha}}$ to determine the aerodynamic center of pressure $x_{\mathrm{cp}}$. The aerodynamic center of pressure, as so determined, is expressed as a percentage of body length from the nose and is presented as a function of Mach number in Figure 48 along with the center-of-pressure locations for the vehicle without fins. The latter represent a combination of theoretical calculations 19,20 and experimental data. 18 Since the vehicle center of mass is at 63 percent of its length, the static margin without fins is 5.3 percent. The effect of the fins is therefore to increase the static margin to 6.2 percent at Mach numbers above 3.5. The center of pressure is seen to move aft (increasing static stability) as the Mach number decreases; thus a maximum static margin of 7.4 percent occurs at Mach 1.8, while at Mach 0.9 , the minimum static margin of 3.8 percent is obtained.

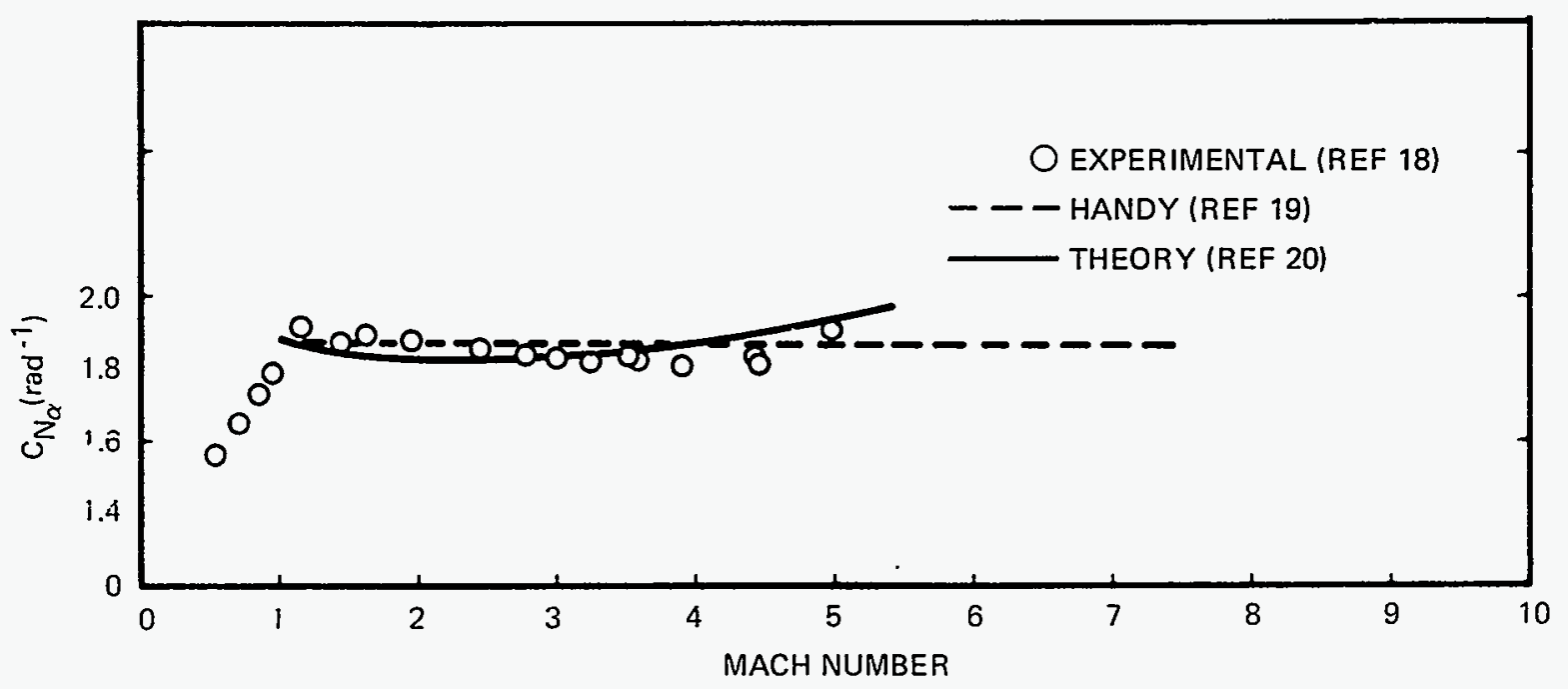

Figure 47. Normal Force Coefficient (At $\alpha=0^{\circ}$ ) vs. Mach Number 


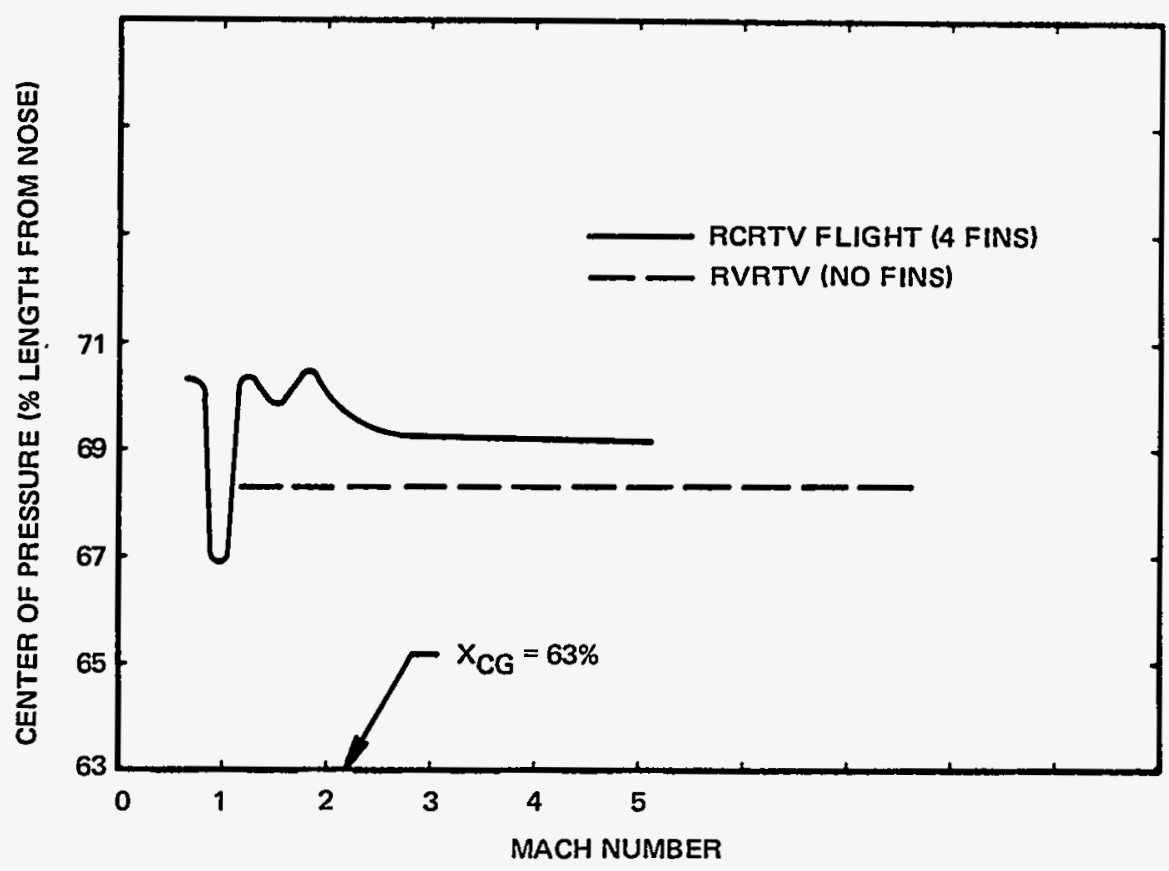

Figure 48. Aerodynamic. Center-of-Pressure Location With and Without Fins vs. Mach Number

\section{Dynamic Stability}

The dynamic stability coefficients are determined from the aerodynamic damping factors $\lambda_{N}$ and $\lambda_{P}$, which appear in Equation (1). Both damping factors are necessary for determining the pitch damping coefficient. Unfortunately, both values were determined only for a brief period at approximately $\mathrm{T}=4.0$ seconds, and even then the damping factors were not well determined. Consequently, the damping coefficients could not be obtained reliably. Nevertheless, the rapid convergence of the angle of attack after the vehicle breaks out of roll resonance (Figure 34 ) is ample evidence that the vehicle experienced good dynamic stability. A brief period of angular divergence, occurring at approximately $T=5.0$ seconds after separation, is attributed to the vehicle passing through the sonic condition. At this time, the trim angle of attack, composed of both principal-axis tilt and center-of-gravity offset, increases. The trim due to cg offset increases significantly because of the large increase in drag at Mach 1, and the angle of attack subsequently converges.

The conclusion is that the vehicle exhibited good dynamic stability throughout the flight and that the fins produced no adverse effects on stability. 
Rolling Moment Coefficient

The total rolling moment coefficient is given by the following relation:

$$
\mathrm{C}_{\ell_{\mathrm{T}}}=\frac{\dot{\mathrm{p}} \mathrm{I}_{\mathrm{x}}}{\mathrm{QSd}}
$$

where

$$
\dot{\mathrm{p}} \text { - roll rate time derivative }\left(\mathrm{rad} / \mathrm{s}^{2}\right)
$$

$I_{x}$ - vehicle roll moment of inertia (slug-ft ${ }^{2}$ )

$\mathrm{Q}$ - freestream dynamic pressure $\left(\mathrm{lb} / \mathrm{ft}^{2}\right)$

$S$ - vehicle reference area-- base area $\left(\mathrm{ft}^{2}\right)$

$\mathrm{d}$ - vehicle reference length -- base diameter $(\mathrm{ft})$

The roll rate from the rate gyro output was sectionally fitted with a cubic spline, and the fit was then differentiated to determine $\dot{p}$. The total rolling moment coefficients $C_{\ell_{T}}$ determined from Equation (9) are shown in

Figure 49. Included in the total rolling moment coefficients are the contributions of the vehicle asymmetries and the roll control system.

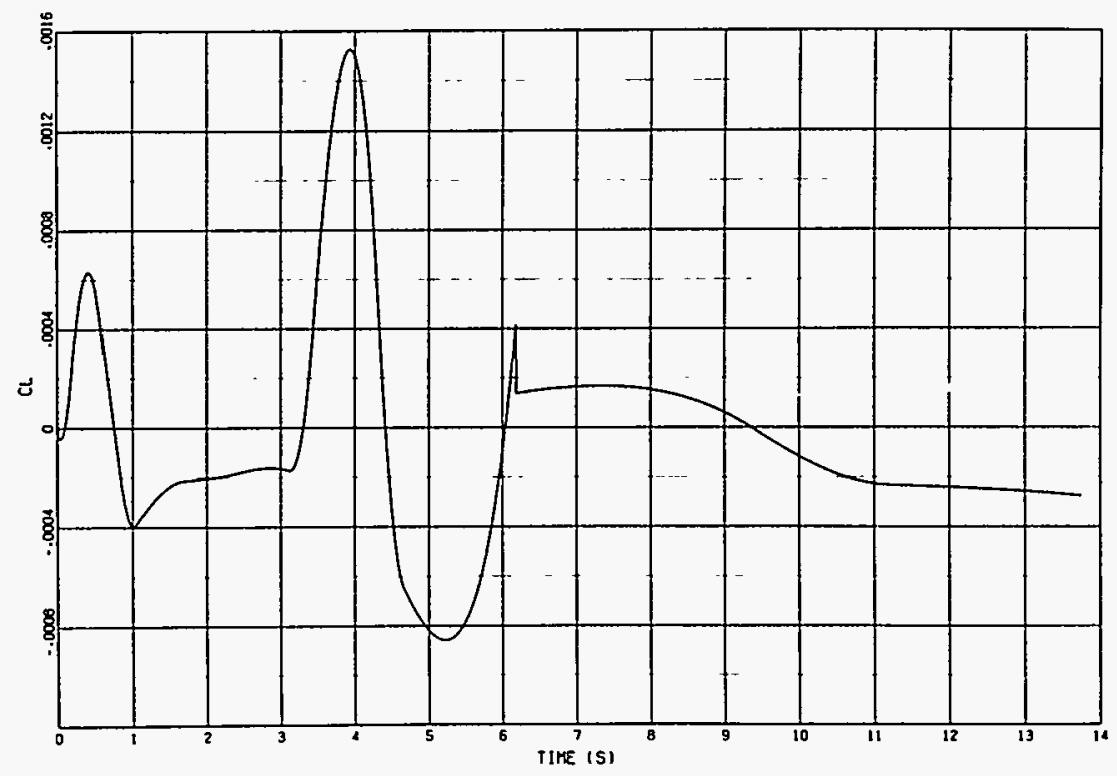

Figure 49. Total Rolling Moment Coefficient 
The contribution to rolling moment coefficient due to the vehicle asymmetries (trim angle due to principal axis inclination and center-ofmass offset) may be computed from the lateral accelerometer history and the known preflight vehicle mass and inertia asymmetries. The asymmetry roll moment coefficient $\mathrm{C}_{\ell_{A}}$ is given by the following:

$$
C_{\ell_{A}}=\frac{\mathrm{W} \mathrm{A}_{\mathrm{y}_{0}} \mathrm{z}}{\mathrm{QSd}}-\frac{\mathrm{WA} \mathrm{z}_{0}}{\mathrm{QSd}}
$$

where

$\mathrm{C}_{\ell_{\mathrm{A}}}$ - nondimensional rolling moment coefficient due to vehicle

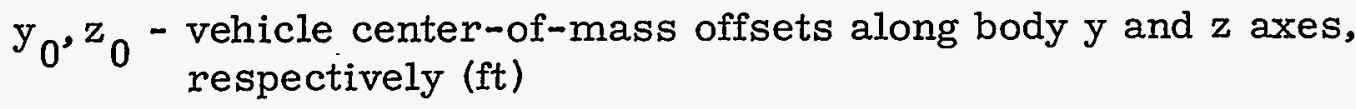

W - vehicle weight (1b)

$\mathrm{A}_{\mathrm{y}}, \mathrm{A}_{\mathrm{z}}$ - vehicle lateral accelerations along body $\mathrm{y}$ and $\mathrm{z}$ axes,

$\mathrm{Q}$ - freestream dynamic pressure $\left(\mathrm{lb} / \mathrm{ft}^{2}\right)$

$\mathrm{S}$ - vehicle reference area--base area $\left(\mathrm{ft}^{2}\right)$

$\mathrm{d}$ - vehicle reference diameter--base diameter (ft)

The resulting coefficients are determined as a function of time from vehicle separation and are shown in Figure 50. These data are not reliable after about $T=4.0$ seconds since the acceleration levels are at small values, thus yielding a small signal-to-noise ratio. The peak value of -0.0009 at $T=3$ seconds is in good agreement with the preflight expected value. The rolling moments produced by the intentional vehicle asymmetries were therefore sufficient to produce a sustained roll resonance instability in the absence of a roll control system.

Theoretical Fin Aerodynamics

The variables and nomenclature used in describing the fin aerodynamic characteristics are shown in Figure 51. It has been determined both analytically 21,22 and experimentally $23,24,25$ that the roll coefficient provided by spin fins is a highly nonlinear function of the vehicle angle of attack and the roll orientation of the fins relative to the angle-of-attack plane. The nonlinearities are caused by the relatively large surface cross-flow angularity when the vehicle is at an angle of attack. The cross-flow angle combines with the geometric fin-cant angle to yield an effective fin angle of attack. 


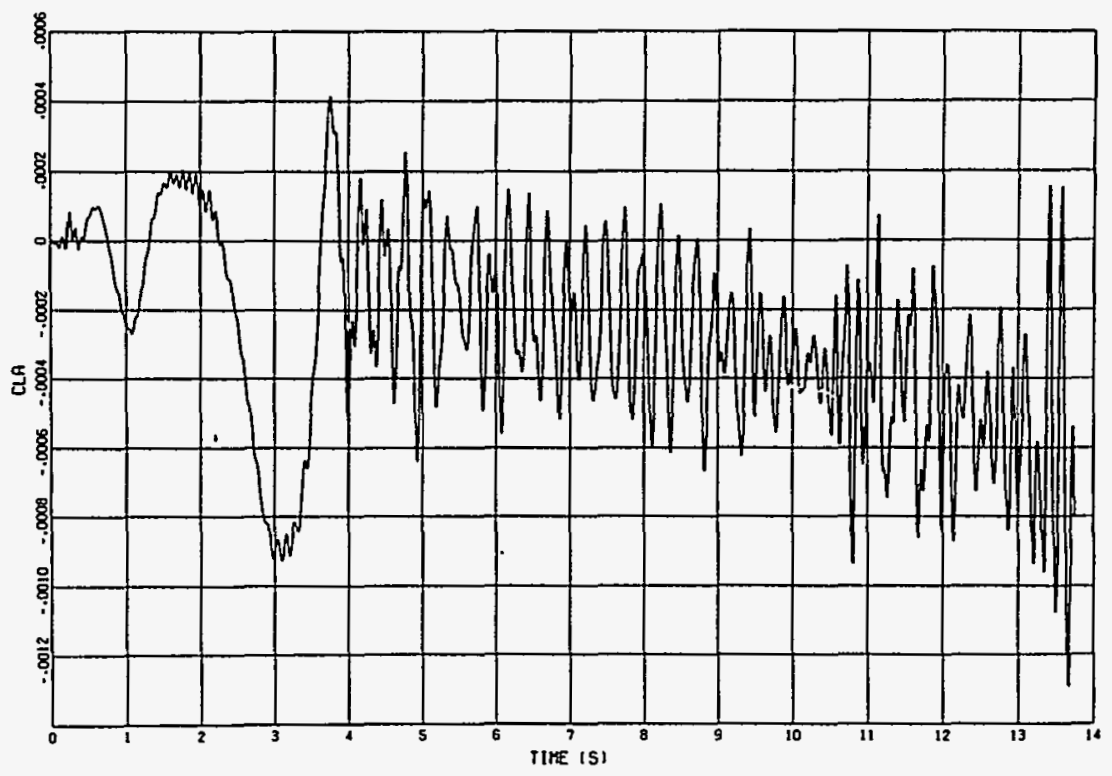

Figure 50. Roll Moment Coefficient Due to Vehicle Asymmetries 
This effect produces an induced roll moment and an induced side-force and moment, both of which can have a deleterious effect on the vehicle roll rate and flight stability. 26,27

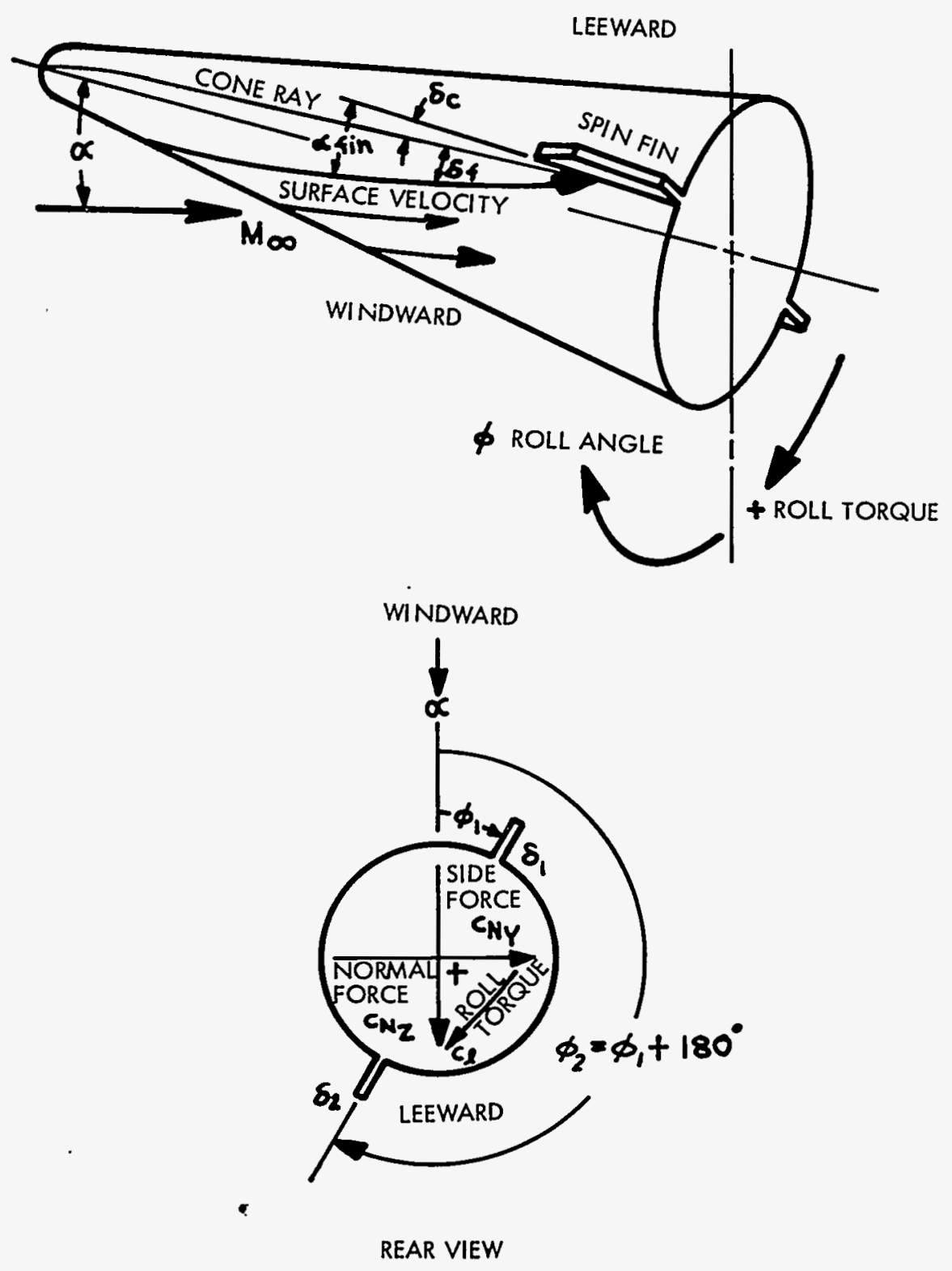

Figure 51. Spin Fin Aerodynamics 
The maximum cross-flow angle is shown in Figure 52 for sharp and blunt cones as a function of vehicle angle of attack. As shown, the maximum cross-flow angle is equivalent to the geometric fin-cant angle (about 10 degrees) for sharp cones and is greater by a factor of 2 or 3 than the geometric cant for blunt cones. The variation in cross-flow angle around the body is a sinusoidal function.

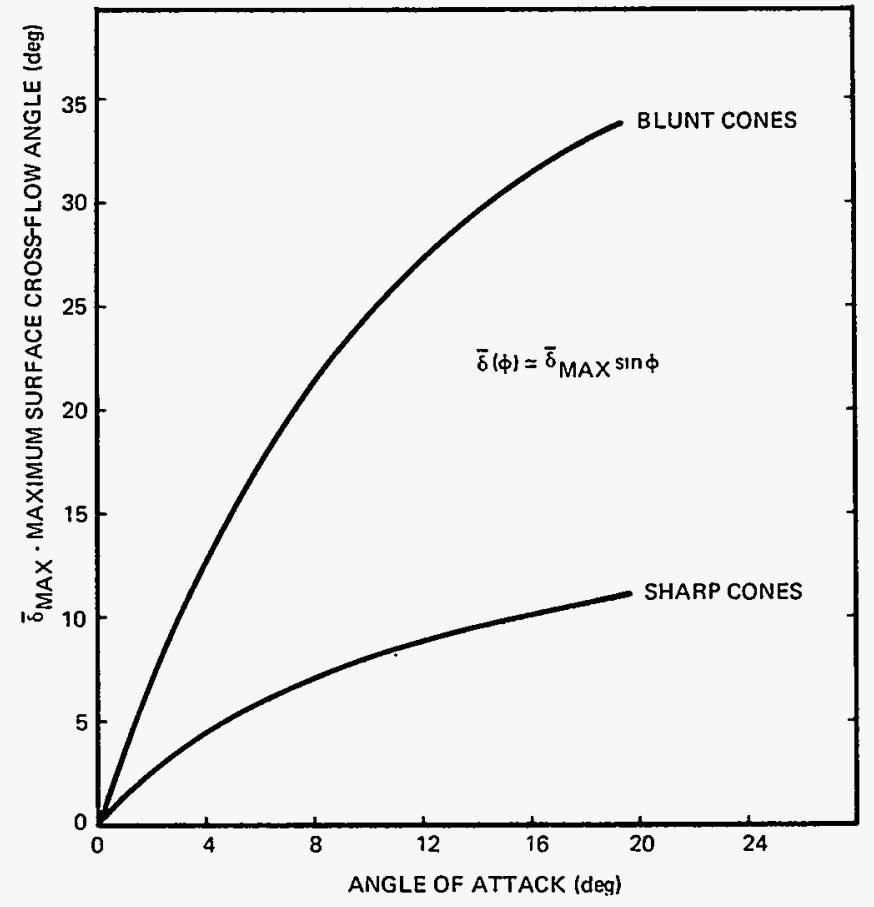

Figure 52. Theoretical Cross Flow Angle for Blunt and Sharp Cones

An analytic technique for determining the fin aerodynamic coefficients as functions of the angle of attack and roll orientation angle has been developed. The details and a description of the computer program, FANDY, which calculates the fin aerodynamics, are presented in Reference 22.

An example demonstrating the accuracy of the analytic technique is given in Figures 53 and 54. In these figures, the experimental roll moment coefficients for a two-finned vehicle from References 23, 24, and 25 are given along with theoretically determined values obtained from the FANDY program. Reference 26 has shown that the roll moment coefficient for a two-finned vehicle can be represented as follows:

$$
C_{1}=C_{1_{\delta}}(\alpha) \delta+C_{1_{\phi}}(\alpha, \delta) \sin 2 \phi
$$




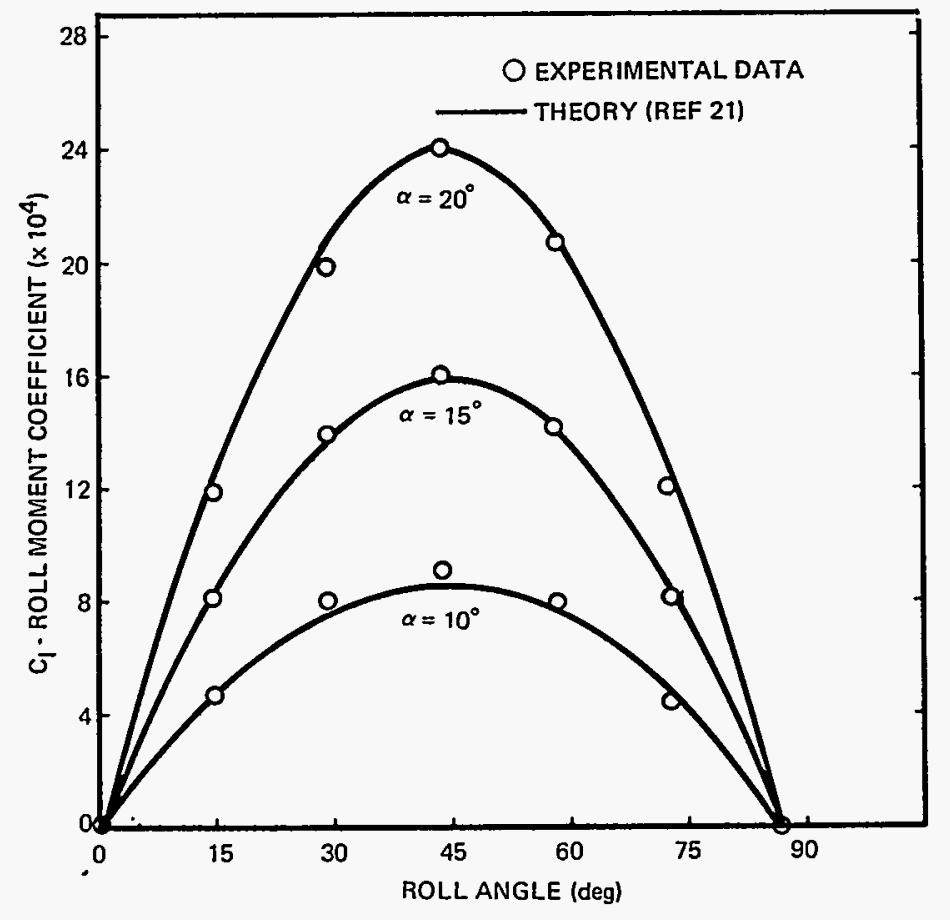

Figure 53. Fin Roll Moment Coefficient Correlation (Fin Cant, $\delta=0^{\circ}$ )

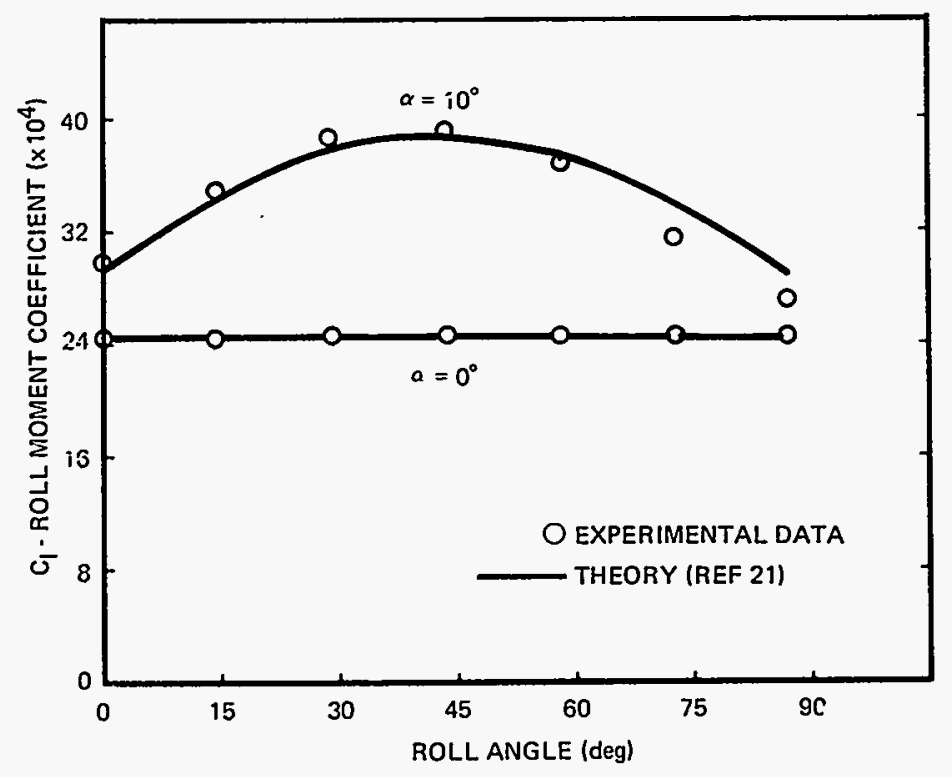

Figure 54. Fin Roll Moment Coefficient Correlation (Fin Cant, $\delta=10^{\circ}$ ) 
The first term is due to fin cant (and vanishes for no fin cant), while the second arises from the roll orientation dependence (and vanishes for angle of attack equal to zero). Both terms are nonlinear functions of angle of attack. As Figure 53 shows, considerable roll torque exists (depending on roll orientation), even for the case of no fin cant. The roll coefficients are well represented by the above expression. The fin-cant term which is the control system output is independent of roll orientation, while the induced effect $\mathrm{C}_{1_{\phi}}$ is very nearly independent of fin cant. It is possible for the induced nonlinearity to dominate the fin-cant roll moment and produce the flight instabilities described in References 26 and 27. This is particularly true for the more blunt configurations since the cross-flow angularity increases with increasing bluntness.

To minimize the induced nonlinearity, the two-fin configuration is modified to a four-fin system. The second pair of fins is fixed on the body at a zero cant angle, and the plane of this set is orthogonal to that of the first. This arrangement introduces an additional roll coefficient expansion similar to the previous expression, with the exception that the roll orientation for the second set is advanced by $\pi / 2$. By adding the two expressions, the total roll moment coefficient is given by

$$
\mathrm{C}_{1_{\mathrm{T}}}=\mathrm{C}_{1_{\delta}}(\alpha) \delta+\overline{\mathrm{C}}_{1_{\phi}} \sin 2 \phi
$$

The amplitude of the term dependent on the roll angle is now reduced considerably because of the addition of the fixed fins, and it vanishes at zero fin cant. This analysis has been verified by extensive wind tunnel tests.

The theoretically determined fin cant and induced roll moment coefficients for the RCRTV (at a Mach number of 5) are presented in Figures 55 and 56, respectively. These values are obtained as functions of vehicle angle of attack from the FANDY computer program. A comparison is made in Figure 56 of the induced roll moments for the two-fin and four-fin configurations, and there is more than a factor-of-three reduction at the worst condition (maximum fin cant of 10 degrees). At zero fin cant, the value of $\overline{\mathrm{C}}_{1_{\phi}}$ is zero.

Effects of High Spin Rate

Since the payload flight is at low Mach numbers (low vehicle velocity), it is important to consider the effects of the relatively high spin rate as compared with low vehicle total velocity. The tangential velocity of the fin gives rise to an effective fin cant angle given by the following: 


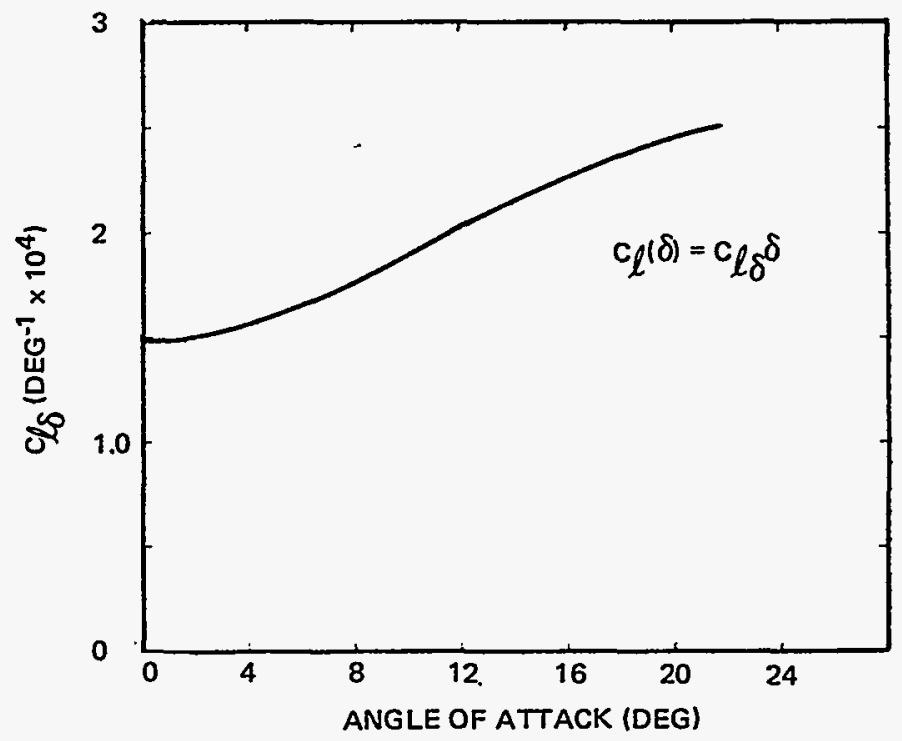

Figure 55. RCRTV Theoretical Roll Moment Coefficient Due to Fin Cant

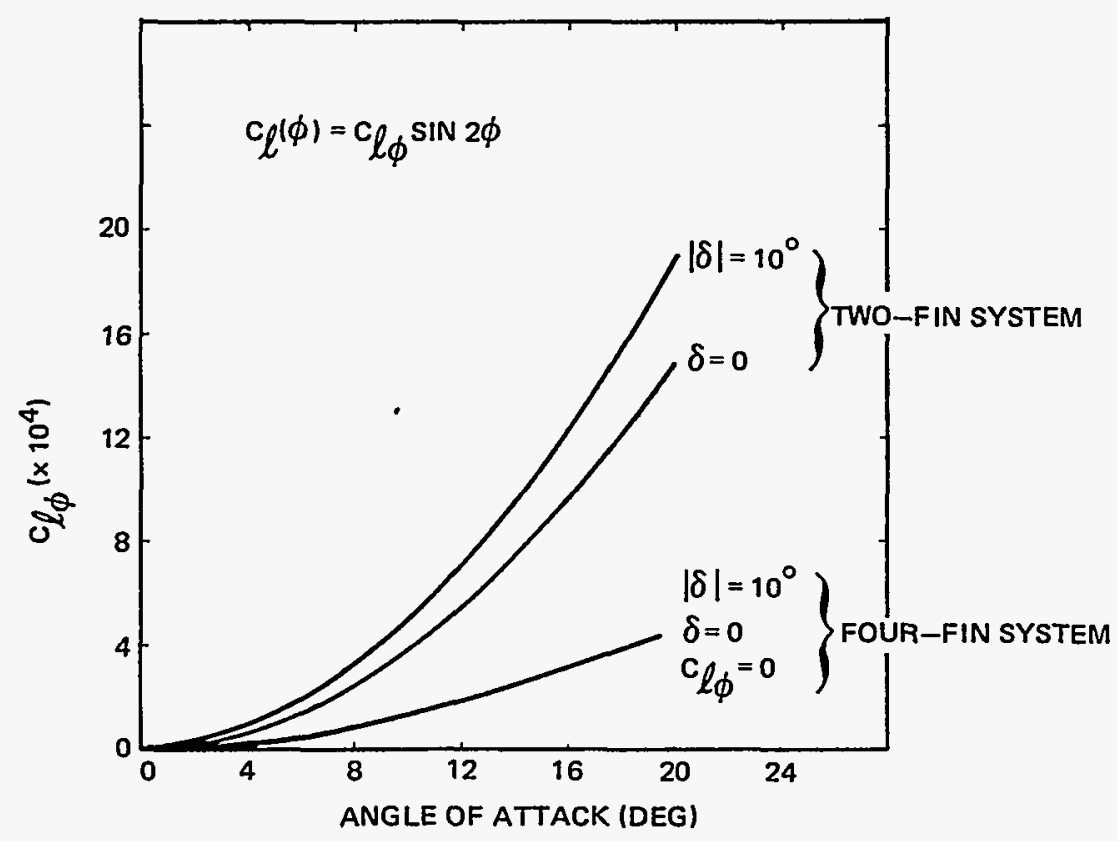

Figure 56. RCRTV Theoretical Induced Roll Moment Coefficient 


$$
\delta_{e f f}=\tan ^{-1}\left(\frac{P z}{V}\right)
$$

where

$$
\begin{aligned}
& \delta \text { eff } \\
& \quad \text { - fin effective cant angle due to spin } \\
& z_{f} \text { - location of fin relative to vehicle longitudinal axis (ft) } \\
& V \text { - vehicle total velocity (ft/s) }
\end{aligned}
$$

As the vehicle total velocity decreases, the effective cant angle becomes larger, and this effective fin cant produces a negative roll torque throughout the trajectory. For example, the effective fin cant for RCRTV at Mlach 5 and with a spin rate of $6 \mathrm{cps}$ is approximately 0.25 degree for each fin. On the basis of the theoretical fin aerodynamic characteristics, a spin-down roll moment coefficient of $-1 \times 10^{-4}$ is obtained. However at Mach 1 , the effective cant is approximately 1.1 degree, thus producing an effective roll moment coefficient of $\mathrm{C}_{\ell_{\epsilon}}=4.4 \times 10^{-4}$. Although this effect is negligible for hypersonic reentry, it is important for the RCRTV flight.

\section{Fin Aerodynamic Characteristics}

The asymmetry effects may be removed from the total roll moment coefficient to obtain the contribution provided by the control system. The roll moment data, however, were not of sufficient quality to provide a welldefined control system coefficient history for the entire trajectory. Where the data were considered unreliable, trajectory simulations were used to match the measured roll history and obtain the roll moment characteristics. This procedure provided a roll control moment due to fin cant of $\mathrm{C}_{\ell_{\delta}} \cdot$ It is

assumed that the roll moment coefficient provided by the control system can be expressed as outlined in the previous section. The fin cant coefficient $\mathrm{C}_{\ell_{\delta}}$ thus determined, is presented in Figure 57 as a function of flight Mach number. Shown also in Figure 57 is the theoretically determined $\mathrm{C}_{\ell_{\delta}} \cdot$ There is excellent agreement between the theory and the flight-derived $\mathrm{C}_{\ell_{\delta}}$ at the higher Mach numbers (Mach 2.5 to 5). Although the theory predicts an increase in fin effectiveness with decreasing Mach number, the flight derived $\mathrm{C}_{\ell_{\delta}}$ remains constant down to Mach 2.5 and then decreases. 


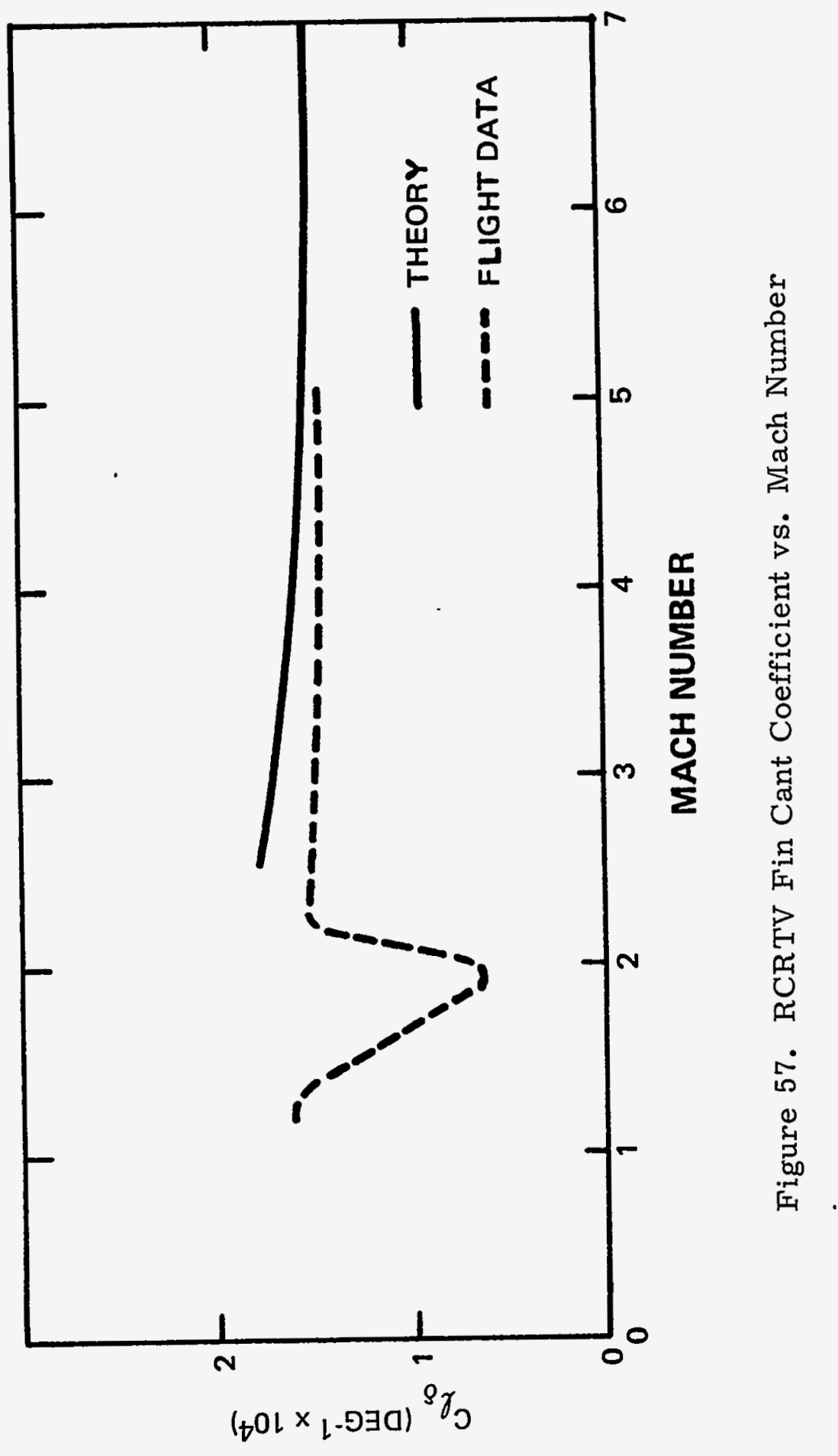


The conclusion is that the theory accurately represents fin ae rodynamic characteristics at the higher Mach numbers (Mach $\geqq 2.5$ ) but cannot be extrapolated to the low, transonic Mach number range (Mach $\leqq 2.5$ ).

\section{Roll Control System Performance}

In this section a description of the roll control system, its physical properties, and its flight test performance and evaluation are presented. In addition, trajectory simulations of the flight vehicle with and without the roll control system are discussed. These simulations incorporate the actual flight launch conditions and trajectory parameters, as well as the flightderived aerodynamic characteristics presented previously.

\section{$\underline{\text { Roll Control System Dynamics }}$}

Although the actual design of the spin-fin system is somewhat complex, it is considered a simple spring-mass damper. The complete differential equations of motion which govern the internal moving masses (and fin deflections) are given in detail in References 8 and 9. A simplified form of this model will perhaps facilitate a discussion of the system. If it is assumed that the two proof masses are equivalent and are properly positioned in the vehicle (no misalignment errors, etc.), the control mass position $\rho$ is given by

$$
\overline{\mathrm{m}} \ddot{\rho}+\mathrm{C} \dot{\rho}+\mathrm{k}\left(\rho-\rho_{0}\right)=\mathrm{F}_{\mathrm{AERO}}-\mathrm{f}+\overline{\mathrm{m}} \rho \mathrm{P}^{2}
$$

where

$$
\begin{aligned}
& \overline{\mathrm{m}} \text { - effective control mass (slugs) } \\
& \mathrm{C} \text { - effective damping coefficient(lb-s/ft) } \\
& \mathrm{k} \text { - effective spring constant (lb/ft) } \\
& \rho \text { - control mass position relative to vehicle centerline (ft) } \\
& \rho_{0} \text { - relaxed spring position (ft) } \\
& \mathrm{P} \text { - spin rate }(\mathrm{rad} / \mathrm{s}) \\
& \text { F AERO - aerodynamic feedback force on control mass (lb) (Due to } \\
& f \text { - total friction force (1b) }
\end{aligned}
$$


The total friction force includes a term which is proportional to the vehicle axial acceleration, since under such a condition, the control masses are loaded against the housing cylinders. The geometric fin cant $\delta$ is determined from the mass position by the linear relation

$$
\delta=\delta_{0}-\phi_{L}\left(\rho-\rho_{I}\right)
$$

in which $\delta_{0}$ is the maximum fin deflection, $\phi_{\mathrm{L}}$ is the fin-mass linkage constant, and $\rho_{I}$ is the mass position at maximum fin deflection.

The roll control system is therefore considered as a lumped parameter model characterized by Equation (14) and effective values of spring constant, damping, and so on. An extensive ground test program was carried out to determine these parameters and to find out if the control system actually does conform to the second-order model.

\section{Roll Control System Physical Properties}

The ground test program and experimental data are described in detail in Reference 3, and the important roll control system performance parameters determined during the test program are summarized in Table VII. The design spin rate was found to be approximately 7.0 cycles per second. Since under axial loads the sensing masses are loaded against the housing cylinders, the total frictional force is dependent on axial acceleration. This induced frictional force was determined to be 0.13 pound per axial $\mathrm{g}$ (Table VII).

TABLE VII

ROLL-CONTROL SYSTEM PERFORMANCE PARAMETERS

\begin{tabular}{ll}
\hline Sensing mass & $0.75 \mathrm{lb}$ \\
Effective spring constant & $98.4 \mathrm{lb} / \mathrm{ft}$ \\
Effective damping coefficient & $5 \mathrm{lb}-\mathrm{ft} / \mathrm{s}$ \\
Effective spring preload & $8.0 \mathrm{lb}$ \\
Total mass travel & $1.0 \mathrm{in}$ \\
Maximum fin deflection & $10^{\circ}$ \\
Minimum fin deflection & $-7^{\circ}$ \\
Effective linkage constant & $17 \mathrm{deg} / \mathrm{in}$ \\
Static friction (1 g environment) & $0.2 \mathrm{lb}$ \\
Axial loading-dependent friction & $0.13 \mathrm{lb} / \mathrm{axial} \mathrm{g}$ \\
Design spin rate & $7.0 \mathrm{cycles} / \mathrm{s}$ \\
\hline
\end{tabular}


Simulation tests ${ }^{28}$ were also conducted in the Sandia, Livermore, Flight Dynamics Laboratory (FDL) ${ }^{29}$ which permits an evaluation of the system response under conditions which closely simulate those encountered in actual flight. These were "system-in-the-loop" tests in which the control system test unit was mounted on a CARCO* angular motion simulator whose flight table was driven by the hybrid-computer solution of the trajectory equation of motion. The facility permits a direct comparison of the dynamic response of the actual control system with that given by the mathematical model of the system, and this series of simulation tests verified that the system is accurately represented by the second-order lumped-parameter model.

Recovery of the flight vehicle permitted postflight roll control system testing, which indicated essentially no change in the properties listed in Table VII.

Uncontrolled Flight Performance

In the absence of roll control, certain types of asymmetric flight vehicles will exhibit a sustained roll resonance instability (roll lock-in), an instability characterized by a roll rate equal to the vehicle natural pitch frequency $\left(\mathrm{P}_{\text {crit }}\right)$ and by a divergence of the total angle of attack. To ensure similar behavior, the RCRTV flight vehicle has built-in mass and inertial asymmetries (nominally a 0.25 degree principal axis inclination and a 0.10 inch center-of-mass offset normal to the inertial asymmetry), as indicated in Table I. It is the roll torque produced by these combined asymmetries that tends to stabilize the roll rate about the natural pitch frequency (sustained roll resonance). The purpose of the RCRTV flight test program, then, is to demonstrate the capability of the spin-fin roll control system to control the roll rate of a vehicle with such asymmetries.

The RVRTV program, ${ }^{16,17}$ on the other hand, is a continuing study by Sandia Laboratories to investigate roll-pitch coupling under simulated reentry conditions. To date, the following flight tests have been conducted with vehicles having an external configuration the same as that of the RCRTV and dealing with: (1) aerodynamic and mass asymmetries to produce roll lock-in, (2) aerodynamic and mass asymmetries with a hydrazine reaction jet roll control system, and (3) inertial and mass asymmetry to produce roll lock-in. These flights verified the analytic and simulation techniques used to determine the vehicle flight performance.

To establish the vehicle flight performance without roll control, the flight-derived aerodynamic data presented previously, the vehicle physical properties, and the payload separation conditions are used in the SPINFIN

\footnotetext{
*CARCO Electronics Model S440-R3 three-axis flight table.
} 
trajectory simulation computer program. The flight parameters for the uncontrolled trajectory are illustrated in Figures 58 and 59. In Figure 58, where vehicle spin rate $P$ and natural pitch frequency $P_{\text {crit }}$ appear as functions of flight time, the vehicle spins down to near zero roll rate, thus demonstrating a stable roll lock-in. During this time, the total angle of attack, shown in Figure 59, diverges to an amplitude of about 60 degrees. Thus it is quite clear that with no roll control system, the flight vehicle would have experienced sustained roll lock-in.

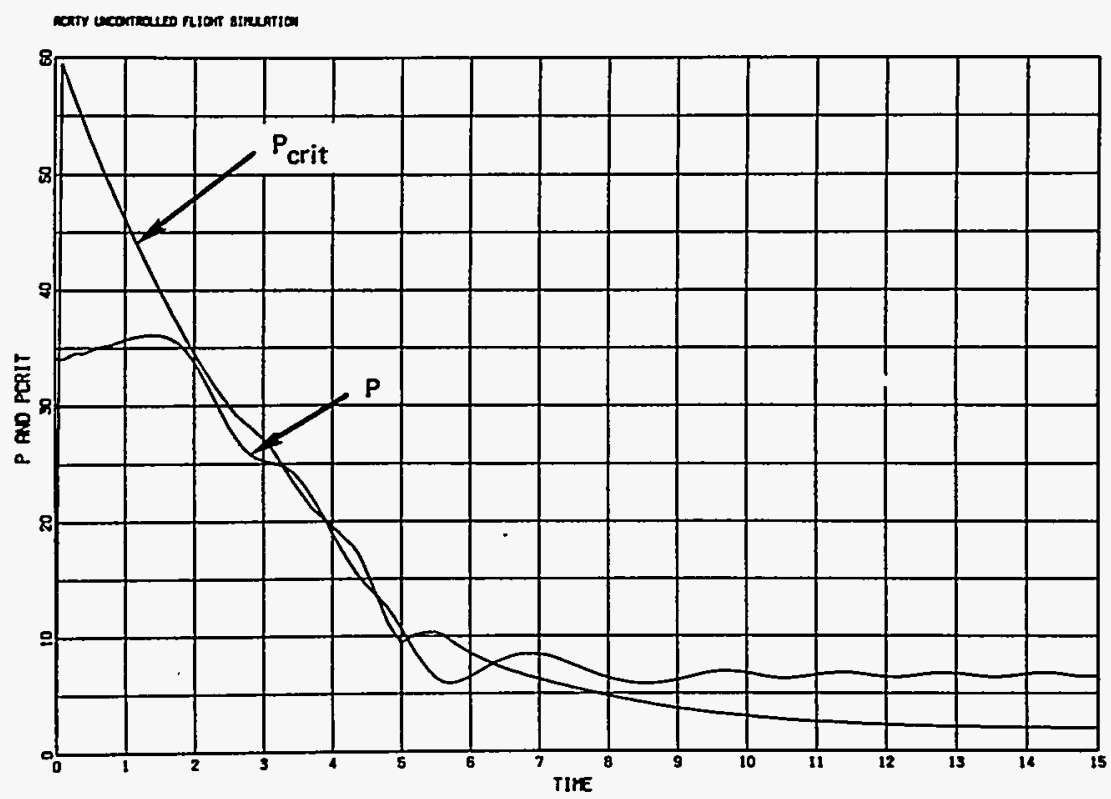

Figure 58. RCRTV Spin Rate and Natural Pitch Frequency for Uncontrolled Trajectory

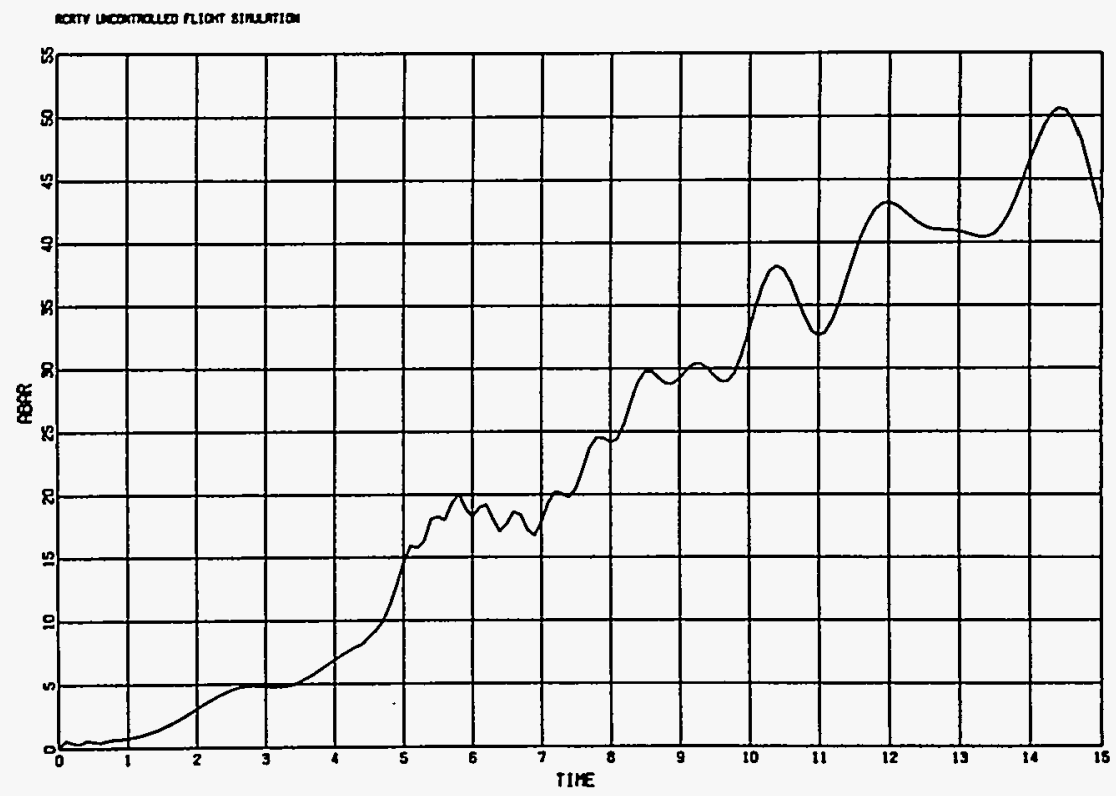

Figure 59. RCRTV Total Angle of Attack for Uncontrolled Trajectory 
Control System Flight Performance

The important variables which characterize the vehicle and roll control system flight dynamic performance (spin rate $p$,critical pitch frequency $\mathrm{P}_{\text {crit }}$, total angle-of-attack $\alpha$, and fin cant $\delta$ ) are presented in Figures 60,61 , and 62 . The spin rate (Figure 60 ) is that obtained from the rate gyro, while the critical pitch frequency is computed from the relation

$$
P_{\text {crit }}=\sqrt{\frac{-C_{M_{\alpha}}{ }^{Q S d}}{I-I_{x}}}
$$

by using the previously derived static stability coefficient $\mathrm{C}_{\mathbb{M}_{\alpha}}$ and the

flight dynamic pressure history. Since the initial spin rate of $34 \mathrm{rad} / \mathrm{sec}$ is considerably below the system design value of $44 \mathrm{rad} / \mathrm{sec}$, a rapid increase in spin rate takes place; and this increase causes the vehicle to experience resonance early in the flight ( $t \cong 0.8$ second), resulting in an early divergence of the total angle of attack (Figure 61). This occurrence is followed by a prolonged spin-down from $T=0.8$ to $T=3.3$ seconds, during which time the spin rate is locked into resonance and decreases to about $32 \mathrm{rad} / \mathrm{sec}$. At $T=3.3$ seconds, the control system causes the spin $r$ ate to recover to the nominal value of $44 \mathrm{rad} / \mathrm{sec}$, and the angle of attack converges. The flight fin cant history is presented in Figure 62.

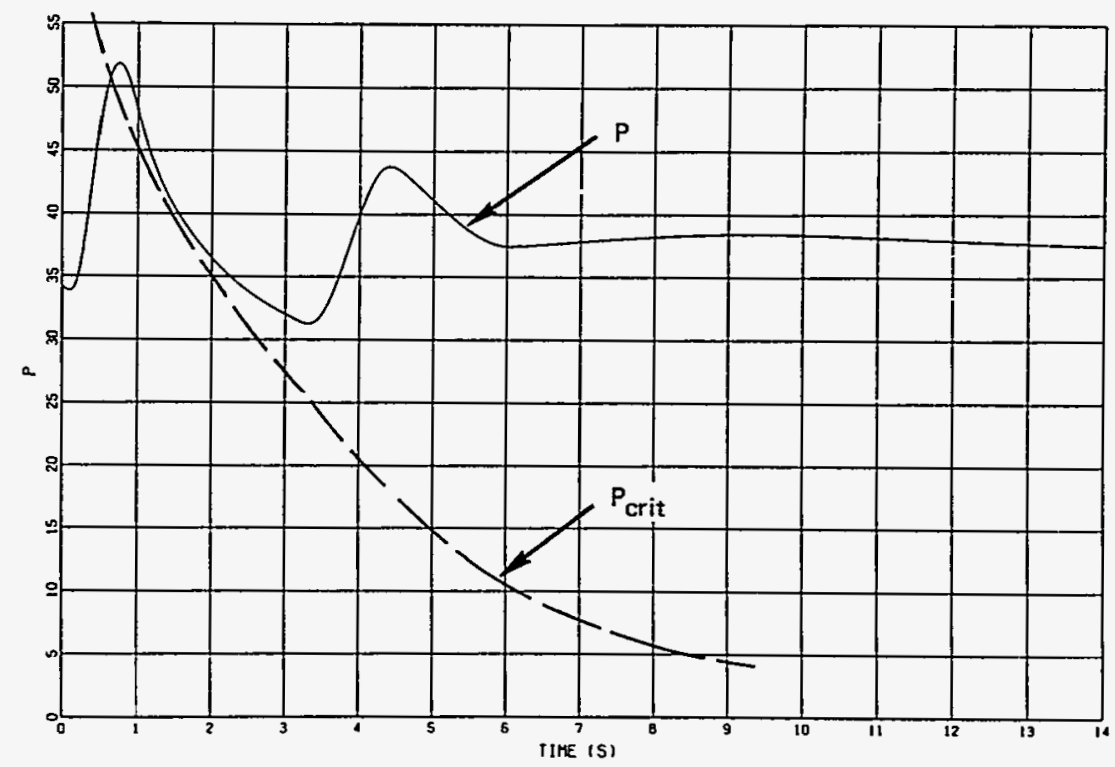

Figure 60. Flight Vehicle Spin Rate and Natural Pitch Frequency History 


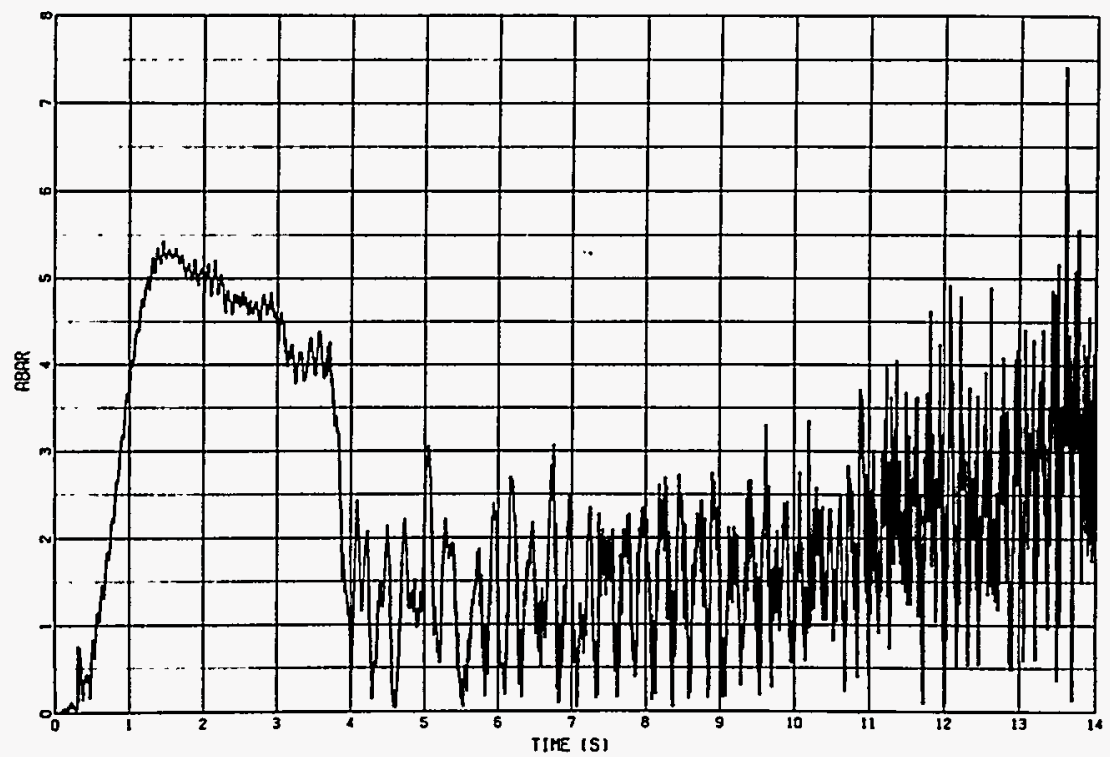

Figure 61. Flight Vehicle Total Angle-of-Attack History

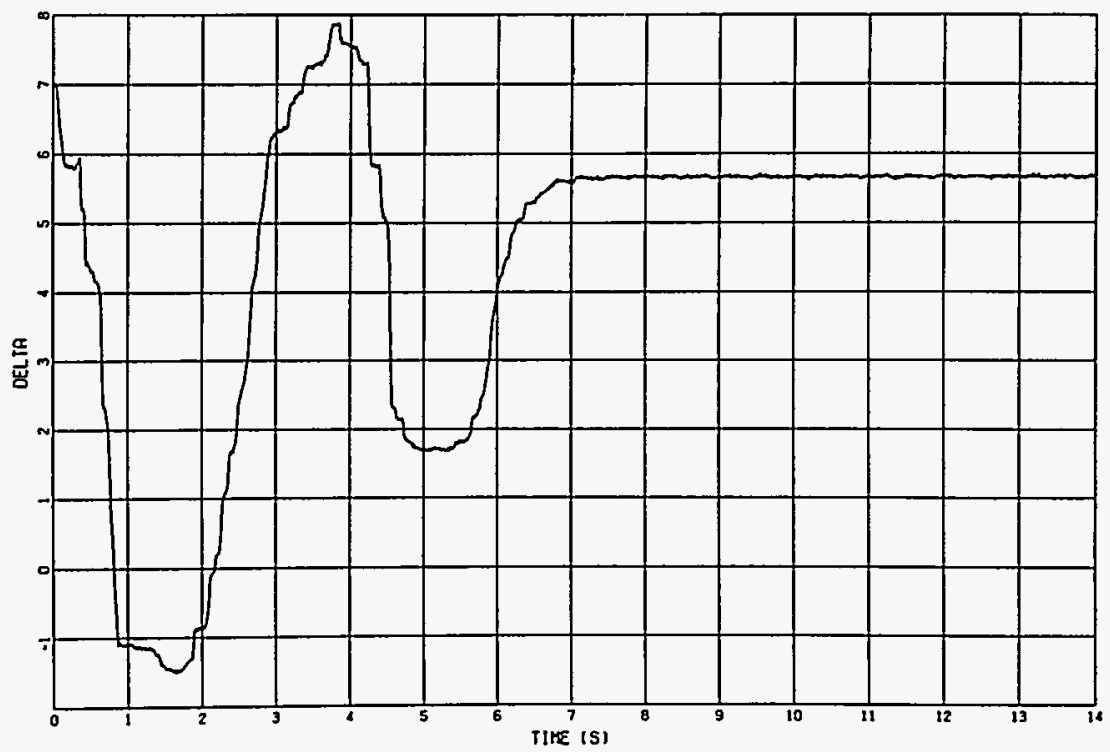

Figure 62. Flight Vehicle Fin Cant History 
On the RCRTV flight, a difference between the expected and observed performance was obtained. The discrepancy arose from two sources:

(1) differences between the expected and actual payload separation conditions, and (2) differences between the predicted and flight-derived fin and body aerodynamic characteristics. In order to construct the postflight simulation, these effects must be taken into account. Thus they are discussed in the following pages.

\section{Flight Simulations}

The results of a postflight simulation, initiated at the actual payload separation conditions (Table VI) and using predicted fin and vehicle aerodynamic characteristics, are presented in Figures 63 and 64. A comparison of the vehicle rolling velocity obtained from the flight and from the simulation is shown in Figure 63. The vehicle does not immediately spin up, following payload separation, even though the fins are canted at approximately 7 degrees. The belief is that pressure disturbances due to the proximity of the booster at this time can produce a significant change in the pressure profile over the vehicle surface and in the neighborhood of the fins. Similar effects are apparent in the axial force coefficients shown in Figures 41 and 42 . Thus until the payload gets free of the booster and fully establishes its wake, the fin characteristics may be greatly affected. In any case, the delay in initial spin-up is incorporated in the simulation, and the spin rate obtained (Figure 63 ) is in good agreement with the flight values until about 2.0 seconds after separation. At this time the simulated rolling velocity breaks out of resonance, is stabilized at $44 \mathrm{rad} / \mathrm{sec}$ at $\mathrm{T}=3.5 \mathrm{~seconds}$, and is maintained thereafter.

A comparison of the simulated with the flight test angle-of-attack upper envelope history (Figure 64) shows good agreement in both the initial divergence and the peak amplification. An early convergence of the angle of attack is obtained with the simulation, as expected, due to the early breakout of the simulated spin rate from resonance.

The initial spin-up is attributable primarily to the low separation roll rate. However, the spin-down after $\mathrm{T}=2.0$ seconds, which is not accounted for, is due to a decrease in fin aerodynamic effectiveness, which is in turn attributable to the flight Mach number variation.

A second postflight simulation was performed in which the flight-derived fin aerodynamic characteristics (Figure 57) are employed, and the results are presented in Figures 65,66 , and 67, with the flight test values included for comparison. In each case the agreement is excellent between the simulation and the flight test for spin rate, for angle of attack, and for fin cant history. The conclusion is that the SPINFIN simulation, which uses the actual flight separation conditions and the flight-derived aerodynamic characteristics, accurately represents the flight performance. 


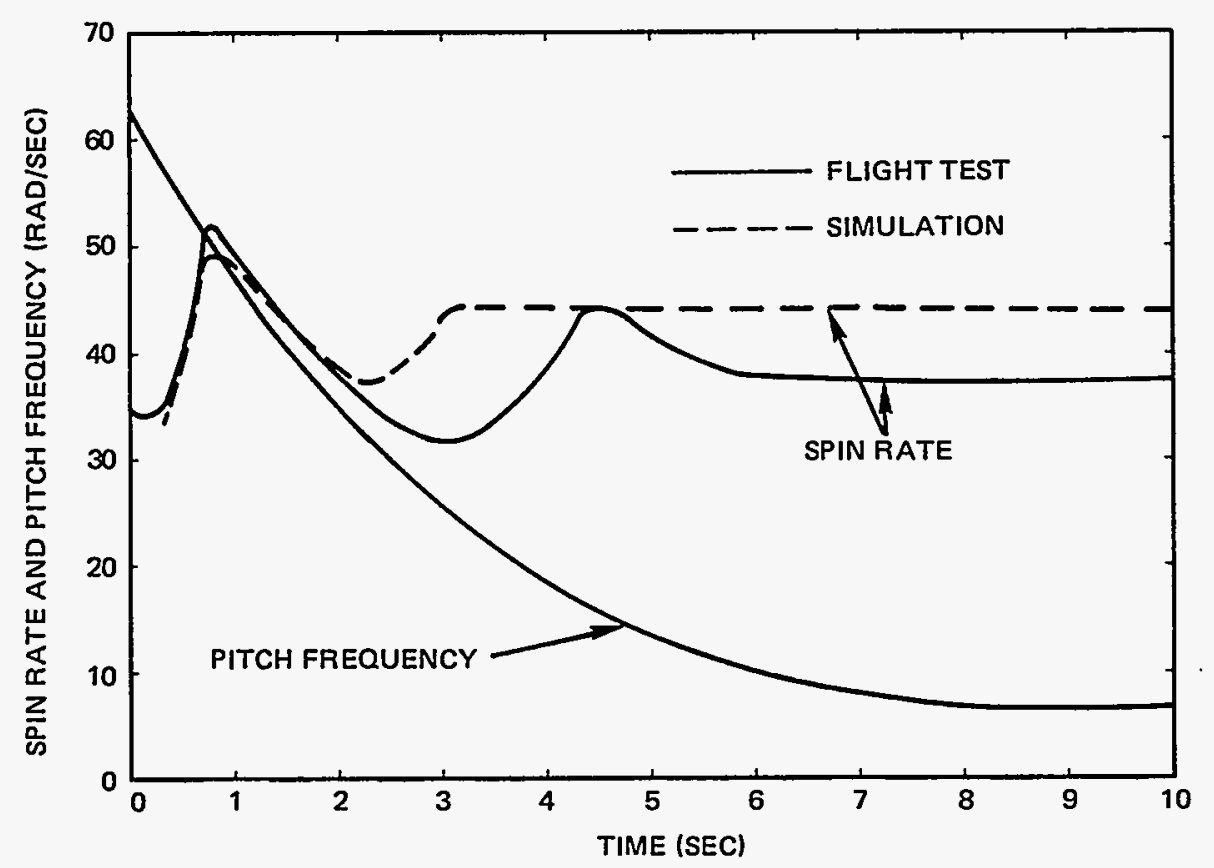

Figure 63. Spin Rate and Natural Pitch Frequency (Preflight Simulation with Flight Separation Conditions)

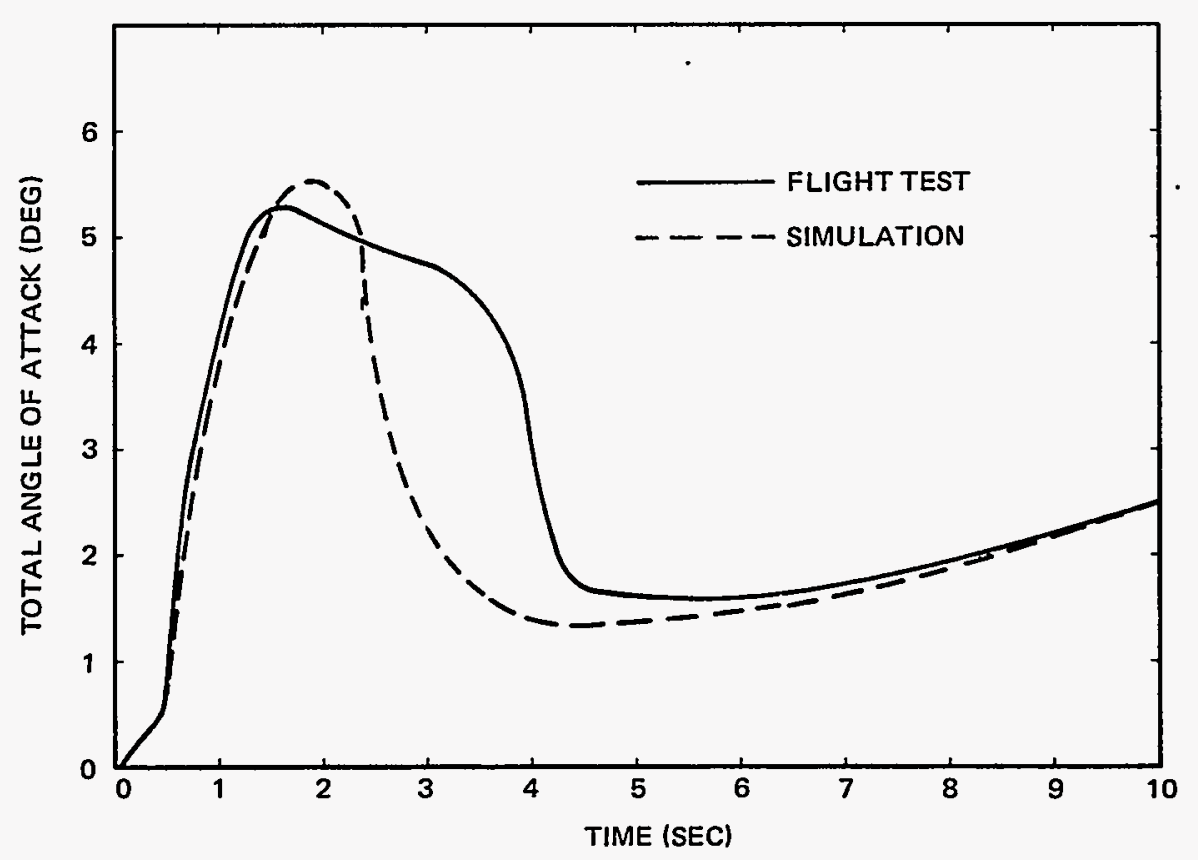

Figure 64. Total Angle of Attack (Preflight Simulation With Flight Separation Conditions) 


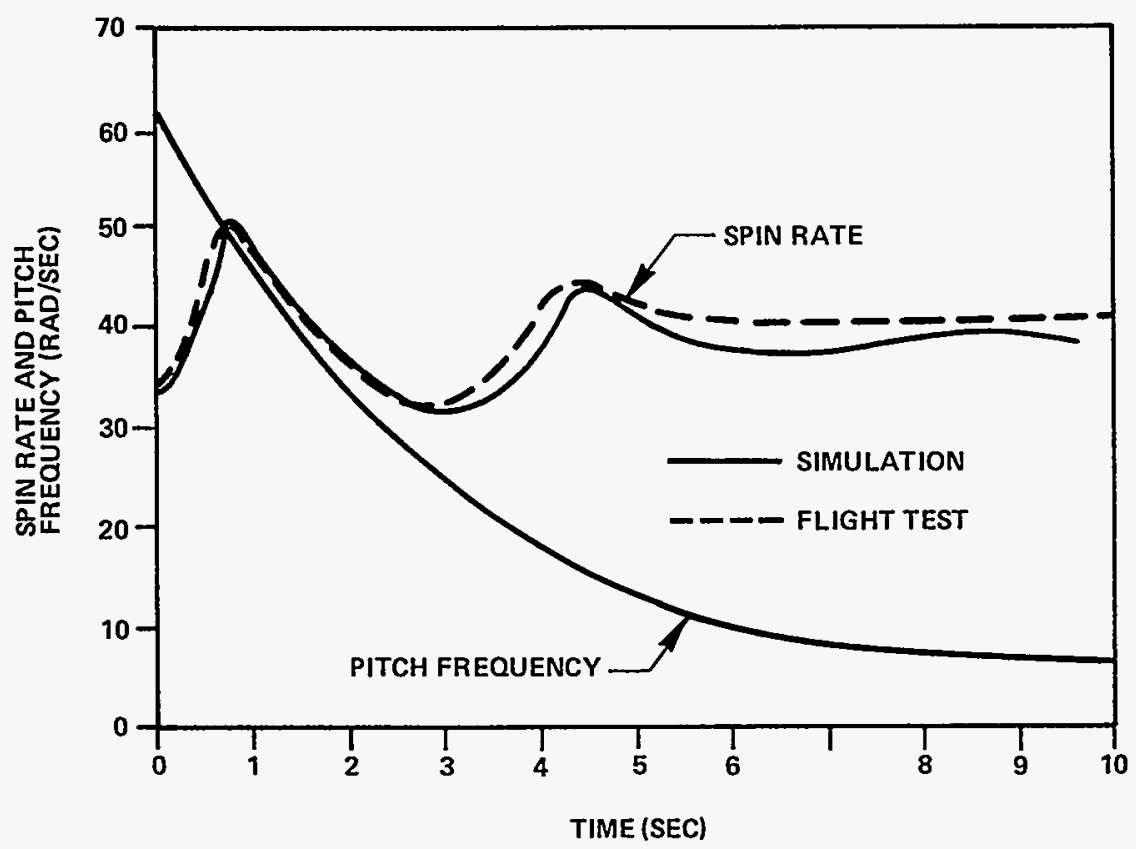

Figure 65. Spin Rate and Natural Pitch Frequency (Postflight Simulation with Flight Derived Aerodynamics)

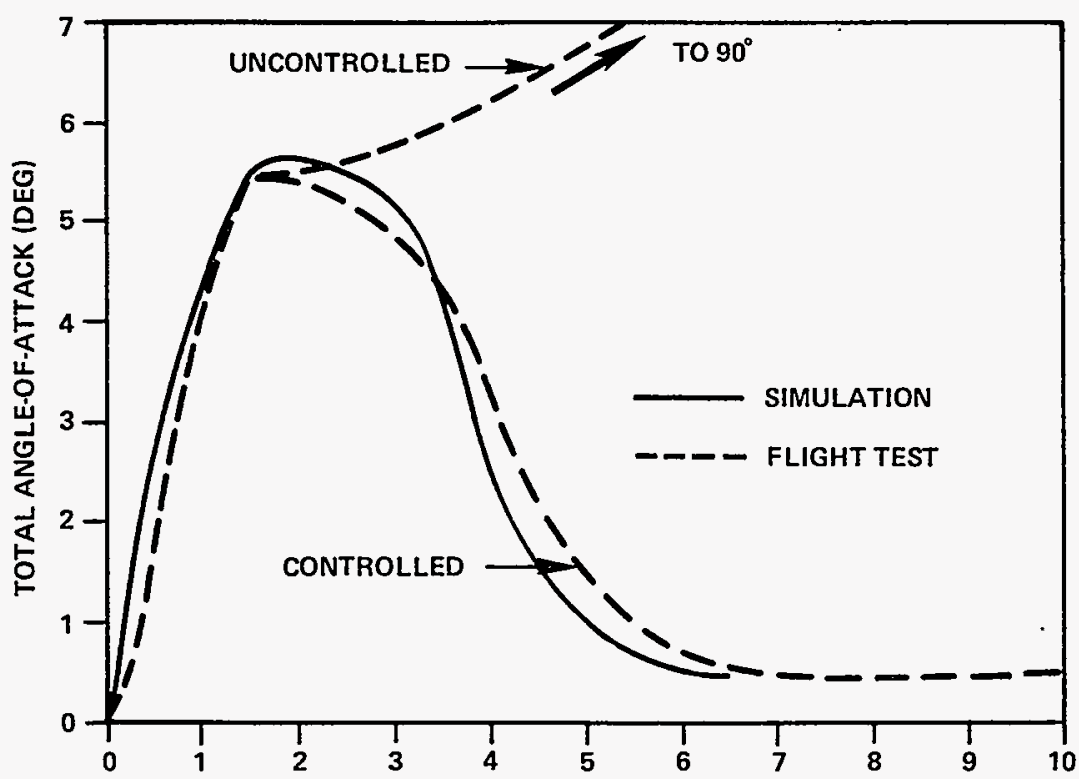

TIME (SEC)

Figure 66. Total Angle of Attack (Postflight Simulation with Flight Derived Aerodynamics) 


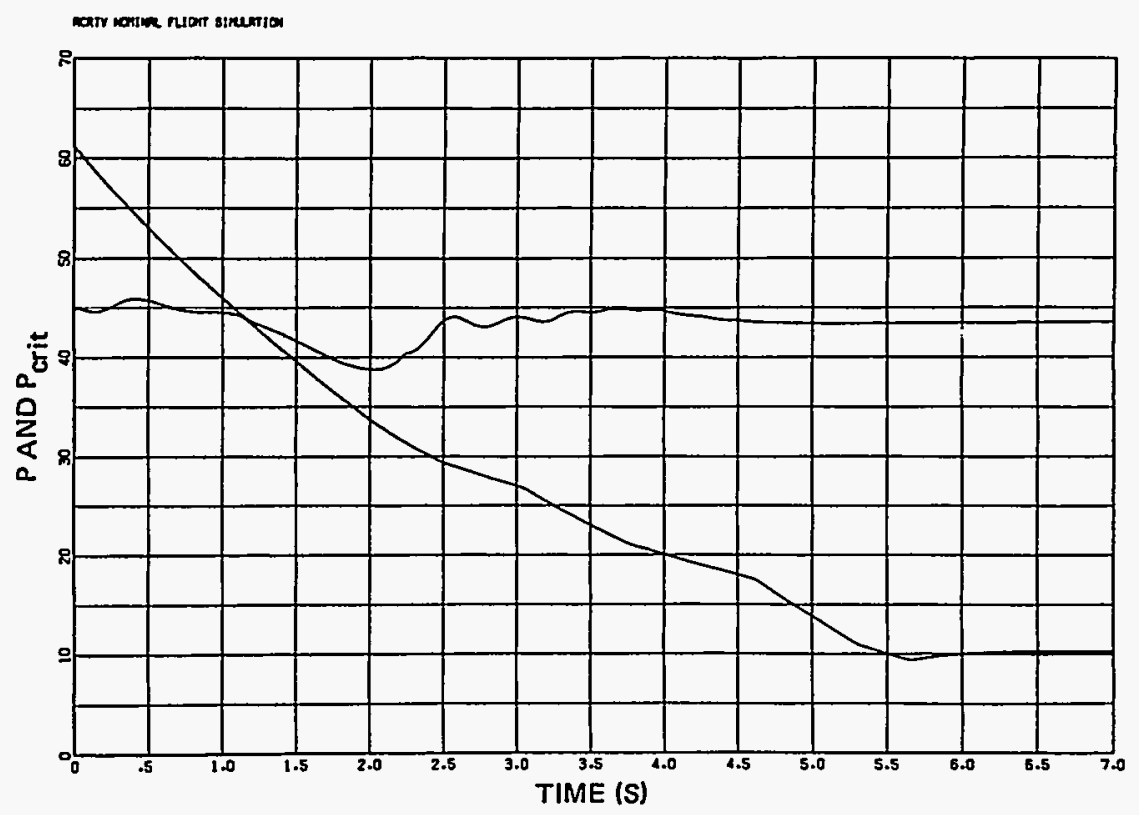

Figure 67. RCRTV Flight Simulation from Steady State Starting Conditions--Spin Rate and Natural Pitch Frequency

\section{Roll Control System Evaluation}

Before an actual second-resonance encounter, the vehicle would be at a steady-state rolling velocity with the fins at a near-zero cant angle. Therefore, in order to evaluate properly the control system performance during second resonance, a simulation was performed in which the system was initially at the design condition. In such a manner, the adverse effects of the initial separation conditions were eliminated, thus making possible a more meaningful evaluation of performance. The simulation, which also used the flight-derived fin and vehicle aerodynamic characteristics, was initiated at the separation conditions listed in Table VI, except that the initial spin rate was set at 7.2 cycles/second. The results of the simulation are summarized in Figures 67, 68, and 69.

There was considerably less roll excursion during simulation than there was during the flight. Although the angle-of-attack amplification was the same as the flight value, convergence was obtained much sooner because the roll rate was controlled. Therefore, the conclusion is that most of the spin rate variation obtained on the flight occurred because the roll control system had to recover from a spin rate considerably below the operating value. Further, on a typical full-scale reentry trajectory, there is considerably less roll rate deviation from the design value if the system is at steady-state operating conditions before the resonance encounter occurs. 


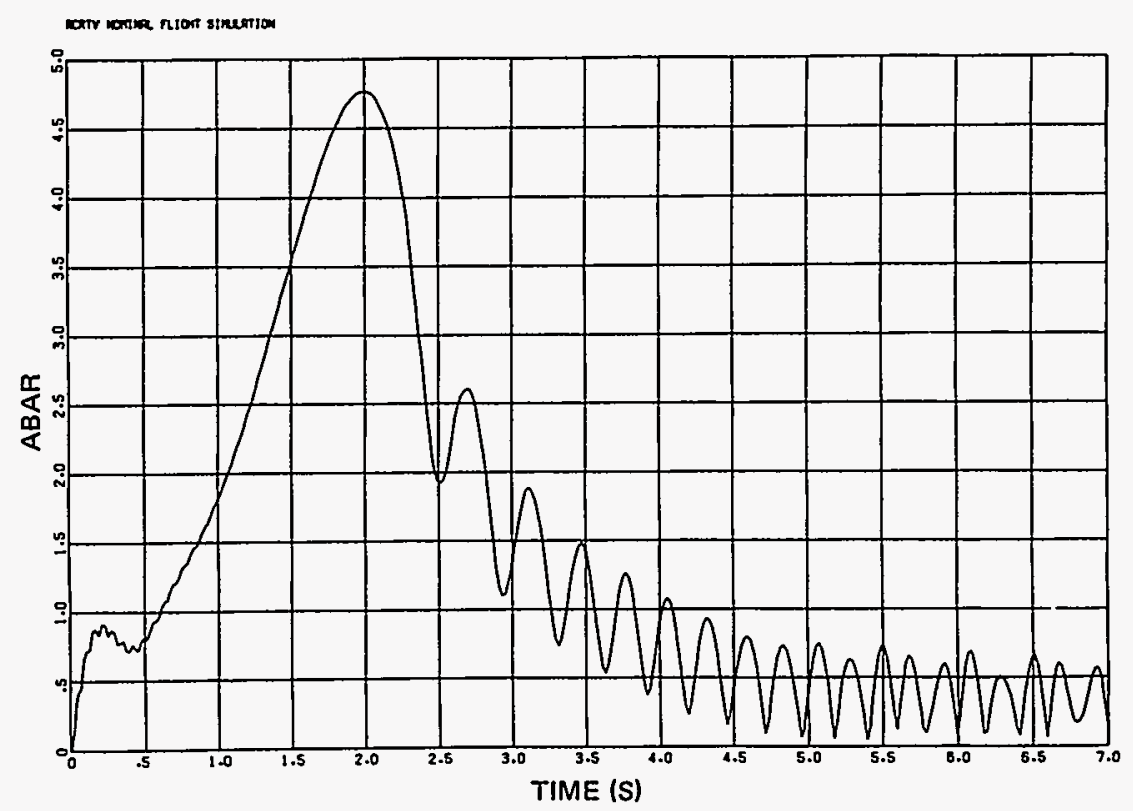

Figure 68. RCRTV Flight Simulation from Steady State Starting Conditions--Total Angle of Attack

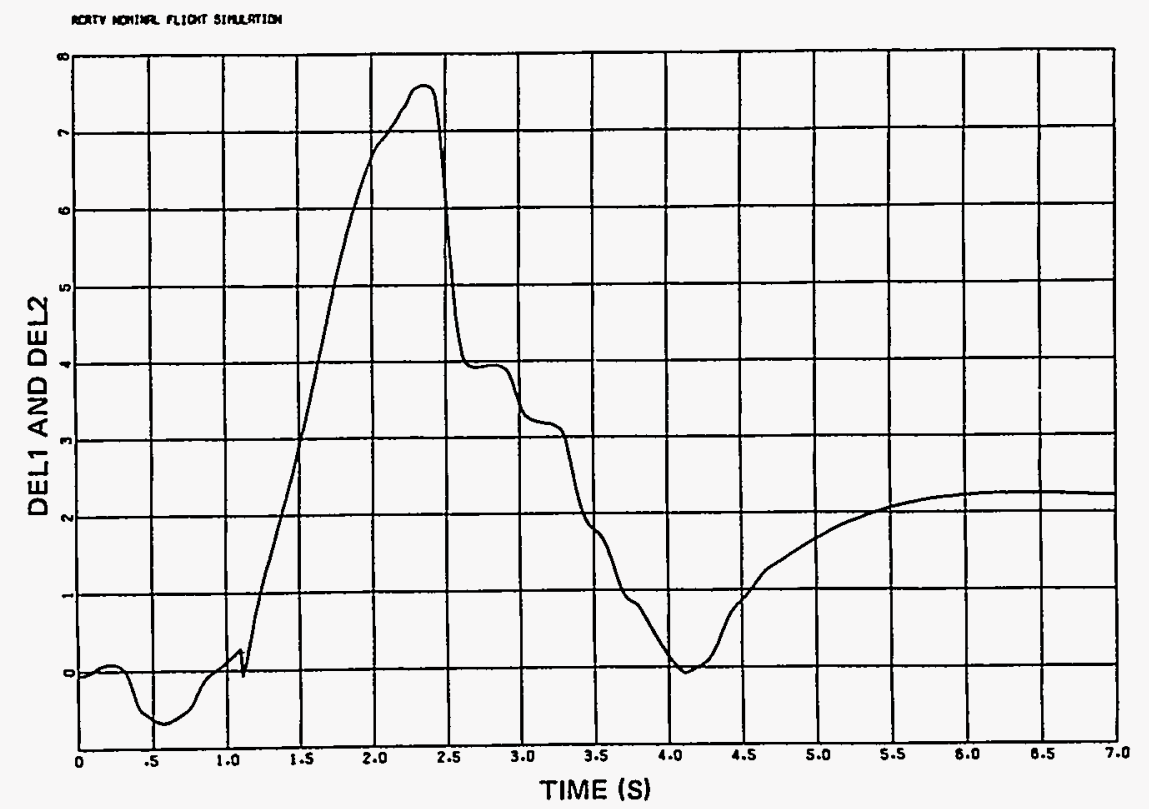

Figure 69. RCRTV Flight Simulation From Steady State Starting Conditions--Fin Cant 
Thermodynamic Analysis

Thermodynamic Data

The flight vehicle thermodynamic instrumentation consisted of calorimeters which measure heat flux on the cone surface and fin leading edges. One calorimeter was located on the leading edge of each fixed fin (oriented at 90 degrees and 270 degrees clockwise from the vertical). The cone surface heating calorimeters were located at two stations along the axis of the body. The first two were located at the fin station 4.75 inches forward from the vehicle base at orientations 135 degrees and 315 degrees clockwise from the vertical. The second pair were similarly oriented but were positioned 14.5 inches forward from the vehicle base. In addition to this heating instrumentation, four thermocouples were included to measure shell backface temperature. Two of them were mounted at each of the two axial stations described above, and at each station, they were oriented at 45 degrees and 225 degrees clockwise from the vertical. In addition to the foregoing sensors, there was passive thermodynamic instrumentation in the form of heat-sensitive (temperature-sensitive) Tempilaq paint used on certain portions of both the interior and exterior of the flight vehicle. Tempilaq tints sensitive to various temperatures were placed on the top and sides of each fin, on the fin platform, and also on the cone surfaces aft of the fins and on either side of each fin. A detailed description of the Tempilaq placement is given in Reference 5 .

The cone surface heating at the fin station (4. 5 inches from the base) is given in Figures 70 and 71 , and the heating obtained at the forward station (14. 5 inches from the base) is provided in Figures 72 and 73 . A peak of $90 \mathrm{BTU} / \mathrm{ft}^{2}-\mathrm{s}$ was obtained from each calorimeter at the fin station at about $T=8$ seconds after launch. This is, as expected, slightly less than the $100 \mathrm{BTU} / \mathrm{ft}^{2}-\mathrm{s}$ maximum obtained at the forward station. The transmission from one of the forward calorimeters (Q5, Figure 73) was not reliable during the peak heating and is therefore not used.

The data obtained from the fin leading-edge calorimeters (Figures 74 and 75) are in excellent agreement and indicate peak heating of about 425 $\mathrm{BTU} / \mathrm{ft}^{2}-\mathrm{s}$ just before $\mathrm{T}=8$ seconds after launch.

The flight vehicle shell backface temperature at the fin station is shown in Figures 76 and 77. The two thermocouple outputs are in excellent agreement and show a maximum temperature of about $300^{\circ} \mathrm{F}$ at $\mathrm{T}=11$ seconds after launch. The data from the forward station thermocouples (Figures 78 and 79) appear somewhat questionable, however, from $T=8.0$ to 11.0 seconds. Nevertheless, the maximum temperature at $\mathrm{T}=11.0$ seconds appears to be about $330^{\circ} \mathrm{F}$. 


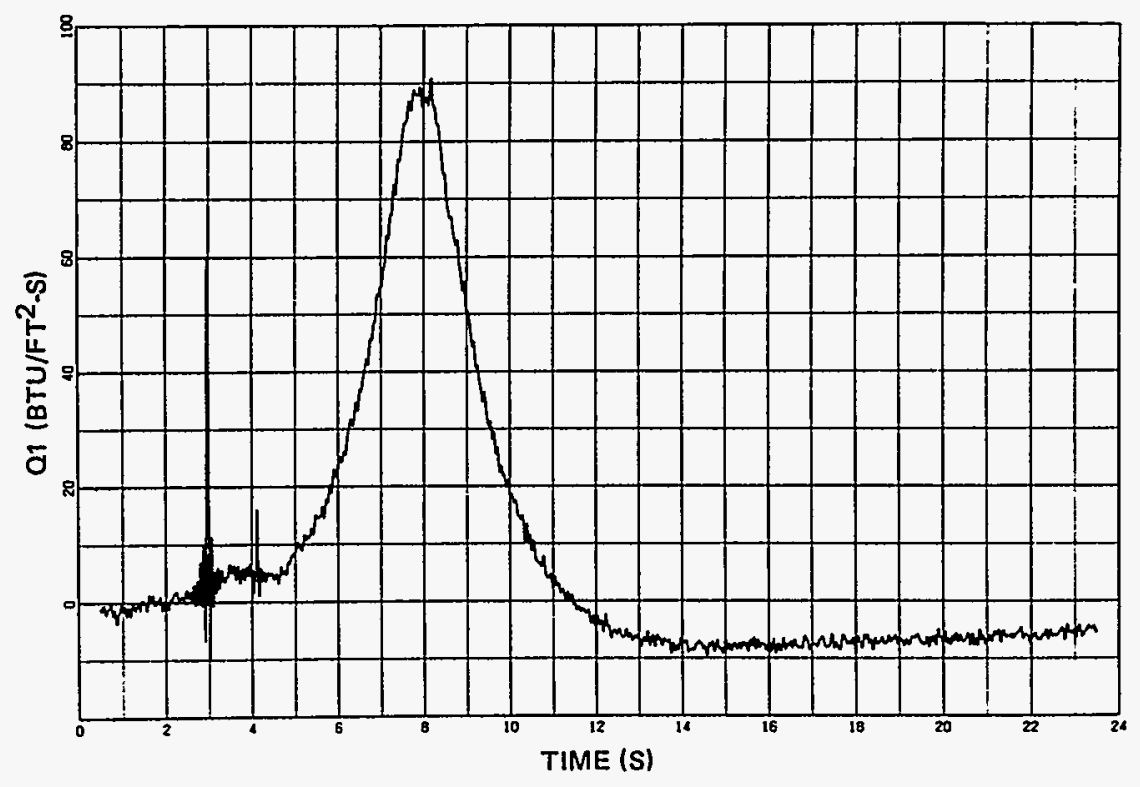

Figure 70. Cone Surface Heat Flux at Fin Station (4. 75 in From Base @ 135 Orientation)

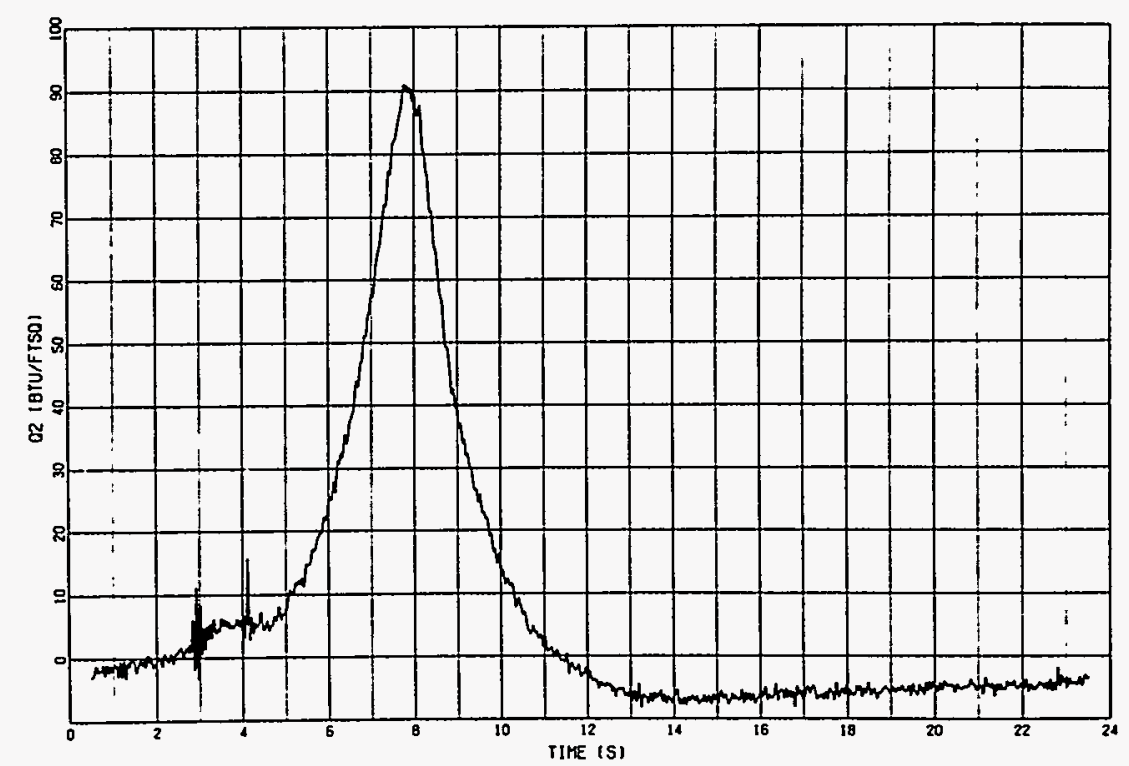

Figure 71. Cone Surface Heat Flux at Fin Station (4. 75 in From Base @ $315^{\circ}$ Orientation) 


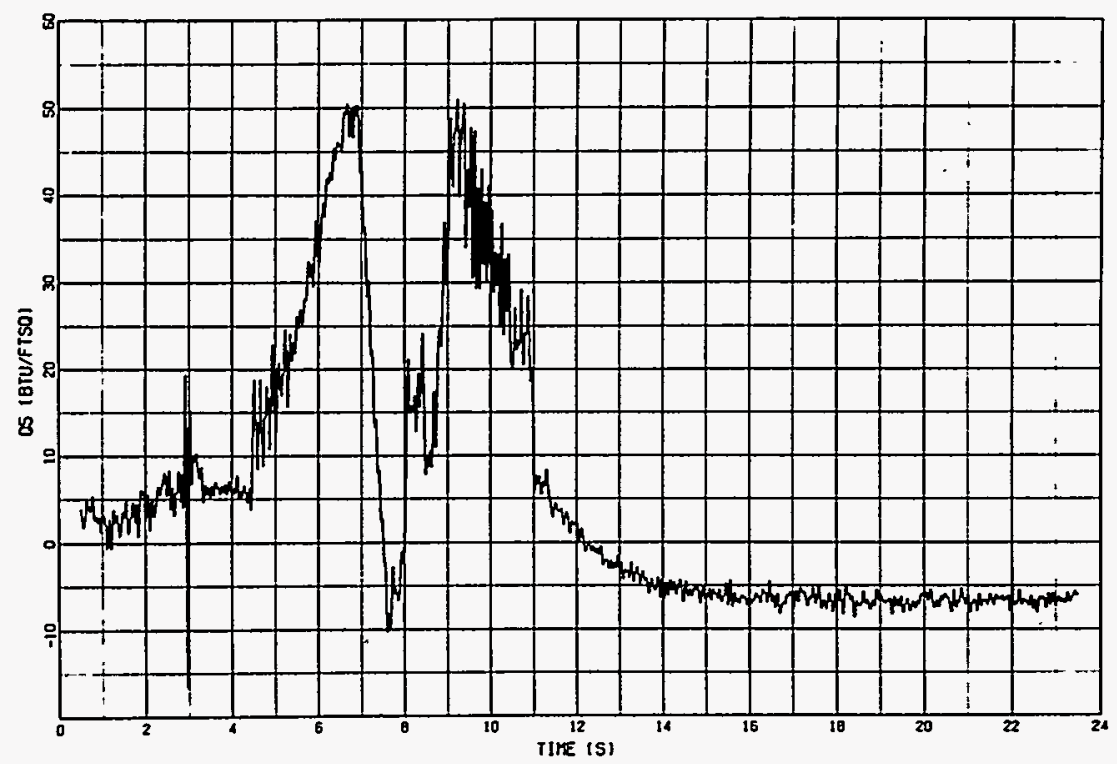

Figure 72. Cone Surface Heat Flux at Forward Station (14.5 in From Base @ 135 Orientation)

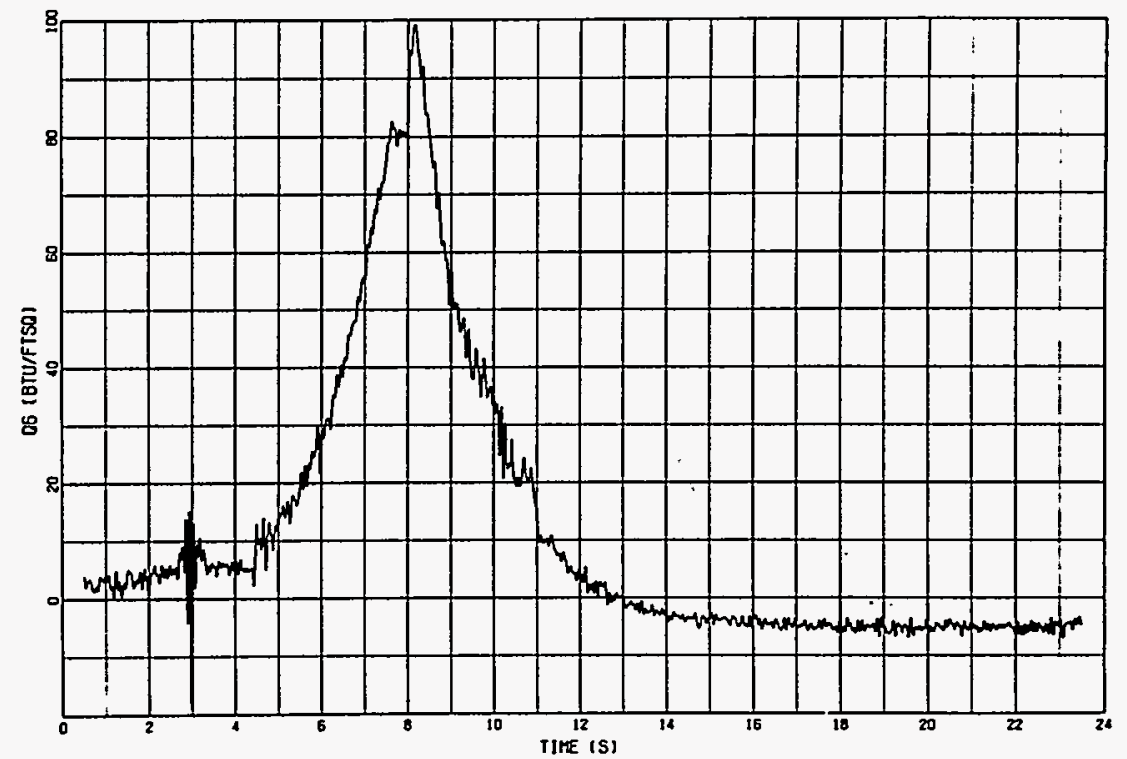

Figure 73. Cone Surface Heat Flux at Forward Station (14. 5 in From Base @ $315^{\circ}$ Orientation) 


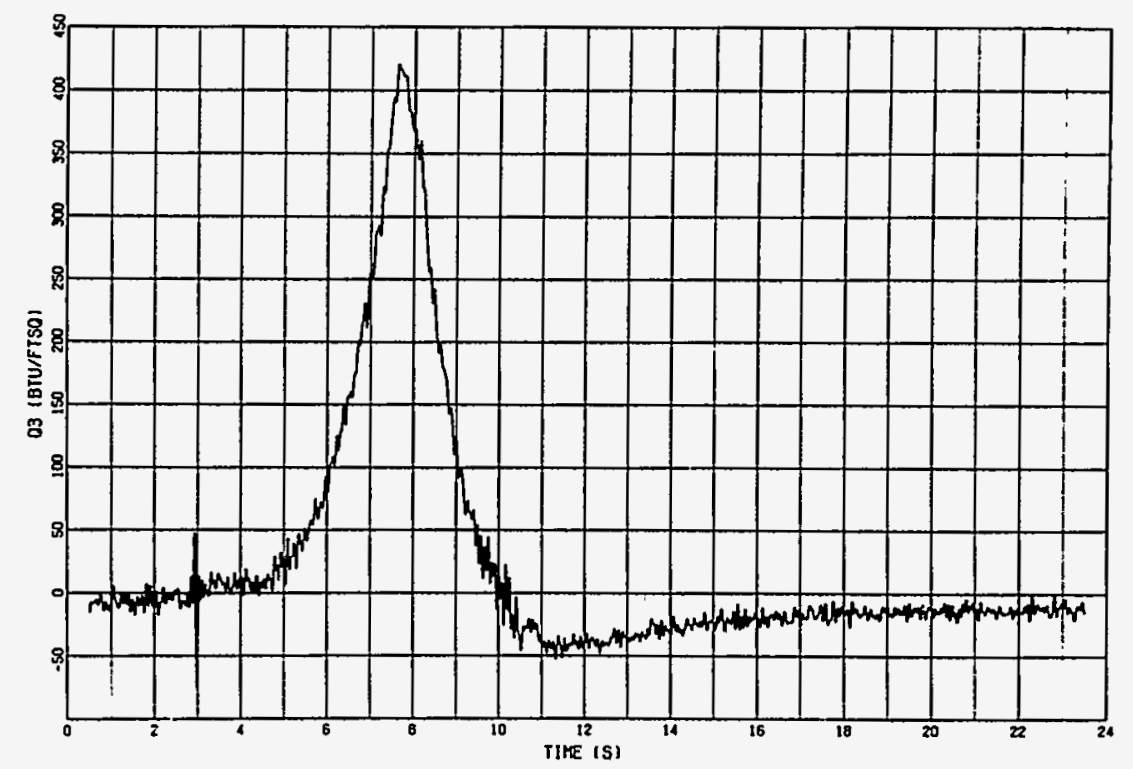

Figure 74 . Fin Leading Edge Heat Flux $\left(90^{\circ}\right.$ Orientation)

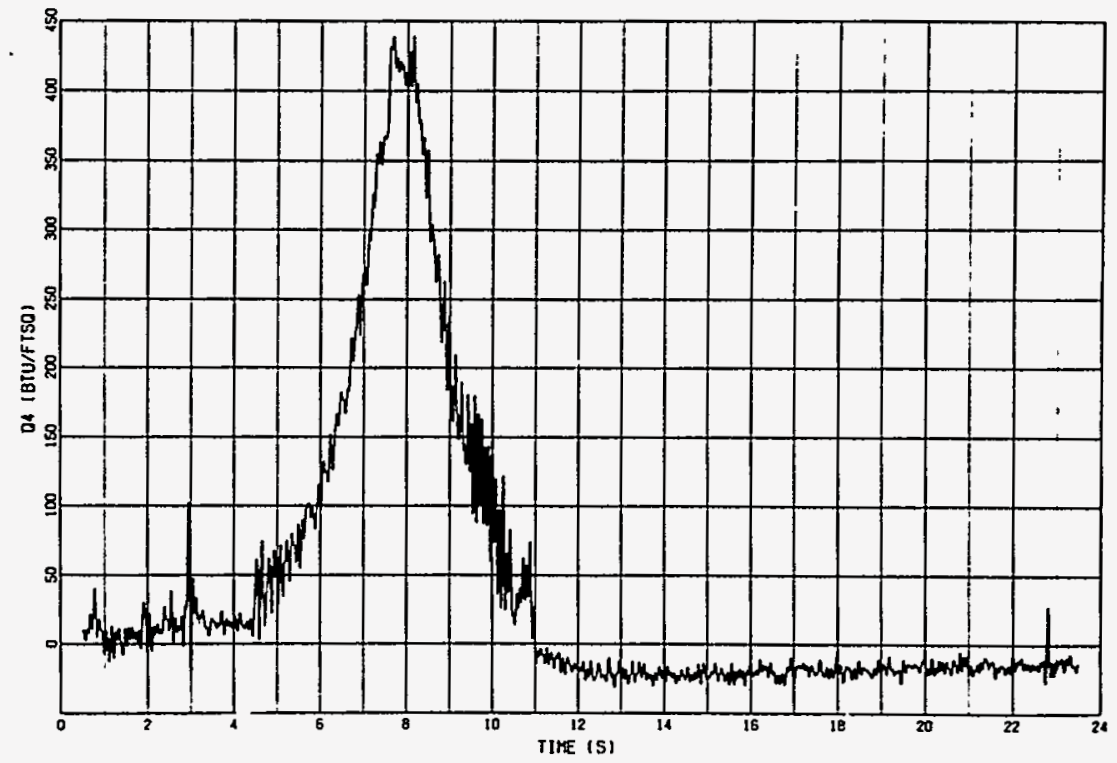

Figure 75. Fin Leading Edge Heat Flux (270 Orientation) 


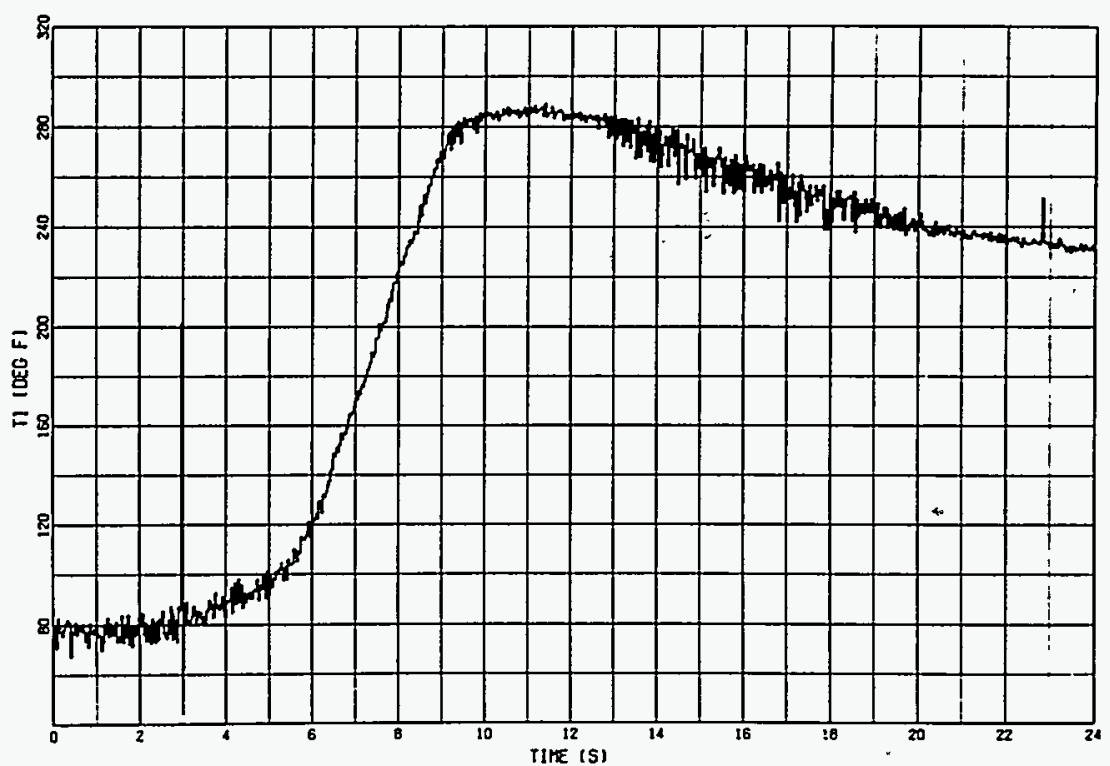

Figure 76. Cone Shell Backface Temperature at Fin Station (4.75 in From Base @ $45^{\circ}$ Orientation)

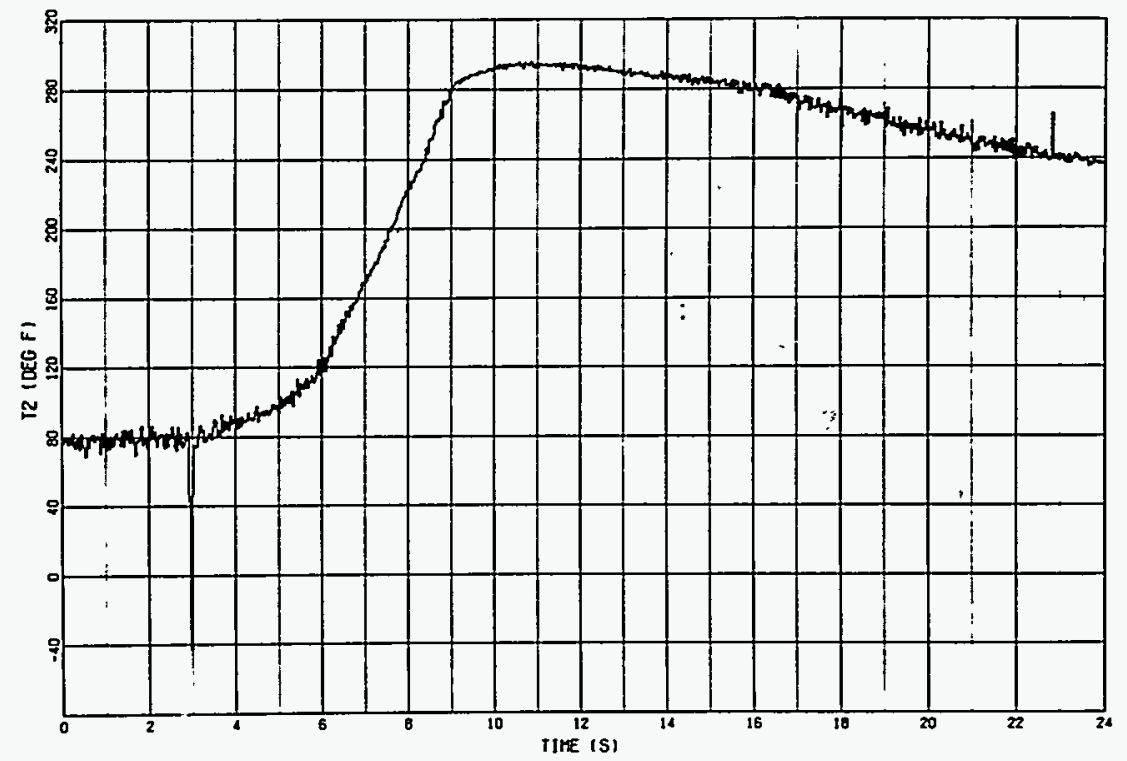

Figure 77. Cone Shell Backface Temperature at Fin Station (4.75 in From Base @ 225 Orientation) 


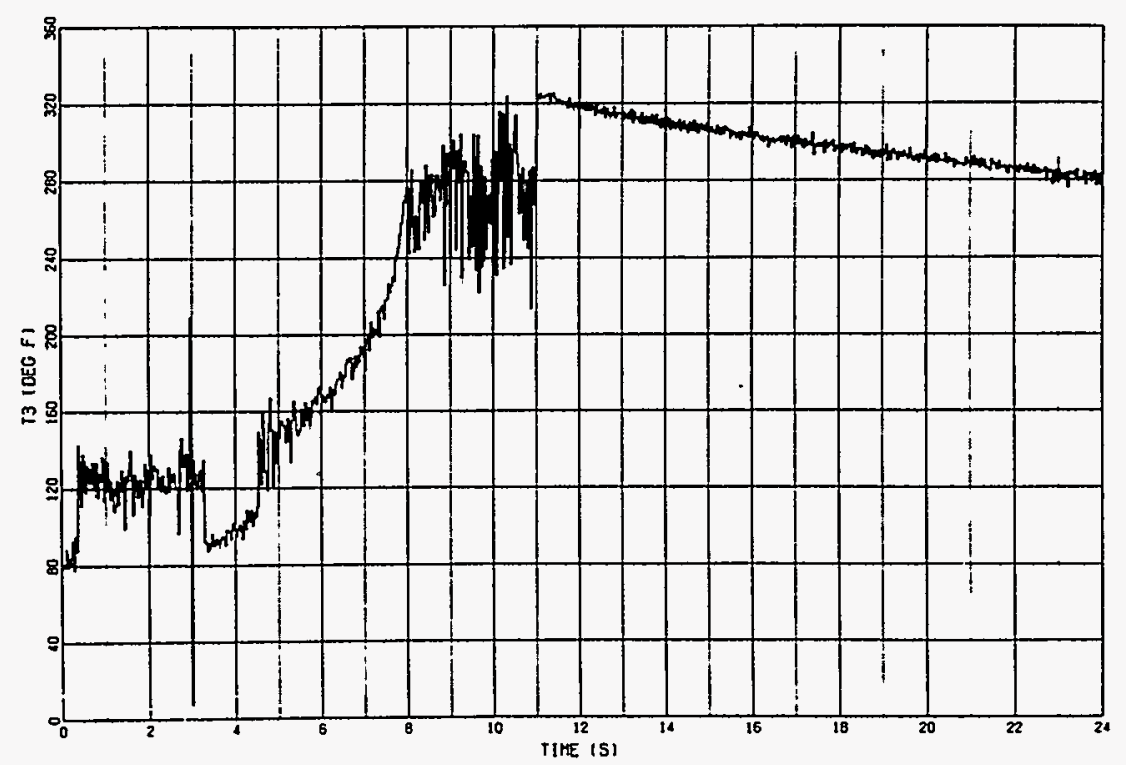

Figure 78. Cone Shell Backface Temperature at Forward Station (14. 5 in From Base @ $45^{\circ}$ Orientation)

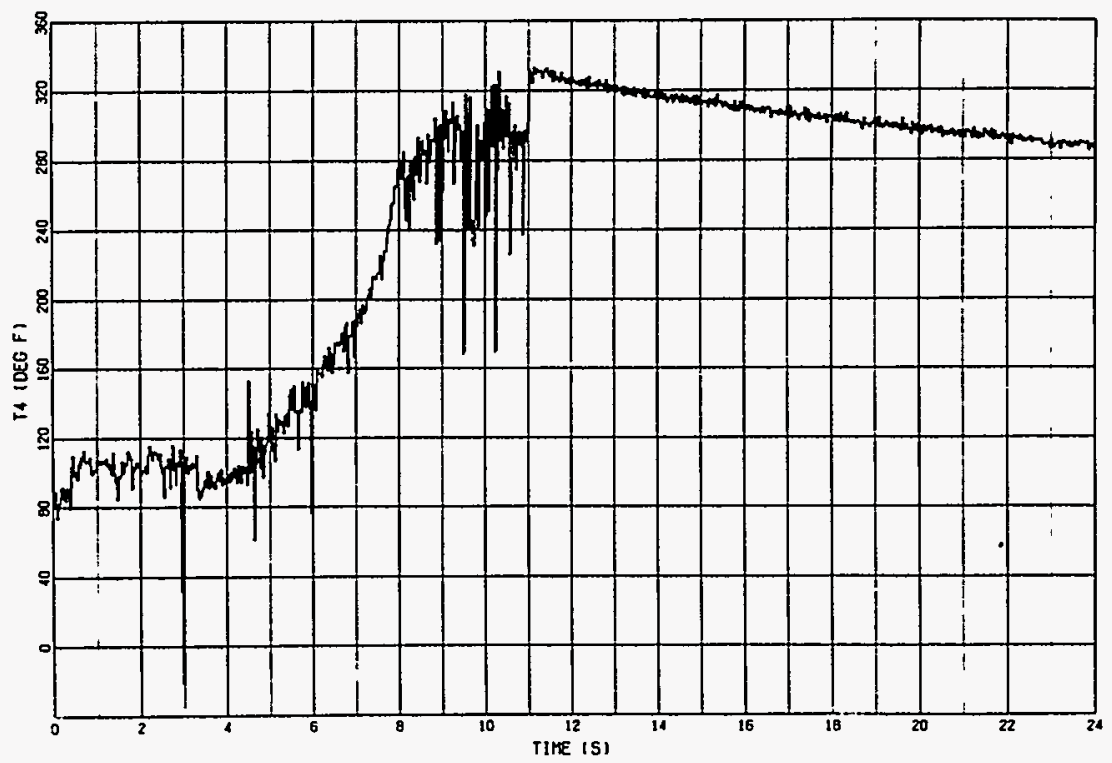

Figure 79. Cone Shell Backface Temperature at Forward Station (14. 5 in From Base @ 225 Orientation) 
Aerothermodynamic Analysis

Preliminary analysis for the prediction of the aerodynamic heating of fins on reentry vehicles is discussed in detail in References 30 through 33. These methods were used for the preflight analysis and prediction of fin and cone heating for RCRTV. As a result of an extensive aerothermodynam ic wind-tunnel testing program on various fin geometries, a more comprehensive analytic model of fin heating has been developed. This analysis ${ }^{31}$ was used for pos tflight predictions of fin leading-edge heat transfer coefficients which were then used as boundary conditions in a twodimensional thermal model of the fin leading-edge calorimeters in order to obtain the fin heat flux. Results of the computational procedure are compared with the heat flux data obtained from the two fin leading-edge calorimeters (Q3 and Q4) in Figure 80. Good agreement was obtained, thus verifying the analytical technique, the details of which are given in Reference 32.

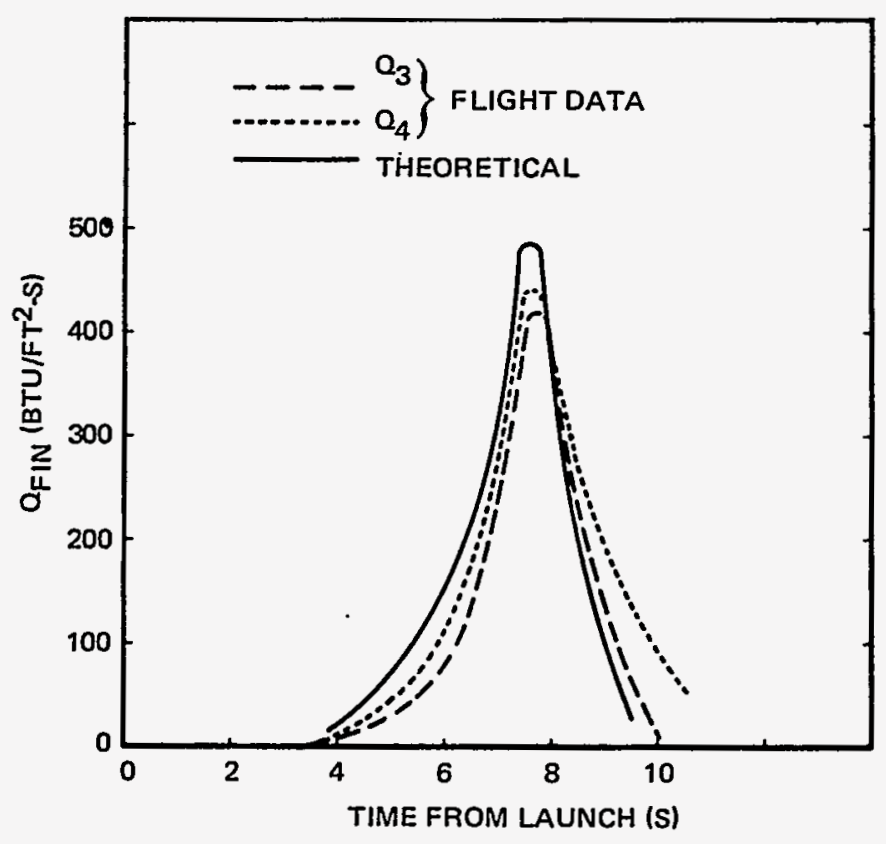

Figure 80. Comparison of Actual and Theoretically Determined Fin Leading Edge Heat Flux

A similar approach was used for calculating the cone heating. Heat transfer coefficients were predicted by means of the SLAP aeroheating computer program. 33 Results of the calculations for the two body stations where calorimeter data were obtained are compared with the data in Figures 81 and 82 . Again the data are well represented by the theory. 


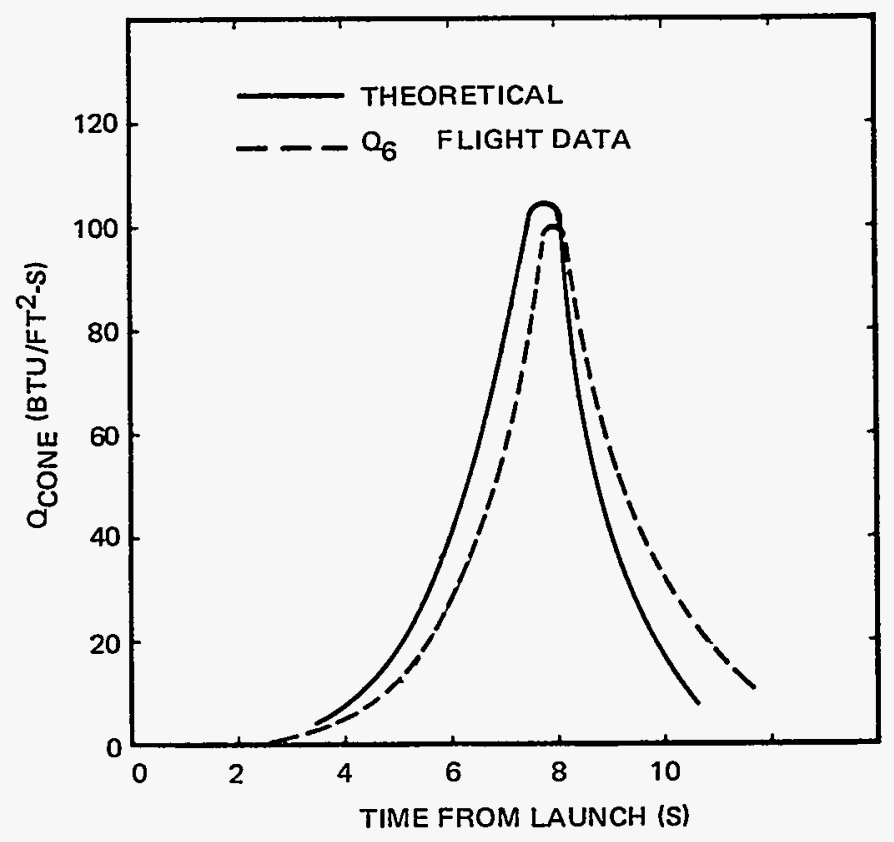

Figure 81. Comparison of Actual and Theoretically Determined Cone Surface Heat Flux at Forward Station (14.5 in From Base)

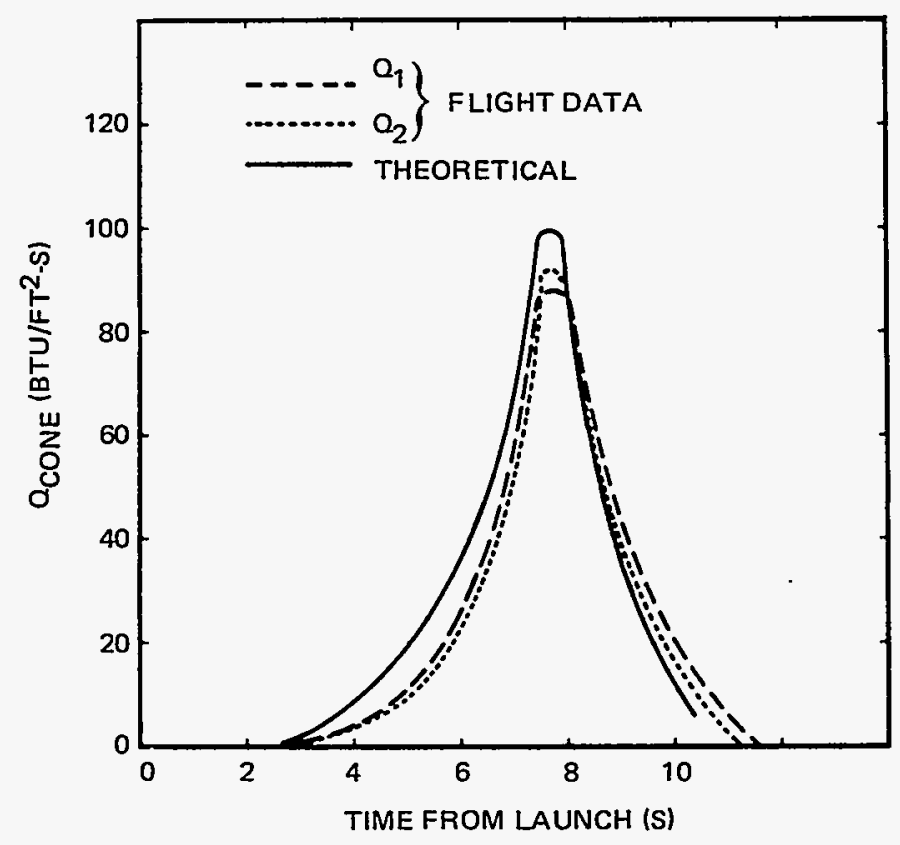

Figure 82. Comparison of Actual and Theoretically Determined Cone Surface Heat Flux at Fin Station (4.75 in From Base) 
As outlined in the first section of this report, the aerothermodynamic objectives were to obtain fin leading-edge and cone surface thermodynamic data (heat flux and temperature) and to verify analysis methods developed in support of the flight program. As indicated by the data obtained, these objectives were successfully accomplished, and the theoretical methods were fully verified.

\section{Tempilaq Experiment}

In order to obtain qualitative thermodynamic information on fins, passive thermodynamic instrumentation, Tempilaq, 35 was used on both the interior and exterior of the flight unit. Tempilaq is an inexpensive heatsensitive (temperature-sensitive) paint, various formulations of which change phase at predetermined critical temperatures. Tempilaq of various formulations was applied on the top and sides of the fins, on the fin platforms, on the cone surface aft of the fins, and on either side of each fin. This experiment yielded important and inexpensive qualitative information concerning the nature of the flow field and heat transfer in the vicinity of the fins. Examples of the Tempilaq patterns before and after the flight are shown in Figures 83 through 86.

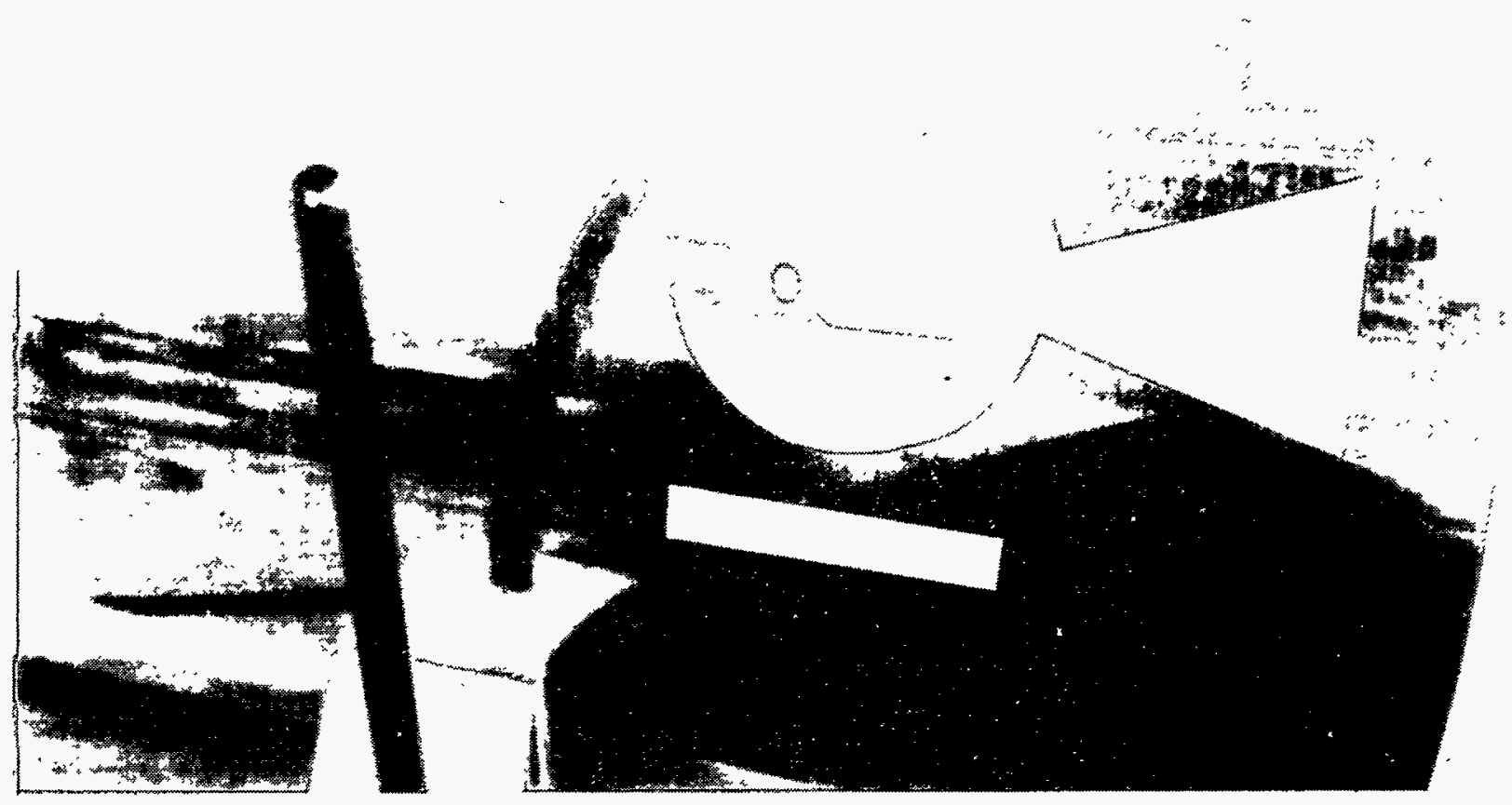

Figure 83. Preflight Fixed-Fin Tempilaq Pattern 


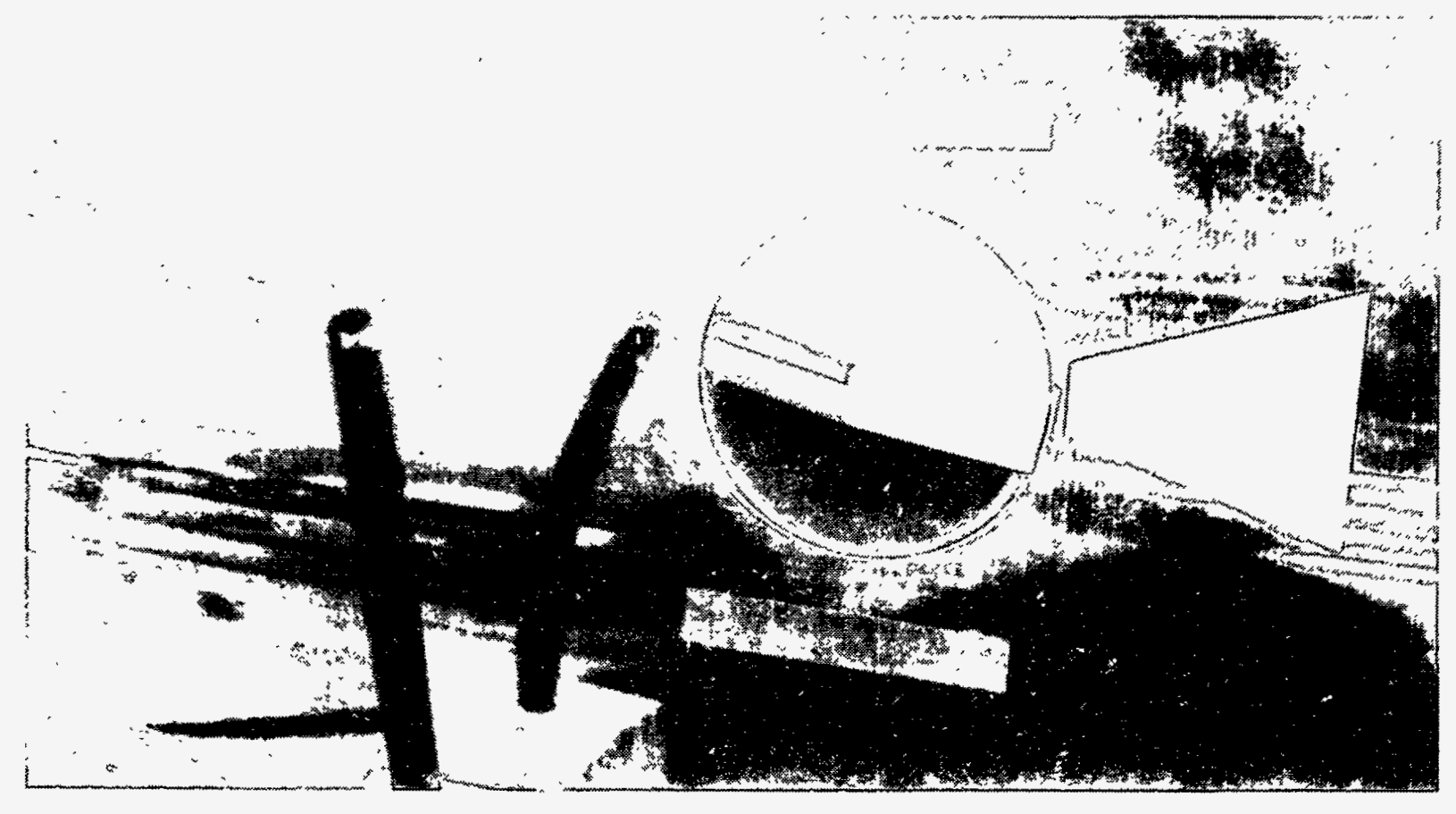

Figure 84. Preflight Moving-Fin Tempilaq Pattern

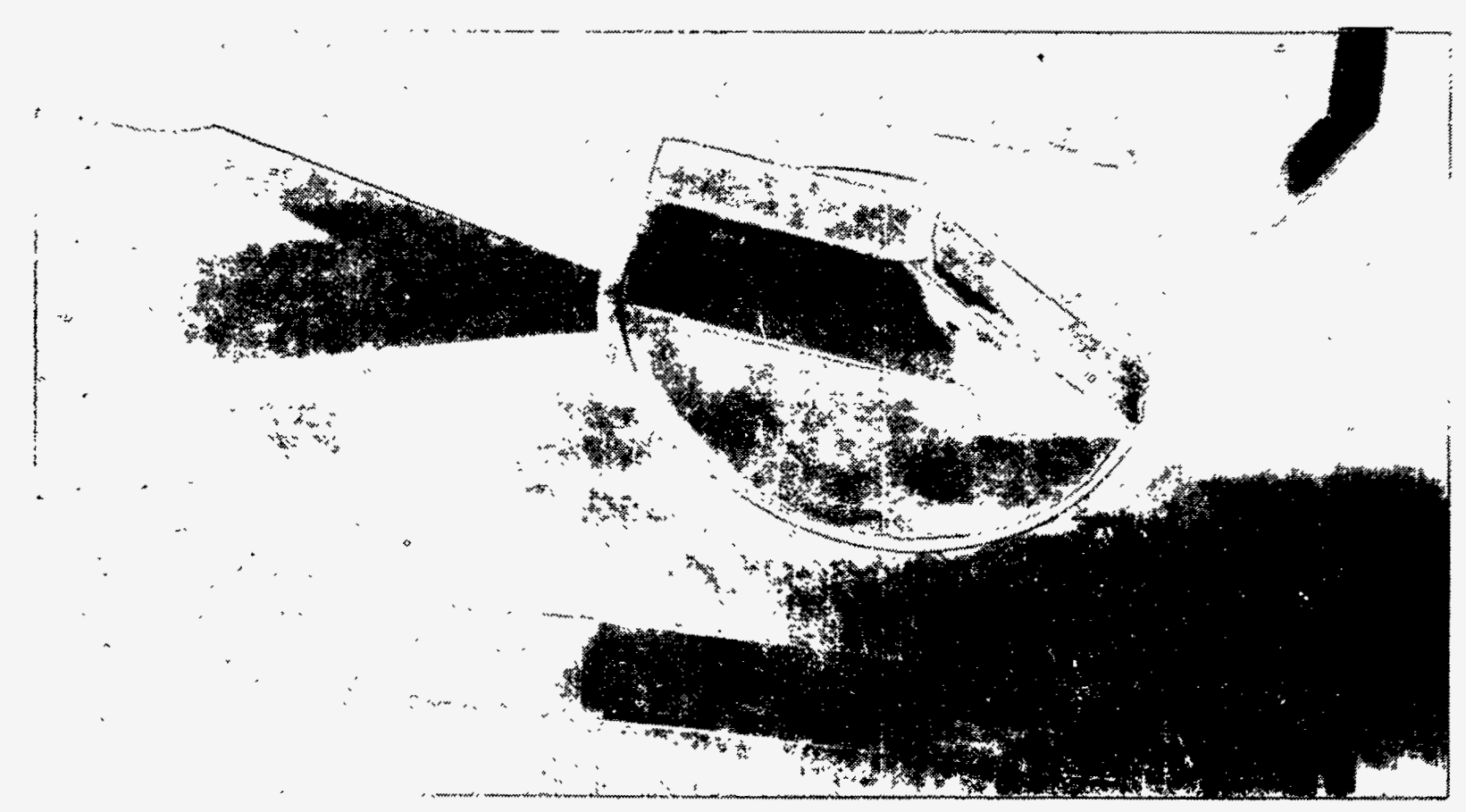

Figure 85. Postflight Fixed-Fin Tempilaq Pattern 


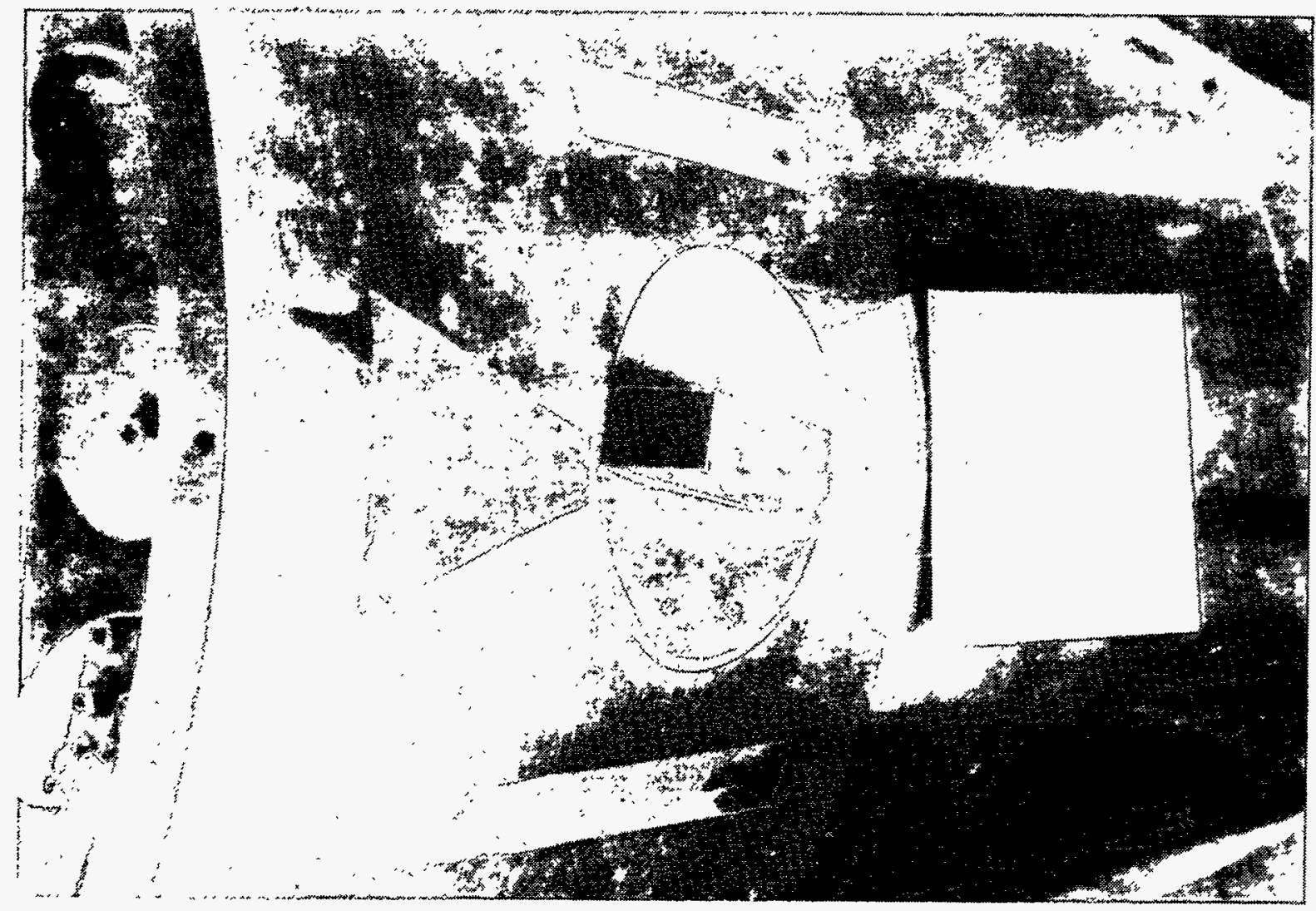

Figure 86. Postflight Moving-Fin Tempilaq Pattern

Summary and Conclusions

The RCRTV flight test was conducted in order (1) to demonstrate the capability of the spin-fin roll control system to control the roll rate of an asymmetric flight vehicle through a roll resonance encounter, and (2) to obtain detailed flight performance data to verify, and to compare with that obtained from the analysis procedures used. The flight test data and postflight analyses have led to the following conclusions:

1. All flight subsystems performed properly. The payload was boosted to the desired separation conditions. The booster drag brake system and payload separation system functioned nominally with no detectable separation disturbances imparted to the vehicle. The on-board instrumentation and payload 
telemetry system performed properly and yielded high-quality data from each sensor. The payload parachute recovery system functioned as planned, thus allowing the vehicle to be recovered intact and permitting postflight investigation and analys is to be made. Also, because the flight system employed in the RCRTV program represents a unique and relatively inexpensive means for low-altitude flight testing, it constitutes an attractive test bed for flight verification of proposed systems.

2. The flight vehicle trajectory was reconstructed from goodquality radar, optical tracking, meteorological, and telemetry data. The payload flew the desired trajectory, which simulated a severe second-resonance encounter and yielded a good test of the roll control system performance.

3. Good-quality data was obtained from the payload MARS stable platform, tri-axis rate gyro, and linear accelerometers. These data made possible a detailed investigation and analysis of the reentry vehicle flight dynamics. The flight motion was analyzed by means of the linear tricyclic theory. Well-determined histories for the characteristic model amplitudes and frequencies of the angular motion were obtained from the MARS data. Reconstruction of the angle-of-attack history from the lateral accelerometers confirmed the MARS data analysis.

4. The flight dynamics analysis led to a determination of the various aerodynamic coefficients. These included the aerodynamic drag, pitching moment, center of pressure, and fin roll moment characteristics. The effects of fins on the body aerodynamics were determined. Of particular interest are the following:

a. The four fins increase the total drag coefficient by 35 percent at Mach 4. The drag increment drops to +13 percent near Mach 1 and returns to +40 percent at subsonic velocities.

b. An increase in static stability $\left(\mathrm{C}_{\mathrm{M}_{\alpha}}\right)$ of 20 percent was observed at Mach numbers of 3.0 and greater. The conclusion was that this increase is due solely to an increase in static margin. At Mach numbers greater than 3.0 , the static margin is 6.2 percent for the finned vehicle, as opposed to 5.3 percent for the configuration without fins.

c. The vehicle exhibited good dynamic stability throughout the flight. No adverse effects on dynamic stability were attributed to the fins. 
d. The rolling moment coefficient due to the vehicle asym'metries was concluded to be more than sufficient to cause roll lock-in. The roll control moment coefficient due to fin cant $\left(\mathrm{C}_{\ell \delta}\right)$ was found to be in excellent agreement with the theoretical values for Mach numbers of about 2.5 and greater. The theory cannot be extrapolated to Mach numbers below about 2.5.

5. The roll control system performed properly, and it completely satisfied all mission requirements. The system exhibited good stability, and it controlled the spin rate as desired, thus demonstrating fully its capability to control a severe roll resonance instability.

6. Postflight simulations revealed:

a. In the absence of roll control, the vehicle would have exhibited a sustained roll resonance instability, with the total angle of attack amplifying to 60 degrees or greater.

b. The postflight simulation, which incorporated the actual payload separation conditions and the flight-derived aerodynamic characteristics, closely matched the flight performance parameters. Thus the analytic models of the control system, aerodynamics, and so on, as well as the simulation program, accurately represented the physical system.

7. Good quality aerothermodynamic data were obtained, including cone and fin leading-edge heat flux, as well as cone temperature. These data verified the fin heat transfer theory which was developed in support of the program. The Tempilaq experiment demonstrated the feasibility of using temperature-sensitive paint and yielded inexpensive qualitative information on fin aerothermodynamics.

8. All program and flight test objectives were successfully accomplished. In addition, the aerodynamic, aerothermodynamic, and flight simulation analysis methods for finned reentry vehicles were fully verified. 


\section{REFERENCES}

1. J. K. Kryvoruka, Roll Control Resonance Test Vehicle (RCRTV) System Preflight Report, SCL-DR-720038, Sandia Laboratories, May 1972.

2. L. M. Spivey, Roll Control Test Vehicle (RCTV) Preflight Test Report, SCL-DR-720071, Sandia Laboratories, October 1972.

3. T. J. Weber, Design and Testing of a Hydraulically Operated Fin Roll Control Mechanism for Ballistic Reentry Vehicles, SCL-DR720068, Sandia Laboratories; October 1972.

4. Internal Memorandum, J. K. Kryvoruka, 8176, to R. H. Lanes, 7283, Instrumentation for SLL Spin Fin Roll Control Resonance Test Vehicle, Sandia Laboratories, April 20, 1971.

5. Internal Memorandum, T. J. Weber, 8176, to A. B. Cole, 7511, Tempilaq Instrumentation for RCRTV, Sandia Laboratories, November 19, 1971.

6. R. E. Howell, 9310A, and R. D. Robinett, 9310A, Sandia Range Instrumentation Order for Test No. R-416507, Sandia Laboratories, December 22, 1971.

7. Internal Communication from L. R. Rollstin 5624, Sandia Laboratories.

8. J. K. Kryvoruka, A Formulation of the Equations of Motion for Flight Vehicles with Semi-Passive Roll-Control Systems, SCL-RR-720007, Sandia Laboratories, April 1972.

9. J. K. Kryvoruka, SPINFIN: A Computer Program for Trajectory Simulation of Flight Vehicles with Semi-Passive Roll-Control Systems, SCL-DR-720025, Sandia Laboratories, July 1972.

10. Internal Memorandum from C. S. Callender 9425. 
11. Internal Communication from W. R. Guntrum 8412 and L. S. Converse 8411.

12. J. D. Nicolaides, On the Free Flight Motion of Missiles Having Slight Configurational Asymmetries, BRL Report No. 858, U. S. Army Ballistic Research Laboratories, 1952.

13. R. S. Eikenberry, Analysis of the Angular Motion of Missiles, SC-CR-70-6051, Sandia Laboratories, February 1970.

14. J. K. Kryvoruka, Analysis of the Motion of Free Flight Missiles from Body-Fixed Sensors, SCL-RR-70-41, Sandia Laboratories, May 1970.

15. J. K. Kryvoruka, Effects of Inadequate Mathematical Models on Dynamic Data Analysis, SCL-DR-69-84, Sandia Laboratories, September 1969.

16. E. L. Clark, A. E. Hodapp, Experimental Determination of Asymmetry-Induced Trim Angles of Attack, AIAA Paper No. 72-1032, AIAA 7th Aerodynamic Testing Conference, September 1972.

17. A. E. Hodapp, R. C. Beckman, Flight Test Evaluation of a Fluidically Actuated Monopropellant Hydrazine Roll Control System, AIAA Paper No. 72-975, AIAA 2nd Atmospheric Flight Mechanics Conference, September 1972.

18. R. V. Owens, Aerodynamic Characteristics of Spherically Blunted Cones at Mach Numbers from 0.5 to 5.0, NASA TN D-3088, December 1965.

19. W. T. Ashurst, HANDY, A Computer Program for Predicting Supersonic Aerodynamic Characteristics of Sphere-Cone and Sphere-ConeCylinder-Flare Axisymmetric Bodies at Small Angles of Attack, SCL-DR-70-25, Sandia Laboratories, March 1970.

20. M. Tobak and W. R. Wearend, Stability Derivatives of Cones at Supersonic Speeds, NACA TN 3788, September 1956.

21. J. K. Kryvoruka and W. T. Ashurst, Reentry Vehicle Finned Roll Rate Control, Aerodynamic and Flight Dynamic Analysis, AIAA Paper No. 73-183, 11th Aerospace Sciences Meeting, January 1973, Washington, D.C.

22. Private Communication, March 1971. 
23. Private Communication, December 16, 1971.

24. Private Communication, unpublished.

25. Private Communication with R. F. Ross and D. H. Platus of the Aerospace Corporation, El Segundo, Ca., January 1971.

26. J. K. Kryvoruka and W. T. Ashurst, Reentry Vehicle Finned Roll Rate Control - Aerodynamic and Flight Dynamic Analysis, SCL-DC720087, Sandia Laboratories, November 1972.

27. D. H. Platus, Dynamic Instability of Finned Missiles Caused by Unequal Effectiveness of Windward and Leeward Fins, Aerospace Report No. TR-0066 (5240-30)-6, Air Force Report No. SAMSOTR-70-74, Aerospace Corp., El Segundo, Ca., December 1969.

28. J. K. Kryvoruka and R. W. Phillips, Closed Loop Preflight Testing of the Controller for the Roll Control Resonance Test Vehicle (RCRTV), SCL-DR-720082, Sandia Laboratories, January 1973.

29. R. W. Phillips, The Sandia Flight Dynamics Laboratory, SCL-DC720078, Sandia Laboratories, October 1972.

30. Internal Memorandum, E. C. Lemmon and H. W. Coleman 8351 to R. J. Tockey 8176, Aerothermal Analysis of Fin System for the Tonopah Roll Control Resonance Test Vehicle, Sandia Laboratories, March 10, 1971.

31. E. C. Lemmon and H. W. Coleman, Turbulent Heat Transfer to a Fin Leading Edge--Flight Test Results, SCL-DC-720329, Sandia Laboratories, October 1972.

32. E. C. Lemmon and H. W. Coleman, The Prediction of Aerodynamic Heating of Fins on Reentry Vehicles, SCL-RR-710056, Sandia Laboratories, July 1971.

33. H. W. Coleman and E. C. Lemmon, Turbulent Heat Transfer and Pressure on Leading Edges of Fins Mounted on a Cone, SCL-RR720308, Sandia Laboratories, September 1972.

34. P. O. Witze and D. L. Hartley, SLAP: Sandia-Livermore Aeroheating Program, SCL-DR-69-105, Sandia Laboratories, November 1969.

35. G. L. Eggert, An Evaluation of Tempilaq as a Passive Temperature Sensor for Measuring Transient Thermal Pulses, SC-DR-70-289, Sandia Laboratories, May 1970. 
DISTRIBUTION:

AEC/TIC, Oak Ridge, Tenn.

Aerospace Corporation

Aerodynamics and Propulsion Research Lab

P. O. Box 9257

Los Angeles, CA 90009

Attn: Library Acquisition Group

For: D. H. Platus

R. Hartman

J. Beneviste

Capt. John Gordon

Commander

Air Force Weapons Laboratory (DOUA)

Kirtland Air Force Base, New Mexico 87117

Attn: M. F. Canova

AVCO Corporation

Systems Division, Minuteman

201 Lowell St.

Wilmington, Massachusetts 01887

Attn: R. Cooper

Chief, Technology and Studies Division, Livermore Field Command, Defense Nuclear Agency

Lawrence Livermore Laboratory

P. O. Box 808

Livermore, California 94550

Commander, Field Command

Defense Nuclear Agency

Kirtland AFB

Albuquerque, New Mexico 87115

Attn: Library

Director

Defense Nuclear Agency

Washington, D. C. 20305

Attn: Chief, Technical Library

For: R. R. Bonser, M. C. Adkins, R. E. Jackson

Naval Plant Representative Office

Technical Representative

General Electric Company

3198 Chestnut St.

Philadelphia, Pennsylvania 19101

Attn: J. J. Pettus

L. Marshall 
Kaman Sciences Corporation

Kaman Nuclear Division

Garden of the Gods Road

Colorado Springs, Colorado 80907

Attn: B. R. Follmer

Naval Plant Representative

Lockheed Missiles and Space Company

P. O. Box 504

Sunnyvale, California 94088

U.S. Atomic Energy Commission

Division of Headquarters Services

Library Branch, Room G-049

Washington, D.C. 20545

Attn: Col. William Haidler (1)

Lt. Col. H. Parlett (1)

U.S. Atomic Energy Commission

Albuquerque Operations Office

P. O. Box 5400

Albuquerque, New Mexico 87115

Attn: T. A. Station

University of California

Lawrence Livermore Laboratory

P. O. Box 808

Livermore, California 94550

Attn: Charles A. McDonald, L31

Dr. William W. Carter

Assistant Director, Nuclear Programs

Defense Research and Engineering

Department of Defense, 3E1071

The Pentagon

Washington, D.C. 20310

Commander

Naval Ordnance Systems Command

Department of the Navy

Attn: Nuclear Applications Branch (ORD-0523)

Washington, D.C. 20360

For: Marlin A. Kinna 
USAEC

Division of Military Application

Attn: Maj. Gen. Frank A. Camm

Asst. Gen. Manager for Military Application

Washington, D.C. 20545

Commander, Naval Ordnance Laboratory

White Oak, Silver Spring, Maryland 20910

Attn: Mary C. Ward

For: W. C. Lyons

ABMDA

Commonwealth Building

1300 Wilson Blvd.

Arlington, Va. 22209

Attn: J. B. Gilstein, Director

Advanced Research Projects Agency

1400 Wilson Blvd.

Arlington, $\mathrm{Va} .22209$

Attn: F. A. Koether

Maj. Gen. W. C. Gribble, Jr.

Chief of Research and Development

Dept. of the Army, Room 3D-442

The Pentagon

Washington, D.C. 20310

McDonnell Douglas Corporation

3000 Ocean Park Blvd.

Santa Monica, CA. 90406

Attn: N. S. Beer

Director

Strategic Systems Project Office

Department of the Navy

Washington, D.C. 20390

Attn: Cdr. R. J. Stenner

SAMSO (RS/Col. William R. Manlove)

Norton Air Force Base

California 92409

Attn: B. Gen. H. A. Lyon 
Director of Defense Research and Engineering

The Pentagon, Room 3E-1006

Washington, D. C. 20301

Attn: Dr. John S. Foster

For: Col. J. A. Welch, Jr.

Los Alamos Scientific Laboratory

P. O. Box 1663

Los Alamos, New Mexico 87544

Attn: M. Gillespie

TRW Systems Group

One Space Park

Redondo Beach, California 90278

Attn: Herman S. Heaton

M. Sparks, 1

W. J. Howard, 1000

D. B. Shuster, 1200

W. C. Myre, 1210

R. L. Peurifoy, 1220

H. W. Schmitt, 1223

D. J. Rigali, 1225

W. A. Gardner, 1500

D. M. Olson, 1510

C. H. Mauney, 1530

T. B. Lane, 1540

T. M. Burford, 1700

R. G. Clem, 1730

A. M. Clogston, 5000

A. Y. Pope, 5600

R. C. Maydew, 5620

W. H. Curry, 5621

E. W. Hall, 5623

E. C. Rightley, 5623

J. E. Suazo, 5623

W. R. Barton, 5624

L. R. Rollstin, 5624

A. E. Hodapp, 5625

H. R. Vaughn, 5625

D. W. Johnson, 5626

D. F. McVey, 5626

S. McAlees, 5628

K. J. Touryan, 5640

C. W. Peterson, 5645

T. B. Cook, Jr., 8000

L. Gutierrez, 8100 
J. F. Barham, Jr., 8130

J. Wright, 8131

A. F. Baker, 8137

D. E. Gregson, 8150

R. A. Baroody, 8160

G. E. Brandvold, 8170

A. S. Rivenes, 8175

J. D. Gilson, 8177

J. K. Kryvoruka, 8178

G. W. Henderson, 8178

L. M. Spivey, 8178

G. R. Otey, 8178

C. S. Selvage, 8180

C. H. DeSelm, 8200

B. F. Murphey, 8300

J. W. Weihe, 8320

J. N. Rogers, 8321

G. W. Anderson, 8330

A. N. Blackwell, 8350

A. R. Willis, 8351

C. W. Robinson, Jr., 8352

C. S. Hoyle, 8353 .

D. L. Hartley, 8354

W. C. Scrivner, 8400

R. D. Cozine, 8410

J. D. Benton, 8411

R. J. Tockey, 8412

R. D. Robinett, $9310 \mathrm{~A}$

S. A. Moore, 9470

T. J. Hoban, 9483

R. H. Lanes, 9483

K. W. Shrock, 9483

Technical Publications Division I, 3151

Library Systems and Technical Processes Division, 3141 (4)

D. L. Rasmussen, 8231/Central Technical File, 8232-2

Central Technical File, 8232-2 (4) 